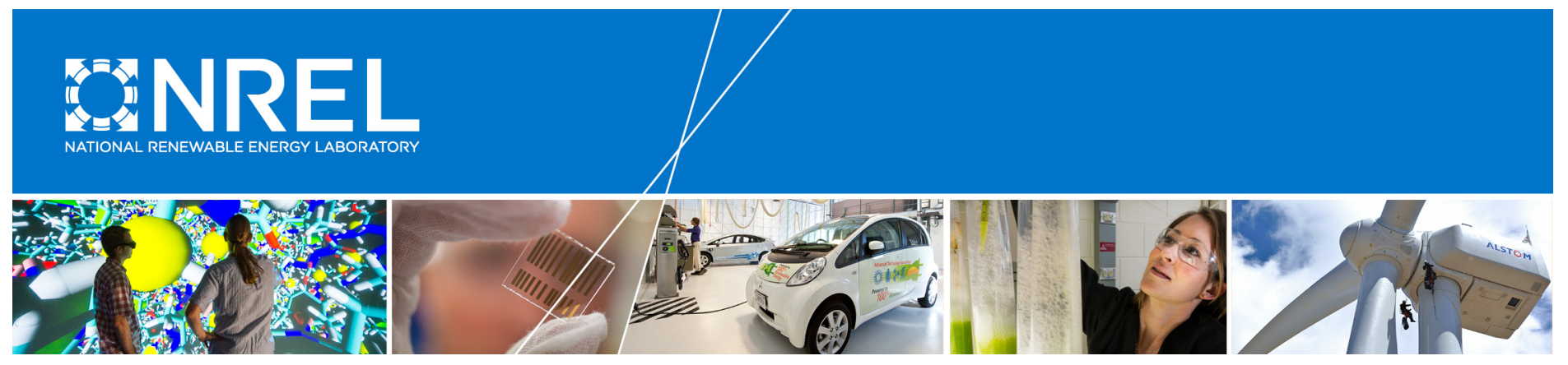

\title{
Uncertainty and Risk Assessment in the Design Process for Wind
}

Rick Damiani

National Renewable Energy Laboratory

NREL is a national laboratory of the U.S. Department of Energy Office of Energy Efficiency \& Renewable Energy Operated by the Alliance for Sustainable Energy, LLC

This report is available at no cost from the National Renewable Energy Laboratory (NREL) at www.nrel.gov/publications.

Technical Report

NREL/TP-5000-67499

February 2018

Contract No. DE-AC36-08GO28308 


\section{Uncertainty and Risk Assessment in the Design Process for Wind}

Rick Damiani

National Renewable Energy Laboratory

Prepared under Task No. WEPG.10346.23.01.04
NREL is a national laboratory of the U.S. Department of Energy Office of Energy Efficiency \& Renewable Energy Operated by the Alliance for Sustainable Energy, LLC

This report is available at no cost from the National Renewable Energy Laboratory (NREL) at www.nrel.gov/publications.

\section{Technical Report}

NREL/TP-5000-67499

February 2018

Contract No. DE-AC36-08GO28308
National Renewable Energy Laboratory 15013 Denver West Parkway

Golden, CO 80401

303-275-3000 • www.nrel.gov 


\title{
NOTICE
}

This report was prepared as an account of work sponsored by an agency of the United States government. Neither the United States government nor any agency thereof, nor any of their employees, makes any warranty, express or implied, or assumes any legal liability or responsibility for the accuracy, completeness, or usefulness of any information, apparatus, product, or process disclosed, or represents that its use would not infringe privately owned rights. Reference herein to any specific commercial product, process, or service by trade name, trademark, manufacturer, or otherwise does not necessarily constitute or imply its endorsement, recommendation, or favoring by the United States government or any agency thereof. The views and opinions of authors expressed herein do not necessarily state or reflect those of the United States government or any agency thereof.

This report is available at no cost from the National Renewable Energy Laboratory (NREL) at www.nrel.gov/publications.

Available electronically at SciTech Connect http:/www.osti.gov/scitech

Available for a processing fee to U.S. Department of Energy and its contractors, in paper, from:

\author{
U.S. Department of Energy \\ Office of Scientific and Technical Information \\ P.O. Box 62 \\ Oak Ridge, TN 37831-0062 \\ OSTI http://www.osti.gov \\ Phone: 865.576.8401 \\ Fax: 865.576.5728 \\ Email: reports@osti.gov
}

Available for sale to the public, in paper, from:

\author{
U.S. Department of Commerce \\ National Technical Information Service \\ 5301 Shawnee Road \\ Alexandria, VA 22312 \\ NTIS http://www.ntis.gov \\ Phone: 800.553 .6847 or 703.605 .6000 \\ Fax: 703.605.6900 \\ Email: orders@ntis.gov
}




\section{Acknowledgments}

Dr. Paul Veers of the National Renewable Energy Laboratory (NREL) was instrumental in organizing the workshop, leading the discussions on the various topics, and supporting the development of this document.

Dr. Veers and the author would like to thank the attendees of the Mini-Workshop on Uncertainty in Design for Wind who contributed to shaping the contents of this paper: Jomaa Ben-Hassine, Res Americas; John Bosche, Chinook Wind; John Dalsgaard Sørensen, Aalborg University/Technical University of Denmark; Katherine Dykes, NREL; Jason Fields, NREL; D.V. Griffiths, Colorado School of Mines; William Holley, former GE; Nick Johnson, U.S. Department of Energy; Mike Robinson, U.S. Department of Energy; Jason Jonkman, NREL; Lance Manuel, University of Texas; Frank Lombardo, University of Illinois; Julie Lundquist, University of Colorado; Dave Maniaci, Sandia National Laboratories; Emil Moroz, AWS Truepower; Juan Pablo Murcia, Technical University of Denmark; Walter Musial, NREL; Amy Robertson, NREL; Michael Sprague, NREL; Peter Vickery, Applied Research Associates; Rochelle Worsnop, University of Colorado at Boulder.

This work was supported by the U.S. Department of Energy under Contract No. DE-AC36-08GO28308 with the National Renewable Energy Laboratory. Funding for the work was provided by the DOE Office of Energy Efficiency and Renewable Energy, Wind Energy Technologies Office. 


\section{Table of Contents}

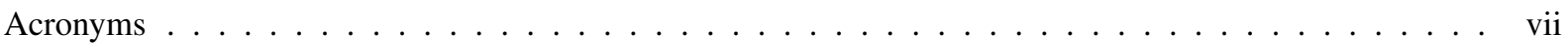

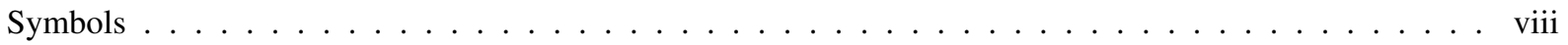

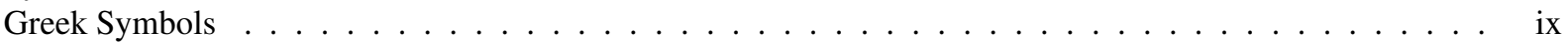

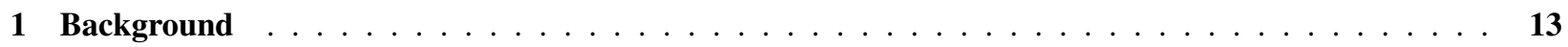

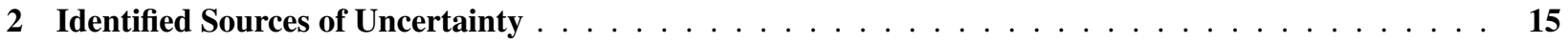

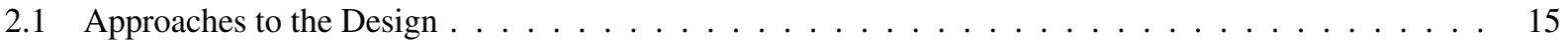

2.2 Uncertainty Affecting Turbine Loads . . . . . . . . . . . . . . . . . . . . . . 17

2.2 .1 Uncertainty in the Inflow . . . . . . . . . . . . . . . . . . . . 18

2.2 .2 Extreme Events . . . . . . . . . . . . . . . . . . . . . . . . . . 19

2.2.2.1 Tropical Cyclones and Other Extreme Loading Environments . . . . . . . . . . . 21

2.2.3 Uncertainty in the Aerodynamics and Controls . . . . . . . . . . . . . . . . . . . 27

2.2 .4 Soil and Foundation Properties . . . . . . . . . . . . . . . . . . . . 28

2.2.5 Uncertainty in the Operational Load Extrapolation . . . . . . . . . . . . . . . . . . . . . 29

2.3 Material and Structure Resistance . . . . . . . . . . . . . . . . . . . . . 32

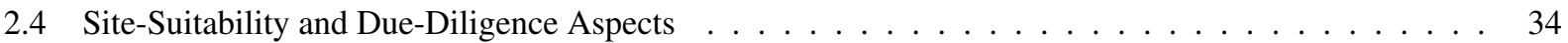

2.4 .1 Performance Risk . . . . . . . . . . . . . . . . . . . . . . . . . . 36

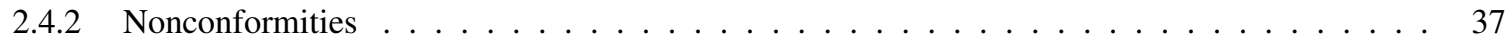

2.5 PSF and Reliability Levels $\ldots \ldots \ldots \ldots \ldots \ldots \ldots$

2.6 Uncertainties in Modeling . . . . . . . . . . . . . . . . . . . . . . . . 39

2.6 .1 Uncertainty Quantification . . . . . . . . . . . . . . . . . . . . . 39

2.6.1.1 Verification and Validation $\ldots \ldots \ldots \ldots \ldots \ldots$

3 Design Criteria Identification and Ranking Table $\ldots \ldots \ldots \ldots \ldots \ldots$

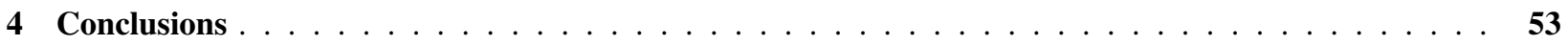

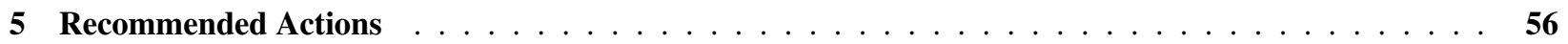

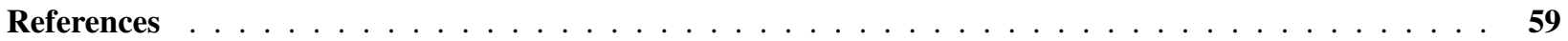

\section{List of Figures}

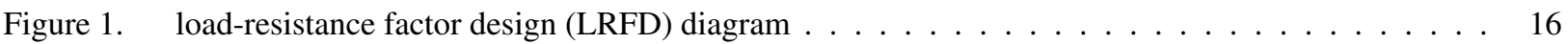

Figure 2. How load factor and assumed load return periods can affect reliability and costs (Damiani and

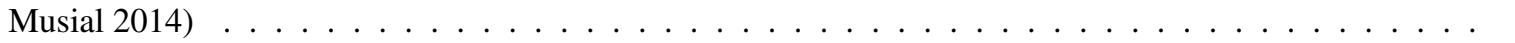

Figure 3. Resulting probability of failures calculated for various safety margins for load extremes assumed as either Gaussian (a) or Gumbel (b) distributed. Courtesy of Bill Holley . . . . . . . . . . . . . . . . . 18 
Figure 4. Thunderstorm events are key sources of extreme wind speed events in the United States. (a) color contours indicate the percentage of annual wind speed maxima ( $3 \mathrm{~s}$ gust) attributable to (nontropical) thunderstorm events in the United States. Courtesy of F. Lombardo. (b) Derived Type I fit for peak gusts as a result of a thunderstorm for Charlotte, North Carolina. Courtesy of P. Vickery . . . . . . . .

Figure 5. Examples of correction factors for gust wind speeds as a result of surface roughness (a), altitude (b), and gust duration (c). Courtesy of P. Vickery . . . . . . . . . . . . . . . .

Figure 6. Example of gust probablity of exceedance (POE) including uncertainty propagation. Courtesy

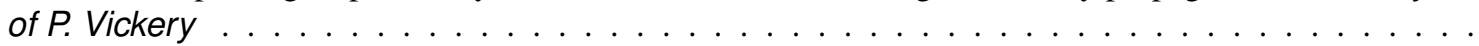

Figure 7. Examples of recorded mean wind profile (a) and gust factor (b) curves that show different behaviors near hub height (shaded region) than what is expected from codified laws (SEI 2010; ISO 1998).

Courtesy of F. Lombardo . . . . . . . . . . . . . . . . . . . . . . . . . . . . . . . . . . . .

Figure 8. Return periods for hurricanes of category 3 and above along the Atlantic Coast. Courtesy of $\mathrm{J}$.

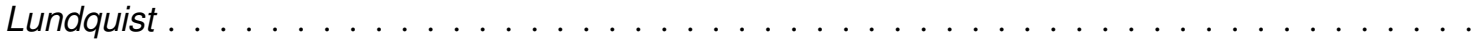

Figure 9. Examples of LES-calculated wind field quantities within a category 5 hurricane: (a) 3-s gust probability density function (PDF) at 50,100, and $200 \mathrm{~m}$ above sea level (a); (b) gust factors as a function of horizontal location at $100 \mathrm{~m}$ above sea level with the black contour indicating a value of 1.4; (c) gust factors as a function of radial distance (R) from the center of the hurricane and as a function of height above sea level. Courtesy of J. Lundquist and R. Worsnop . . . . . . . . . . . . . . . . .

Figure 10. Sample outputs of the synthetic hurricane modeling: (a) three-dimensional wind vector field; (b) expected gust speeds and wind direction at a given geographical location. Courtesy of P. Vickery . . . .

Figure 11. (a) Assessment of synthetic hurricane model errors: calculated vs. observed hurricane wind speeds (hollow (filled) squares denote land-based (offshore)). (b) Example of family of POE curves for gust wind speeds derived from multiple Monte Carlo hurricane N-year simulations. (c) Calculated coefficient of variation (COV) for the 100-year wind speed for various coastal locations in the U.S.. Courtesy of $P$. Vickery . . . . . . . . . . . . . . . . . . . . . . . . .

Figure 12. Examples of hazard curves for a jacket substructure and for different geographical regions. Comparison of the U.S. New England region to the Gulf of Mexico (GOM) and the associated probability of failures for a given safety factor (1.35) (a); overload hazard varying by geographical region (b). (Meaning of the acronyms used in the legend and y-axis: OTM is the overturning moment at the mudline; WEA is wind energy area; CNS and SNS are central and south North Sea regions, respectively). Courtesy of R. Hall . . . . . . . . . . . . . . . . . . . . . . . . . . . . . . . . .

Figure 13. Example of member utilization calculated for an offshore wind turbine jacket located in the South Atlantic region of the United States. (a); colors indicate the utilization ratio. (b) associated hazard curves for design load case (DLC) 6.1 normalized to 100-yr load. The nominal safety margin, defined as $\gamma_{L}$ times the pile axial safety factor ( $=1.25$ per (ISO 2007)), must be at least 1.88 to satisfy the $500-\mathrm{yr}$ robustness check. This translates into a required load partial safety factor (PSF) of $\sim 1.5$, which is larger than the International Electrotechnical Commission (IEC)-recommended 1.35 . . . . . . . . . . . . . .

Figure 14. Monopile mudline bending moment as a function of wave characteristics. Breaking wave loads can differ because of the wave characteristics themselves as well as the dynamic state of the structure at the time of wave impact. Courtesy of A. Myers . . . . . . . . . . . . . . . . .

Figure 15. Tower-base bending moment as a function of wind speed and yaw error under parked conditions for a typical offshore wind turbine (a) (Damiani and Musial 2014). Calculated probability of failures for offshore wind turbines on monopiles for various sites (denoted by the U.S. state abbreviation)(b); effects of yaw error on that probability (c). Courtesy of A. Myers . . . . . . . . . . . . . . . . . .

Figure 16. Impact of uncertainty in the airfoil characteristics in terms of $X_{\text {aero }}$ 's COVs on $\beta$ (left-hand side) and on $\gamma_{L}$ for a given reliability (denoted as $\gamma_{f}$ ) (right-hand side). Source: J. Sørensen . . . . . . . . 
Figure 17. Examples of geotechnical engineering results of studies using (a) event tree, (b) First Order Reliability Method (FORM), and (c)-(d) random finite element method (RFEM). In (a), the probabilities found at each fork along a branch can be combined (multiplied) to attain the final probability of failure. In (b), the FORM-calculated reliability is contoured in the space of the soil variables $c^{\prime}$ and $\phi_{s}$, which is divided into two semiplanes by the thick line denoting the limiting state solution (margin of safety $\mathrm{FS}=1$ ). The same space is shown in (c) (in this case a positive correlation is evident with a 0.8 correlation coefficient between $c^{\prime}$ and $\phi_{s}$ ), where a Monte Carlo approach is used to explore the resulting design limit state in combination with a finite element representation of the soil continuum under a foundation bearing load (d). Courtesy of D. V. Griffiths

Figure 18. Proposed approach to direct reliability based design (d-RBD). Courtesy of J. Ben-Hassine . . .

Figure 19. Comparison of various methods to estimate the $Y_{50}$ load for the root flapwise bending moment: (a) extrapolation (IEC 2005); (b) importance sampling; (c), adaptive stratified importance sampling; (d) all methods on the same plot. Note there are 10 different repetitions for each method. Source: Graf et

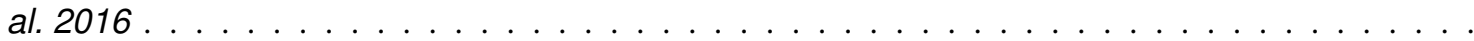

Figure 20. Example of constructed 50-yr environmental surface and search for maximum structural response. The space spans wind speed $(V)$, significant wave height $\left(H_{s}\right)$, and wave peak spectral period

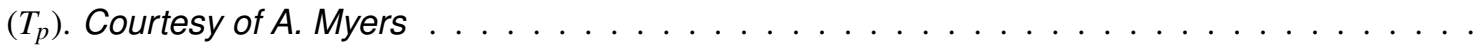

Figure 21. Typical failure-type relative distribution for wind turbine equipment as a function of equipment age throughout a 25-year project lifetime (each bar station represents one year). Source: Sheng and

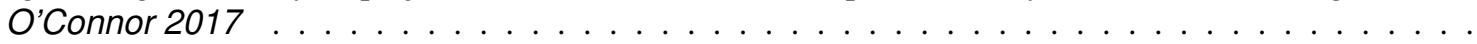

Figure 22. Examples of blade surface erosion. Source: Slot et al. 2015 . . . . . . . . . . . . . . . 34

Figure 23. Effect of data sample size ( $1 \mathrm{yr}$ vs. $11 \mathrm{yr}$ ) on the extreme turbulence model estimate of the windspeed standard deviation (a) and probability of exceedance distributions (b). Note the year-to-year variability in the POE. Courtesy of L. Manuel . . . . . . . . . . . . . . . . . . . . . . . . .

Figure 24. Shear distributions at two different sites with mean shear exponents: 0.05 (a) and 0.15 (b). Courtesy of E. Moroz . . . . . . . . . . . . . . . . . . . . . . . . .

Figure 25. Percent increase in damage equivalent loads for blade root (a) and hub (b) when accounting for variable wind shear as opposed to a fixed shear value. Excerpt from a study by Garrad-Hassan. Courtesy of E. Moroz . . . . . . . . . . . . . . . . . . . . . . . . . . . . . . . .

Figure 26. (a) Wind power plant annual energy production (AEP) prediction uncertainty and central estimates; (b) distribution of the ratio of observed-over-predicted-AEP for 249 wind plants across North America; (c) lack of relationship between standard error in AEP prediction and calculated uncertainties (from AWS Truepower). Courtesy of J. Fields . . . . . . . . . . . . . . . . . . . . . . .

Figure 27. Edgewise vibrational mode (a) and potential chordwise cracking (b). Courtesy of J. Bosche . . 38

Figure 28. Examples of uncertainty propagation onto power (left-hand side), blade root flapwise bending moment (middle), and tower-base fore-aft bending moment (right) obtained via the polynomial chaos expansion (PCE) method for wind field uncertainties as described in Table 4. Courtesy of J. P. Murcia, Technical University of Denmark . . . . . . . . . . . . . . . . . . . .

Figure 29. Configurations examined throughout the Offshore Code Comparison Collaboration (2005-2009)

(OC3) through Offshore Code Comparison Collaboration, Continued with Correlation (2014-2018)

(OC5) projects: (a) diagram showing the configurations examined; monopile (b) and semisubmersible (c) tested in a wave tank; full-scale measurement data from jacket-based offshore wind turbine (d). All models and simulation results from OC 3 and OC5 will be made public after the projects are completed, and will serve as benchmark problems for future investigations and research. Courtesy of A. Robert-

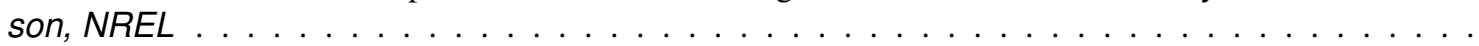


Figure 30. Examples of verification and validation (V\&V) results (various code outputs) from the OC3-

OC5 projects. From left to right, tower-base fore-aft bending moment and tensile loads in the mooring lines at the fairlead. Courtesy of A. Robertson . . . . . . . . . . . . . . . . . . . . . . . 42

Figure 31. System Management of Atmospheric Resources through Technology (SMART) wind plant.

Source: U.S. Department of Energy (DOE) _ . . . . . . . . . . . . . . . . . . . . . . 42

\section{List of Tables}

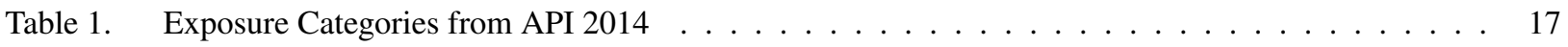

Table 2. Needed Value of $\gamma_{R}$ (material or resistance PSF) to Achieve a Reliability Index $\beta=3.3$ with $\gamma_{L}=1.35$, for Different Levels of Uncertainties of $R$ and $\delta_{R}$ as Indicated by their Respective COVs. . . . . 38

Table 3. Potential Reduction Factor Achieved for $\gamma_{L}$ (Load PSF) under the Indicated Changes in the $X_{d y n^{-}}$ $X_{s t r}$ Uncertainties (as Shown by the Changes in their COVs) (see Eq. (2.1)) . . . . . . . . . . . . 39

Table 4. Parameter Distribution Parameter Values for the Surrogate Construction from Murcia et al. 2016. . 40

Table 5. Design criteria identification and ranking table (DCIRT) Obtained from the Contribution of All Participants to the First Workshop on Uncertainty in Design $\ldots \ldots \ldots$. . . . . . . . . . 45

\section{List of Acronyms and Symbols}

\section{Acronyms}

3D three dimensional

\begin{tabular}{|c|c|}
\hline AEP & annual energy production \\
\hline ASIS & adaptive stratified importance sampling \\
\hline AWEA & American Wind Energy Association \\
\hline $\mathrm{COV}$ & coefficient of variation \\
\hline CPT & cone penetration test \\
\hline d-RBD & direct reliability based design \\
\hline DCIRT & design criteria identification and ranking table \\
\hline DEL & damage equivalent load \\
\hline DLC & design load case \\
\hline DOE & U.S. Department of Energy \\
\hline FEM & finite element method \\
\hline FLS & fatigue limit state \\
\hline FORM & First Order Reliability Method \\
\hline GOM & Gulf of Mexico \\
\hline HPC & high-performance computing \\
\hline
\end{tabular}




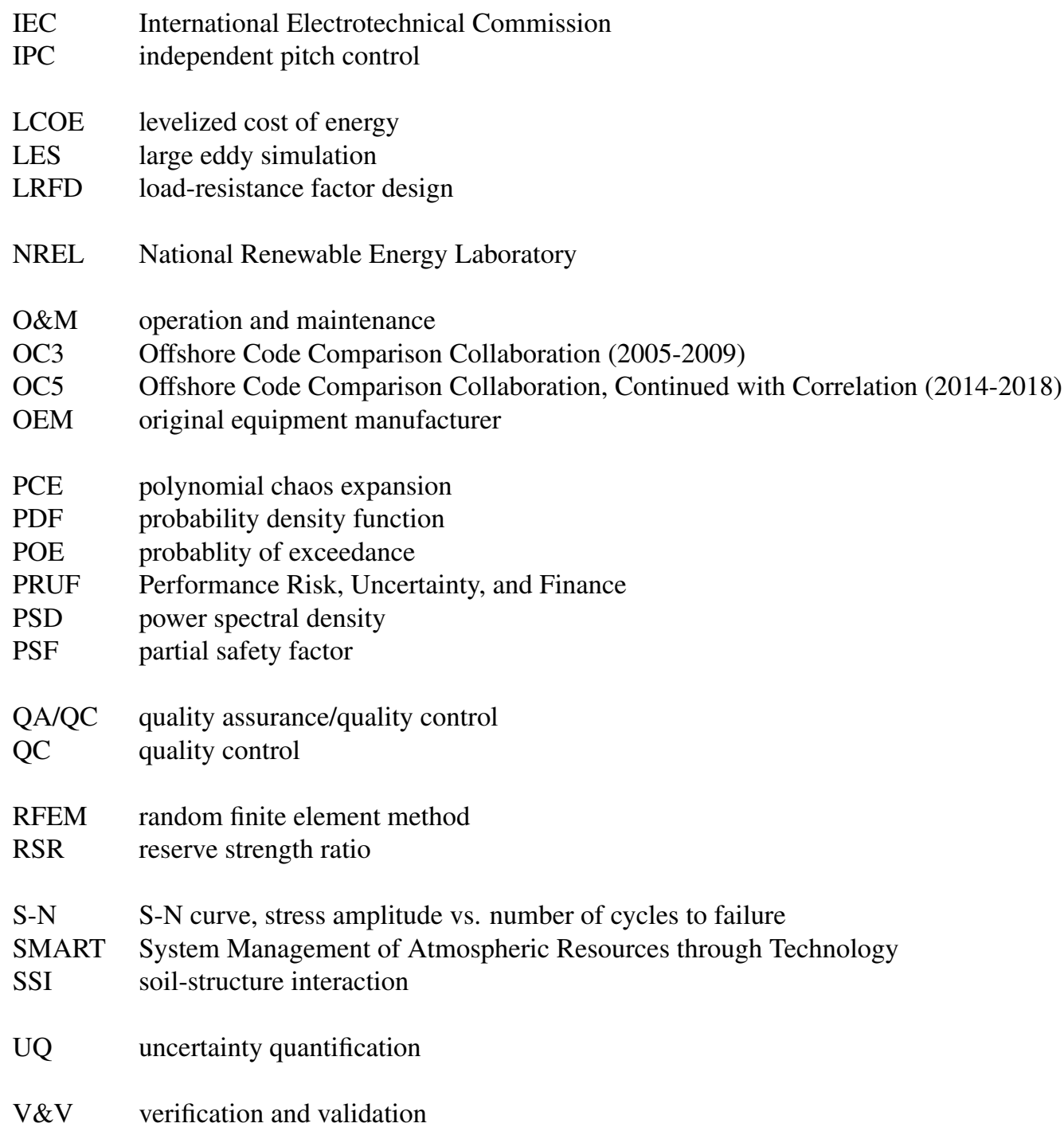

\section{Symbols}

A Weibull distribution scale factor

$C O V_{\text {fat }} \quad$ coefficient of variation for the fatigue load

$C O V_{s c f} \quad$ coefficient of variation in the uncertainty PDF of the stress concentration factor

$C O V_{\text {wind }} \quad$ coefficient of variation in the uncertainty PDF of the wind load

$H_{s} \quad$ significant wave height

$L_{x} \quad$ extreme load

$L \quad$ load

$N_{10 m} \quad$ number of load peaks in a 10-min interval

$P\left(Y<Y_{50}\right) \quad$ probability that load $Y$ is less than load $Y_{50}$

$P_{f} \quad$ probability of failure

$P_{10 m} \quad$ probability that load $Y$ is greater than load $Y_{50}(50-$ yr return period load level) in a 10-min interval

$R_{S} \quad$ structural reliability

$R_{\text {ult }} \quad$ ultimate structure resistance

$R \quad$ resistance 


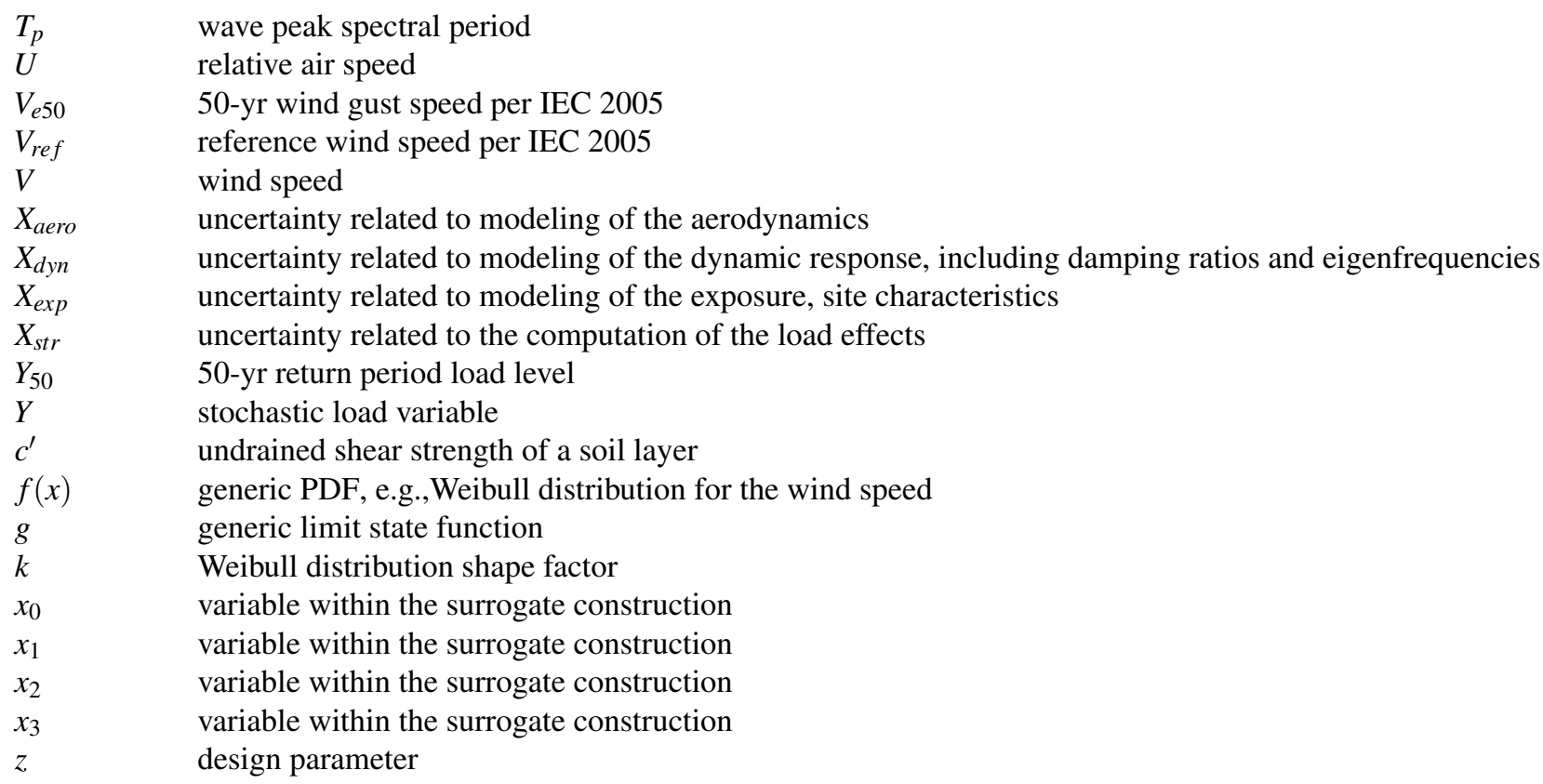

\section{Greek Symbols}

$\begin{array}{ll}\alpha & \text { angle of attack } \\ \alpha_{s} & \text { power law (shear) exponent } \\ \beta & \text { structural reliability } \\ \gamma & \text { yaw error } \\ \gamma_{L} & \text { load PSF } \\ \gamma_{R} & \text { material or resistance PSF } \\ \delta_{R} & \text { uncertainty in the strength model } \\ \mu_{A} & A \text { mean } \\ \mu_{\sigma_{s}} & \sigma_{\alpha_{s}} \text { mean } \\ \mu_{\gamma} & \gamma \text { mean } \\ \mu_{k} & k \text { mean } \\ \mu_{\sigma_{1}} & \sigma_{1} \text { mean } \\ \sigma_{U} & U \text { standard deviation } \\ \sigma_{\alpha_{s}} & \alpha_{s} \text { standard deviation } \\ \sigma_{\gamma} & \gamma \text { standard deviation } \\ \sigma_{\sigma_{1}} & \sigma_{1} \text { standard deviation } \\ \sigma_{1} & \text { turbulence standard deviation } \\ \sigma_{A} & A \text { standard deviation } \\ \sigma_{k} & k \text { standard deviation } \\ \tau_{2} & \text { radius-dependent time constant in the filter dynamics } \\ \tau_{2} & \text { time derivative of } \tau_{2} \\ \phi_{s} & \text { friction angle of a soil layer } \\ \Phi^{-1} & \text { inverse Gaussian distribution function } \\ & \end{array}$

ix 


\section{Executive Summary}

Despite the impressive progress in wind power engineering and the staggering global growth of wind plant installations, turbulent wind operation is still laden with uncertainties that require deepened scientific understanding and that can spur innovation in wind turbine and plant design. The U.S. Department of Energy (DOE) Atmosphereto-Electrons (A2e) program seeks to target these uncertainties through systematic investigation. Whereas various efforts have identified sources of uncertainty affecting wind plant performance, this work, carried out under the A2e program, provides an in-depth and organized perspective on how uncertainty affects turbine design and structural reliability.

This report leverages the concepts and opinions that emerged from an initial study on the subject of uncertainty in wind design that included expert elicitation during an A2e workshop held at the National Wind Technology Center at the National Renewable Energy Laboratory July 12-13, 2016.

Five major categories of uncertainties are identified. The first category is associated with direct impacts on turbine loads, (i.e., the inflow including extreme events, but also aero-hydro-servo-elastic response, soil-structure interaction, and load extrapolation). The second category encompasses material behavior and strength. Site suitability and duediligence aspects pertain to the third category. Calibration of partial safety factors and optimal reliability levels make up the fourth one. And last but not least, is the category associated with uncertainties in computational modeling. The main sections of this paper follow this organization.

The topic of uncertainty in wind turbine and power plant design is very broad and many intermingled pathways could be followed to try and capture the most critical aspects. To organize and prioritize the various phenomena, a design criteria identification and ranking table (DCIRT) was created based on the inputs of many experts in the field (see Section 3). The DCIRT uses color codes (red, yellow, and green) to identify priorities (high, medium, and low) and areas in need of more research. The DCIRT shows many areas as 'red,' as they are perceived as critical to the structural reliability of the wind system and for lowering the levelized cost of energy. From the DCIRT, the key uncertainty sources and a few recommended actions were extracted, and are summarized below and in Section 5.

As the system inflow field is deemed the most important source of uncertainty, targeted high-fidelity modeling is encouraged, specifically to develop simpler, more accessible and applicable engineering tools as well as to refine the standard design criteria. Atmospheric parameters, such as thermal stability, veer, nonaverage shear, and their impacts on the structural reliability and turbine performance should be assessed. By the same token, a critical re-evaluation of the physical meaning and impact of the 10-min and 3-s timescales is needed.

Extreme events are also rare, and lack of measurement data makes it very difficult to include their effects in load simulations. More data from high-fidelity models and field measurements are required to help design structures that are resilient to phenomena such as tropical cyclones and convective storms.

Overall, design standard classes should be extended or improved to include factors and parameters that more closely represent actual conditions in the field. This is particularly important as rotors become larger and more flexible.

Engineering models should also be validated for the physics pertaining to these larger and more complex machines.

A large source of uncertainty is associated with manufacturing nonconformities and poor quality assurance/quality control protocols, which should be advanced and better codified for the wind industry. Including effects of large manufacturing defects or human operational errors within the load simulations could also be a strategy to increase structural reliability.

Some of the challenges in site suitability and due diligence arise from the lack of transparency between turbine original equipment manufacturers and independent engineers, as for example on machine control algorithms, which should be addressed to both understand and reduce uncertainties. 
A rigorous uncertainty quantification and tracking in modeling would clarify the sources of modeling uncertainty, thereby leading to improved optimization schemes for design and a fully probabilistic process.

Finally, a critical reanalysis of the partial safety factor calibration would ensure an optimal level for the structural reliability of wind power plants, especially offshore. Reliability levels, and uncertainties in design, obviously affect the levelized cost of energy and therefore should be addressed from a systems engineering perspective based on socio-techno-economic risk analyses. 


\section{Background}

The U.S. Department of Energy (DOE)'s Wind Energy Technologies Office proposes the development of computational capabilities that will expand the understanding of wind power plant atmospheric flows, and the response of the turbines to those flows. Efforts within DOE's Atmosphere-to-Electrons (A2e) program span from the power performance and preconstruction energy estimates (e.g., Clifton, Smith, and Fields 2016; Tusing and Fields 2016) to the atmospheric multiscale coupling and high-fidelity modeling and validation (Haupt et al. 2015, 2017; Hills, Maniaci, and Naughton 2015; Womble et al. 2015; Maniaci and Naughton, forthcoming; Maniaci et al., forthcoming; Schreck, forthcoming). These aspects primarily deal with the performance of a power plant with ramifications also on site-suitability assessments. The work summarized in this document focuses on the uncertainty on the design and its impact on structural reliability of wind installations and associated due-diligence. In any case, the common goal is the reduction of the levelized cost of energy (LCOE) via technological innovations that can be enabled by leveraging a better understanding of the operational environment. Computational modeling can enable this understanding and lead to changes in the plant operation and design process with reduced uncertainty. The technological applications include wind power plant control, plant-level optimization, and an improved engineering-level design capability. Overall improvement to the design process of wind power plants include opportunities to ameliorate the standards that define the design criteria, to render the design basis more accurate and robust, and to streamline the modeling and computational process.

The expectation is that understanding and quantifying the key uncertainties will lead to refined design guidelines and, as a consequence, lower LCOE. The resulting products will, in fact, be designed and manufactured to take advantage of a more critical appreciation of the manufacturing, environmental, and loading aspects. That renewed level of understanding of the physical processes paired with a more rigorous site-suitability assessment will help wind power plants maintain low probabilities of failure without incurring penalties associated with excess material or design capacity.

The topic of design uncertainty is broad and multifaceted, and it is arduously frameable within prescribed boundaries or categories. Yet, a few considerations can be made that apply to the entire wind field.

First of all, it should be recognized that design conditions and modeling capabilities have inherent uncertainties. In the wind sector, more than other industries, the intrinsic variability and complexity of the turbulent medium and the aerostructural dynamic response create unique challenges that cannot be assessed with deterministic methods, thereby requiring sophisticated approaches within the load-resistance factor design (LRFD) process. To this end, the internationally recognized design standards propose methods and partial safety factors (PSFs) for objectively managing well-understood, repeatable conditions, as well as the uncertainties in both their nature and the ability to model them. The recommended PSFs are generally intended to cover the difference between inherent safety and characteristic values driven by the estimated total uncertainty. Often design conditions and safety margins are adapted from other industries or applications with very similar design problems. For example, the offshore wind industry is grappling with the question of overload hazard, which the offshore oil and gas industry has come to appreciate and codify via a number of dedicated studies and prescriptions, such as the robustness check and the concept of reserve strength ratio (API 2014). Furthermore, from the modeling standpoint, there is no simple way to quantify the variability in the modeling capability that defines the modeling uncertainties. A consequence of the above aspects is that calibration, application, and origin of the PSFs should be revisited in the standards, especially in light of new advances in the understanding of the physics of the environment and modeling capabilities. Although the current approach to the design is safe and reliable, it could limit innovation and require more cost than necessary.

In response to this matter, the National Renewable Energy Laboratory (NREL) held a mini-workshop in the summer of 2016, which was sponsored by the U.S. DOE's Wind Energy Technologies Office. The workshop was aimed at identifying and prioritizing the gaps in the understanding of the design process through assessment of and reduction in its uncertainties, both in terms of the accuracy of analysis tools and of the criteria to be met for reliable operation.

The salient points of the workshop and the expert opinions are summarized in this document, which also intends to provide guidance for future efforts within DOE's Atmosphere to Electrons program, and to serve as a reference for

13

This report is available at no cost from the National Renewable Energy Laboratory at www.nrel.gov/publications 
the industry on potential risks and opportunities. A main goal of this ongoing research is to help improve the design process by addressing the greatest opportunities for uncertainty clarification and/or reduction, while also facilitating the process of consensus on improvements to international standards for wind turbine and wind power plant design.

This document is organized as follows. The major categories of uncertainty and perceived needs by the industry experts are given in Section 2. Section 3 describes the importance and cursory prioritization that experts attributed to each source of uncertainty and associated design criteria. Conclusions and recommended actions for stakeholders are presented in Sections 4 and 5, respectively. 


\section{Identified Sources of Uncertainty}

\subsection{Approaches to the Design}

For a design to be safe and reliable, an appropriate level of structural reliability (probability of nonfailure during the lifetime of the product) must be guaranteed. Regardless of the achieved structural reliability, ${ }^{1}$ failures can still occur. One of the design goals is to bring this possibility to an acceptable level from a holistic standpoint.

The overall design approach includes a combination of theoretical and computational models, investigations of components and materials, and measurements of climatic conditions. Therefore, uncertainties permeate every aspect of the physical, modeling, and statistical data. A first attempt at characterizing these uncertainties already lies in the concept of limit-state design.

The generic limit-state $(g)$ can be formally expressed as a function of the uncertainties related to the dynamic response $\left(X_{d y n}\right)$, aerodynamics modeling $\left(X_{\text {aero }}\right)$, exposure (site conditions) modeling $\left(X_{\text {exp }}\right)$, and load-effects modeling (internal load modeling, $\left.X_{s t r}\right)$, for a given external, extreme load ( $L_{x}$, extrapolated to $50 \mathrm{yr}$ ) (Sørensen and Toft 2014):

$$
g=z \delta_{R} R-X_{\text {dyn }} X_{\text {exp }} X_{\text {aero }} X_{s t r} L_{x} \geq 0
$$

In Eq. (2.1), $z$ is the design parameter (e.g., cross-section bending modulus), $\delta_{R}$ is the uncertainty in the strength model, and $R$ is the resistance.

The diagram in Figure 1 illustrates the main concept behind the LRFD approach, which is the basis of the widely accepted limit-state design. The diagram refers to extreme loads (ultimate limit state [ULS]) but it applies equally to fatigue limit state (FLS) design. The load is statistically distributed about a mean value, and so is the component strength. Two PSFs, one for the load $\left(\gamma_{L}\right)$ and one for the resistance $\left(\gamma_{R}\right)$, are applied to the characteristic values of load $(L)$ and resistance $(R)$, respectively. These values are taken as some quantiles of their respective distributions, and the PSFs then account for the uncertainties declared in Eq. (2.1). With reference to the graph in Figure 1, the limit state equation is rewritten as in Eq. (2.2), and it ensures that the factored load is less than the factored resistance:

$$
\gamma_{L} L \leq \frac{R}{\gamma_{R}}
$$

Eq. (2.2) ensures that the probability of failure (simplistically the area identified by the overlap of the load and resistance distributions in Figure 1) is small. Structural reliability (denoted by either $R_{S}$ or $\beta$ ) and probability of failure $\left(P_{f}\right)$ are related as in Eq. (2.3):

$$
\begin{aligned}
& R_{s}=1-P_{f} \\
& \beta=\Phi^{-1}\left(1-P_{f}\right)
\end{aligned}
$$

where $\Phi^{-1}$ is the inverse Gaussian distribution function, and $\beta$ is the number of standard deviations from the mean. The U.S. oil and gas industry (API 2014) has set clear target reliability values that have also been adopted by international standards (e.g., ISO 2013). For example, for manned offshore structures, the accepted annual failure rate is $P_{f}=3 \cdot 10^{-5}$ or $\beta=4$; for unmanned structures, $P_{f}=5 \cdot 10^{-4}$ or $\beta=3.3$. This latter value also applies to wind turbines in Ed. 4 of the International Electrotechnical Commission (IEC) 61400-1 design standard (61400-1. Wind turbines -Part 1: Design requirements forthcoming). In previous versions of the IEC standard, a reliability closer to $10^{-3}$ (i.e., a higher failure rate) was assumed. The choice of a $P_{f}=5 \cdot 10^{-4}$ reliability level corresponds to a 'moderate' consequence of failure and 'relatively high' costs of safety measures. Note that while $P_{f}=5 \cdot 10^{-4}$ is now broadly assumed, a $2 \cdot 10^{-3}$ blade failure rate and $8 \cdot 10^{-4}$ turbine collapse rate have been observed in the 1984-2000 time frame (J. Stalgaard, personal communication).

The spread of the load and resistance distributions in Figure 1 is, in part, caused by the uncertainties in the design process. To account for most of the uncertainty, PSFs are used, and then the design parameters are adjusted to satisfy

\footnotetext{
${ }^{1}$ Structural reliability does not include routine replacement of parts or unplanned repairs involving minimal downtime and with no personnel or public risk.
} 


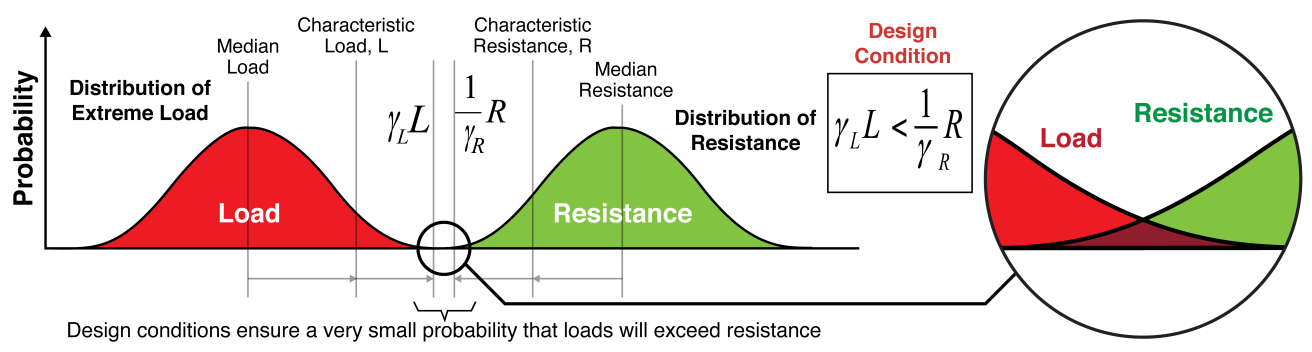

Figure 1. LRFD diagram

Eq. (2.2). Although the PSFs may not adequately represent the actual uncertainty values, they offer a quick and effective way to get a design qualified and even certified.

An alternative to the LRFD is the fully probabilistic design (e.g., Structural Safety 2000). Through this more complex approach, a more effective and economic end result could be achieved. The key steps to perform reliabilitybased design of wind turbine components include:

- Failure modes identification

- Uncertainty modeling:

- Aleatory uncertainty: physical uncertainty

- Epistemic uncertainty: model, measurement, and statistical uncertainties

- Reliability/probability of failure estimation

- Design of components while meeting reliability requirements.

In this variant approach, the design parameters are changed until a target level of reliability is achieved. This method assumes a deeper knowledge of the uncertainty distributions and their effects on the design parameters. The various uncertainties can be assessed and combined by use of Bayesian statistical methods (see also Structural Safety 2000; Sørensen and Toft 2014); the number of sources for uncertainty in a wind power plant or wind turbine design, however, is daunting.

Notwithstanding the approach chosen, a reliability target should be determined. As mentioned earlier, the latest edition of the IEC standard (61400-1. Wind turbines - Part 1: Design requirements forthcoming) assumes a 5 . $10^{-4}$ reliability level. The oil and gas industry has conducted numerous studies to arrive at a reliability level to be guaranteed based on the required safety level or exposure. In Table 1, the so-called 'L'-exposure categories for oil and gas offshore platforms as identified by API (2014) and ISO (2013) are shown. Recent guidance from the American Wind Energy Association (AWEA) (AWEA 2012) declared offshore wind turbines as 'L2' structures. The reason for this seemingly conservative categorization is that although turbines are effectively unmanned structures, the consequence of a design flaw and the subsequent risk of failure in one turbine could rapidly propagate to a large number of units (as opposed to the oil and gas case), thereby penalizing the entire offshore wind industry. However, it is still unclear as to what reliability level would be needed to optimize the life cycle cost of offshore wind turbines (see Figure 2). On land, the risk is reduced and the track record can be used to fine tune the target reliability levels. Offshore, the life cycle cost analysis should be properly conducted to arrive at the optimal probability of failure, thereby minimizing the project socio-economic risk.

From Figure 1, it is evident that uncertainties affect the reliability levels for given PSFs, and PSFs are tuned based on the uncertainties to reach target reliabilities. Hence, one way to categorize uncertainties is to separate those associated with either the loads side or the resistance side of Eq. (2.2). Alternatively, they could be grouped in terms of physical uncertainties, modeling uncertainties, and site-suitability uncertainties. In the next sections, we consider the first of these grouping approaches, but with the understanding that overlaps between categories exist and that a 
Table 1. Exposure Categories from API 2014

\begin{tabular}{c|ccc}
\hline \hline \multirow{2}{*}{ Life-Safety Category } & \multicolumn{3}{|c}{ Consequence Category } \\
& C1 - High & C2 - Medium & C3 -Low \\
\hline S1 - Manned non-Evacuated & L1 & L1 & L1 \\
S2 - Manned Evacuated & L1 & L2 & L2 \\
S3 - Unmanned & L1 & L2 & L3 \\
\hline
\end{tabular}

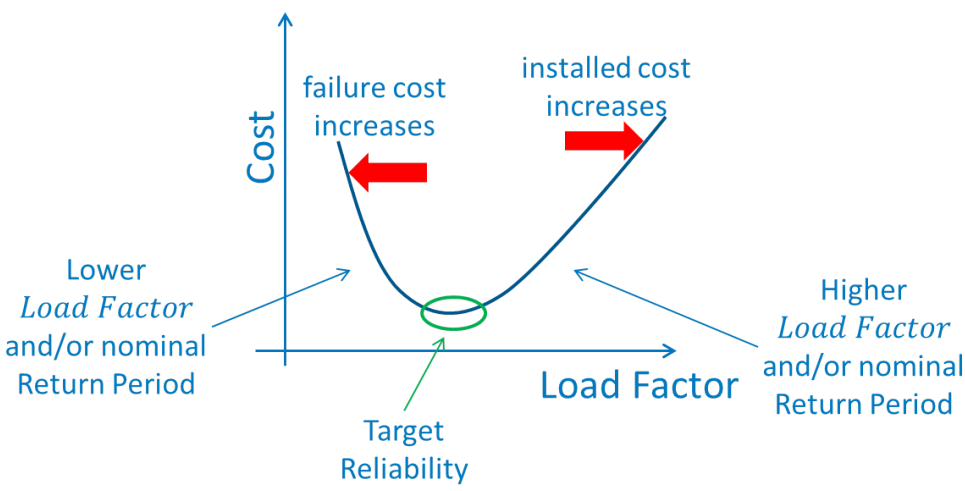

Figure 2. How load factor and assumed load return periods can affect reliability and costs (Damiani and Musial 2014)

clear demarcation is not possible in some cases. Moreover, it can be safely stated that the most fundamental source of uncertainties for wind design is the highly variable wind field itself, which because of its nature can only be described statistically. In addition, other sources of uncertainties are:

- External (to the machine), atmospheric, meteorological ocean, and soil conditions

- Component strength

- Manufacturing repeatability

- Site evaluation and site suitability

- PSF calibration associated with the assumed probabilities of failure

- Calculation and modeling methods.

\subsection{Uncertainty Affecting Turbine Loads}

Turbine loading is governed by both external conditions and turbine operation settings. The standards recommend different PSFs based on the level of variability expected and the criticality of the design situation; load case by load case. The design standards (e.g., IEC 2005) prescribe eight load case categories (i.e., start-up/shutdown, power production, faults, and transportation/installation), each of which can be considered as potentially leading to extreme loads or fatigue damage.

Uncertainties in the load also come from the assumptions that go into modeling those loads, hence their resulting distributions. The power production load cases are addressed stochastically. It is required (IEC 2005) that the extreme load with a 50-yr return period (probability of $3.87 \cdot 10^{-7}$ on a 10 -min interval) be calculated at least for the rotor blades. The extreme value distribution can be characterized by the Poisson model, and the ultimate load could be extrapolated following a procedure described in IEC 2005. In that procedure, the local, short-term distributions derived 


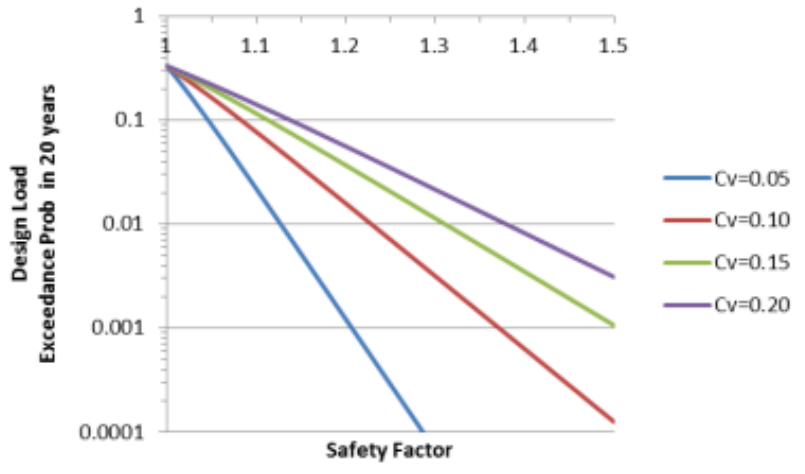

(a)

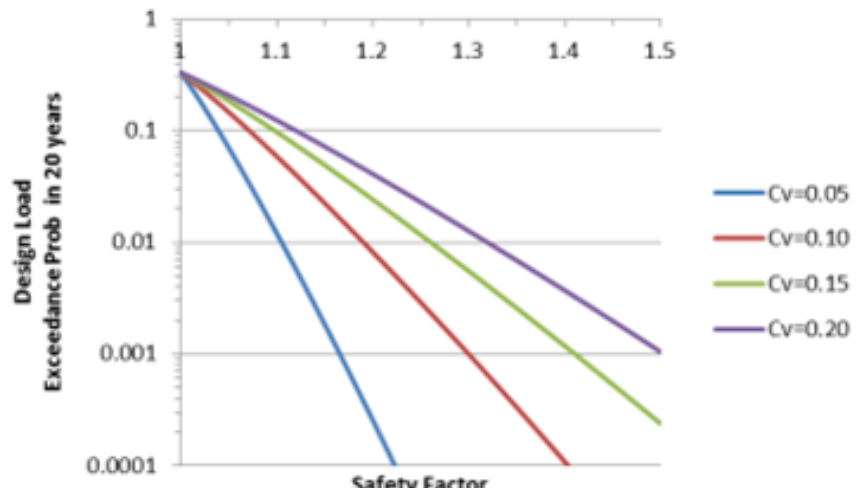

(b)

Figure 3. Resulting probability of failures calculated for various safety margins for load extremes assumed as either Gaussian (a) or Gumbel (b) distributed. Courtesy of Bill Holley

from fitting the load peaks to some model (e.g., the three-parameter Weibull) are convoluted with the wind probability distribution to arrive at the load with the target probability (see also Ragan and Manuel 2008; Graf et al. 2017). Yet, the results are highly sensitive to the choices of short-term fitting (see Figure 3) and the way the load peaks are selected. Different outcomes from varying assumed distributions are to be expected, therefore diverse reliabilities can be calculated depending on the models used (see also Figure 3).

For other load cases, a description of the stochastic models (e.g., coefficient of variation and shape of the distribution) is not available from observations. Therefore, improved validation of simulation-based results against field tests is still an invaluable aid to reducing, or at least characterizing, the uncertainties.

In the following subsections, we describe the uncertainties that end up in the $X$ terms of Eq. (2.1), starting from the most prominent $X_{\text {exp }}$, i.e., the modeling of the inflow.

\subsubsection{Uncertainty in the Inflow}

General consensus indicates that the largest uncertainty in wind design, both at the turbine as well as the plant level, resides in the aleatory and epistemic characteristics of the inflow (both in the air and ocean media). Some of the aspects related to the inflow are:

- Turbulence spectrum and spatial coherence

- Wind velocity component-to-component correlation

- Wind shear

- Stability

- Wake effects

- Terrain effects

- Wind veer

- Offshore wave field characteristics.

The phenomena mentioned earlier impact the load response of wind turbines as well as the performance of the wind power plant. Processes associated with flow phenomena, such as the kinetic energy budget associated with thermal and mechanical production, transport, and dissipation of turbulence, or the interaction between the wave/current flow 
field and the soil dynamics (e.g., scouring) in an offshore environment are examples of complex physics that are difficult to model accurately.

The uncertainty in the inflow conditions propagates to the simulated loads, and the design practice and standards are tools to deal with these load uncertainties. Some level of codification for the inflow is present in the design standards, but validation and verification of the inflow physical models still remains necessary. Although the IEC guidelines recommend the use of inflow turbulence models with prescribed (deterministic) parameters, it is apparent from the uncertainties associated with field experiments (Solari and Piccardo 2001) that even these spectral and coherence parameters are inherently stochastic. Examples of these parameters include turbulence intensity factors, parameters related to the integral length scales of the turbulence, exponential decay coefficients of coherence functions based on Davenport's (1961) model, and cross-coherence scaling factors. Exponential decay parameters reported in the literature, for instance, indicate a large uncertainty (estimated coefficient of variation (COV) of $60 \%$ Solari and Piccardo 2001) in describing the coherence structure of turbulence fields at different frequencies and spatial separations. Kelley et al. (2005) also point out that the lack of stationarity in inflow wind velocity processes, which are not represented in the IEC turbulence models, can be another important factor to be accounted for when calculating wind turbine loads.

Researchers (e.g., Saranyasoontorn and Manuel 2008) have investigated the effect of the uncertainty propagation by spanning the space of the inflow parameter sets and running Monte Carlo simulations. The results show that COV between $20 \%$ and $40 \%$ in the inflow parameter distributions rendered COV between $1 \%$ and $13 \%$ in the blade and tower loads. These results seem to point to a low sensitivity of these inflow parameters on the loads compared to turbulence intensity, yet more studies are clearly needed. To achieve low-dimensional surrogate models that can be efficiently used for design, in fact, high-performance computing (HPC) resources are needed to process the highdimensional random variable and process space.

Similar considerations apply to offshore, wherein wave spectral characteristics, as well as mechanical behaviors associated with steep and breaking waves are still a topic of research and much uncertainty is still present on their effects on the turbine system loads.

\subsubsection{Extreme Events}

The verification of the structural integrity of a wind turbine involves the analysis of fatigue and extreme loading (Larsen et al. 1999). The extreme load to be assessed in a ULS analysis can result from a number of extreme events including transient operation (start/stop sequences) near rated or cut-out wind speeds, faults, and extreme wind events. Note that extreme loads can also be driven by normal operation, which is discussed in Section 2.2.5 together with the need for 'extrapolation' of IEC design load case (DLC) 1.1 loads (IEC 2005).

Faults can be simulated in the field to a certain extent, but simulations are essential to reduce the uncertainties of the consequent loading in most cases. The extreme wind environment, however, is still laden with uncertainties. Examples of extreme events are extreme mean wind speeds with a recurrence period of 50 years, extreme wind shear, extreme wind speed gusts, and extreme wind directional changes. These events can also be associated with severe weather phenomena, such as mesoscale cyclonic storms and hurricanes.

In the United States, convective events (thunderstorms and tornadoes) are responsible for $80 \%$ of the damage to all civil structures (not wind turbines per se), and for the annual maximum recorded wind speeds in many locations (see Figure 4a).

To create design wind maps to be used in civil engineering structural code and standards, all wind measurements (separated in nontropical and tropical events) are corrected for anemometer height, averaging time, exposure, and terrain effects (see Figure 5).

Wind speed probablity of exceedance (POE) curves are then developed using stochastic models (see Figure 6). A Type I distribution generally describes the probability of peak gusts rather well (see Figure 4b). However, uncertainties exist in the parameter estimations (correction factors) as well the stochastic modeling procedure to arrive 


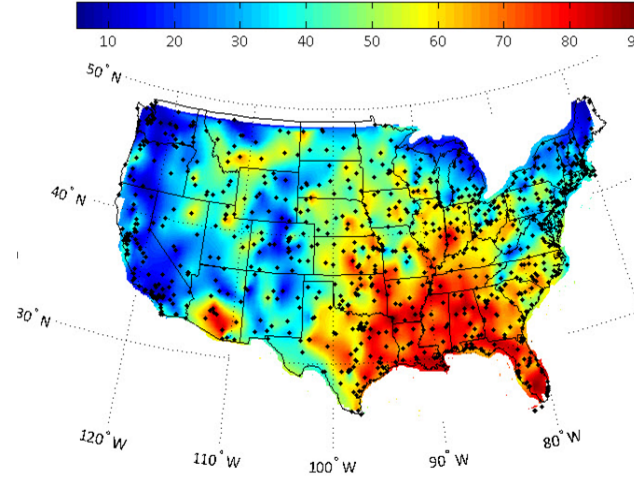

(a)

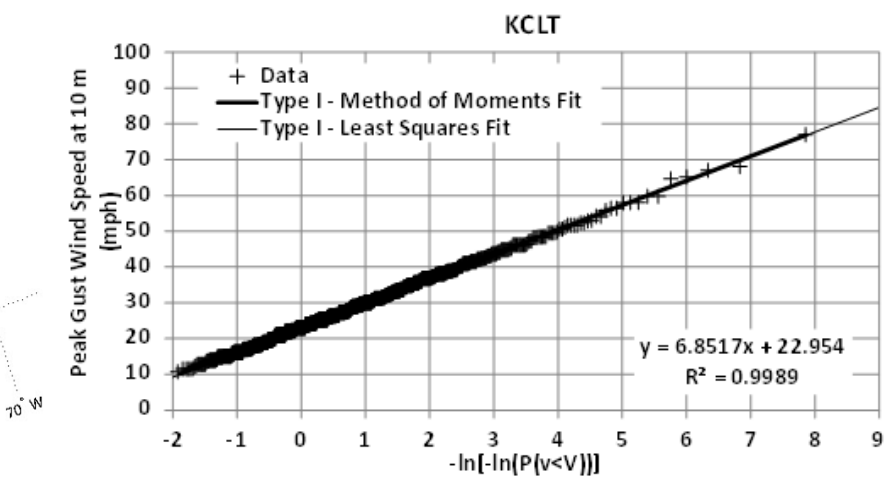

(b)

Figure 4. Thunderstorm events are key sources of extreme wind speed events in the United States.

(a) color contours indicate the percentage of annual wind speed maxima ( $3 \mathrm{~s} \mathrm{gust)} \mathrm{attributable} \mathrm{to}$ (nontropical) thunderstorm events in the United States. Courtesy of F. Lombardo. (b) Derived Type I fit for peak gusts as a result of a thunderstorm for Charlotte, North Carolina. Courtesy of P. Vickery

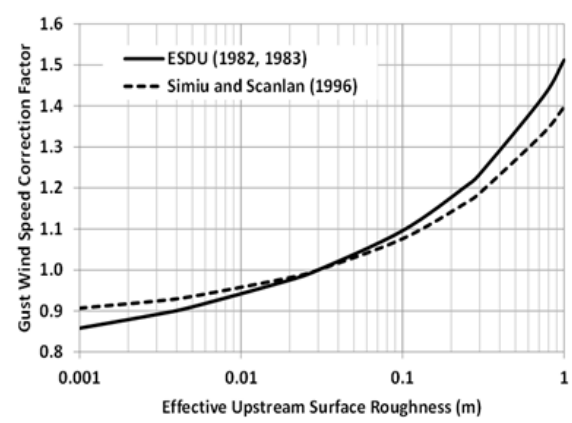

(a)

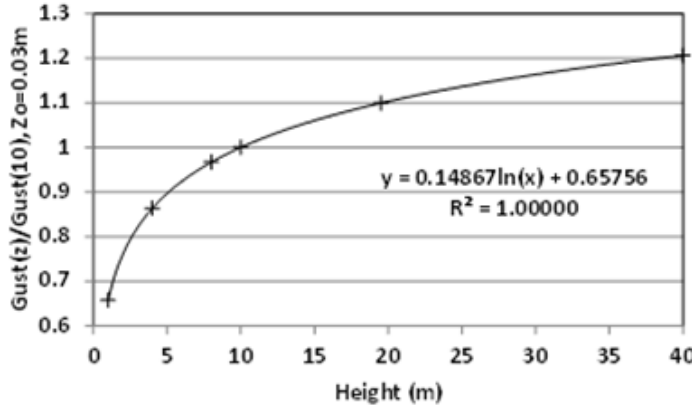

(b)

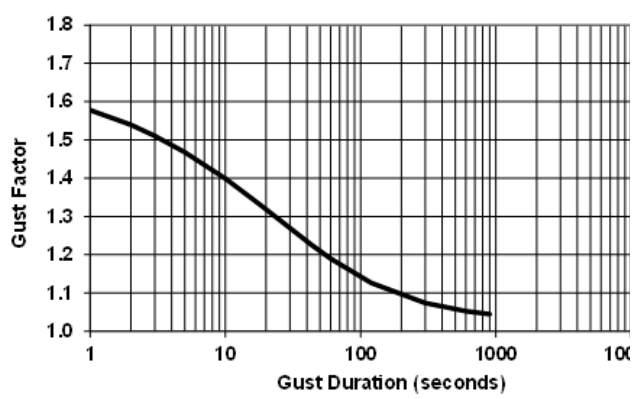

(c)

Figure 5. Examples of correction factors for gust wind speeds as a result of surface roughness (a), altitude (b), and gust duration (c). Courtesy of P. Vickery

at the POE curves (see Figure 6). Wind speed POE curves are to be further combined with the so-called fragility curves (that account for the structural response, material strength, and failure criteria) to arrive at the so-called hazard curves. Hazard curves describe how the load increases with return period, and are discussed later. 


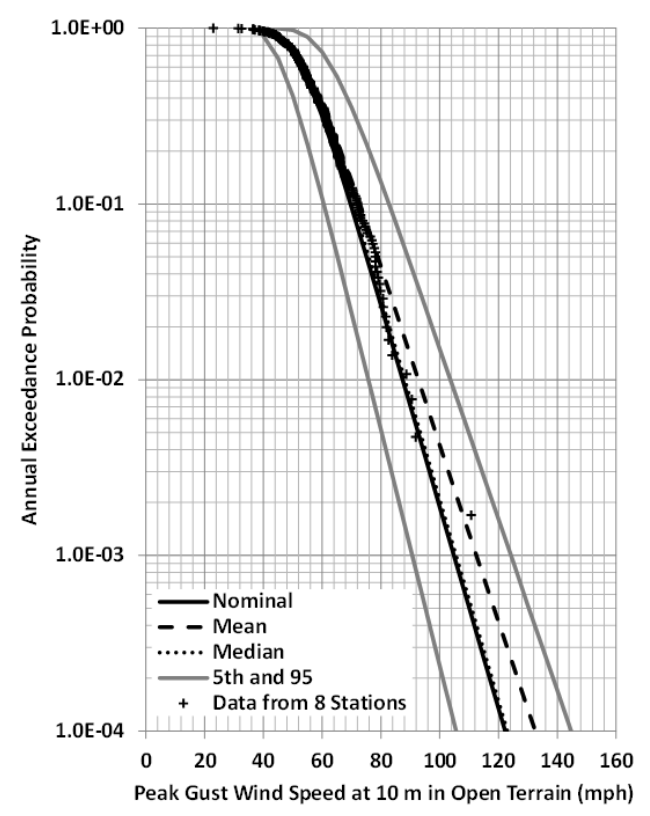

Figure 6. Example of gust POE including uncertainty propagation. Courtesy of P. Vickery

Scholars suggest that the description of these events included in the current design standards is incomplete, partially because of the scarcity of measurement data and lack of physical understanding. Although tornadoes and thunderstorms are relatively localized occurrences, they can still cause a very large amount of damage in the narrow region of maximum wind speed. Uncertainties associated with the physics of these events (e.g., mean wind profiles and gust factors, as shown in Figure 7), and the resulting differences in their probabilistic representation in the design standards increase the project risk. Among the perceived needs are improvements in:

- The classification of atmospheric conditions

- The site-specific characterization in terms of turbulence, shear, veer, and stability

- Measurement and probabilistic modeling capabilities

- Target reliability and resistance levels associated with project economics and the trade-off between capital cost and replacement cost.

Thunderstorms, in particular, show more variability than previously thought. There are still doubts as to whether turbulence and gust structure are well represented in the IEC definition of extreme conditions. Tornadoes, while at low risk for an individual turbine, can be of significant risk for large wind farms. The loading associated with these events should account for rapid changes in wind direction and speed, large vertical component of the wind velocity, and site-specific properties that could change the structure response as indicated by normal events.

The matter of overload hazard and extreme events is thus another aspect that includes a number of uncertainties and with which turbine and wind power plant designers have to contend.

\subsubsection{Tropical Cyclones and Other Extreme Loading Environments}

Offshore, the uncertainty of extreme events is compounded by the more acute scarcity of observational data resulting from the inherent logistical complexity. Other phenomena, beside wind and waves with significant impact on offshore system loading, especially for the United States, are associated with ice floes and deepwater mechanics. But 


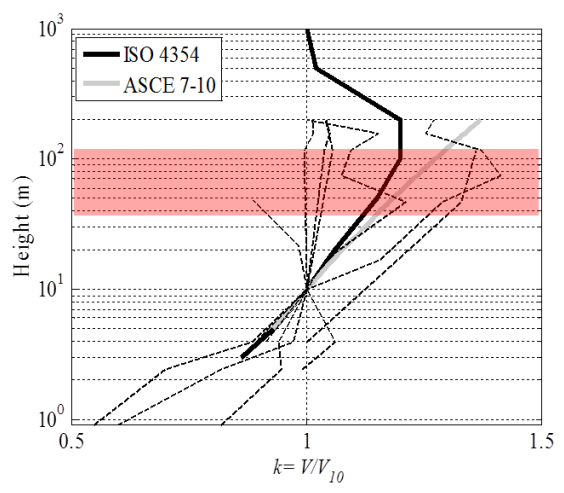

(a)

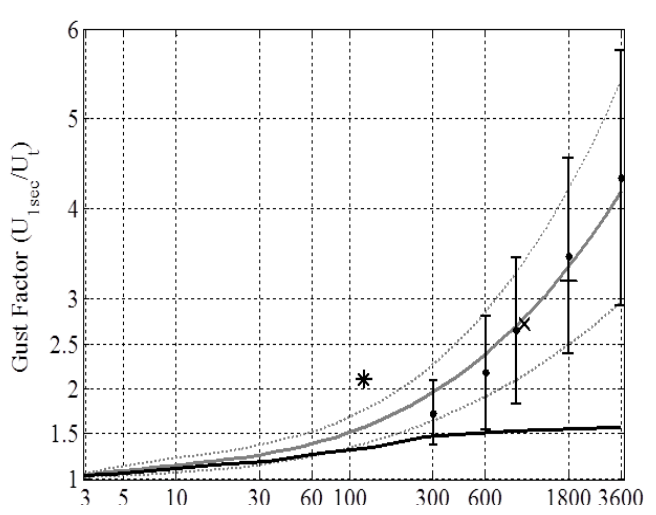

(b)

Figure 7. Examples of recorded mean wind profile (a) and gust factor (b) curves that show different behaviors near hub height (shaded region) than what is expected from codified laws (SEI 2010; ISO 1998). Courtesy of F. Lombardo

perhaps the most important, long-term overload hazard is associated with hurricanes or tropical cyclones, and it is particularly difficult to estimate given the limited records available (see also Figure 8).

Sources of uncertainty for hurricane wind hazard quantification include the occurrence rate, storm trajectory, modeling of key parameters (e.g., minimum pressure and Holland B parameter [Holland 1980]), models for storm weakening, and effects of climate change. Furthermore, data measurements at altitudes comparable to modern turbine hub heights are sparse and there is a need to understand mean wind profiles, gust factors, turbulence intensity, integral scale, turbulence spectra, and coherence in tropical cyclone environments to develop a realistic wind model to be used in design (ABS 2011).

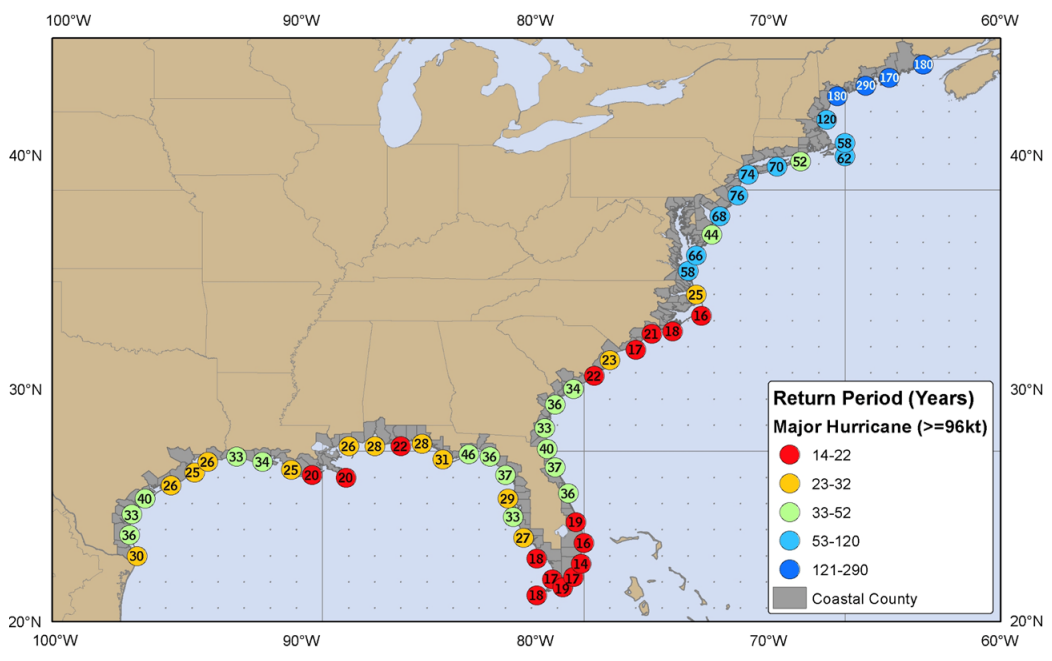

Figure 8. Return periods for hurricanes of category 3 and above along the Atlantic Coast. Courtesy of J. Lundquist

Large eddy simulation (LES) can help achieve this goal by providing three-dimensional fields of turbulent winds at high spatial and temporal resolution (see Figure 9). When compared to LES-derived quantities for category 3 or higher hurricanes, the models in IEC 2005 specify a lower power spectral density (PSD) magnitude and peak fre- 
quency (see Figure ??). Moreover, the LES results show significant gust factor values (in excess of 1.4) associated with 3-s wind gusts in excess of $70 \mathrm{~m} / \mathrm{s}$ (see Figure 9c). A recent study (Worsnop et al. 2017) finds that category 5 hurricanes could have gust factors of 1.7 or higher within the eyewall and near typical hub heights, and that significant wind directional changes $\left(>10^{\circ}\right.$ and in less than $\left.10 \mathrm{~min}\right)$ can also occur along with wind veer of $35^{\circ}$ across the rotor disk for periods of up to $10 \mathrm{~s}$. Further, when considering the extent of the eye of a major hurricane that could encompass most, if not all, of a wind power plant experiencing a direct strike (Worsnop et al. 2017), these results confirm the possibility of excessive loading and damage during significant hurricane events.

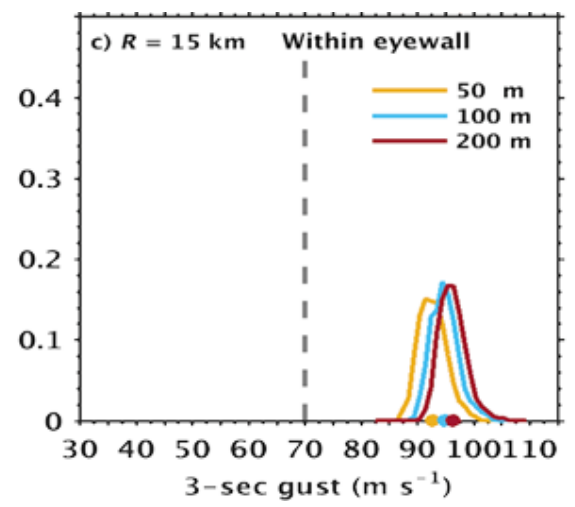

(a)

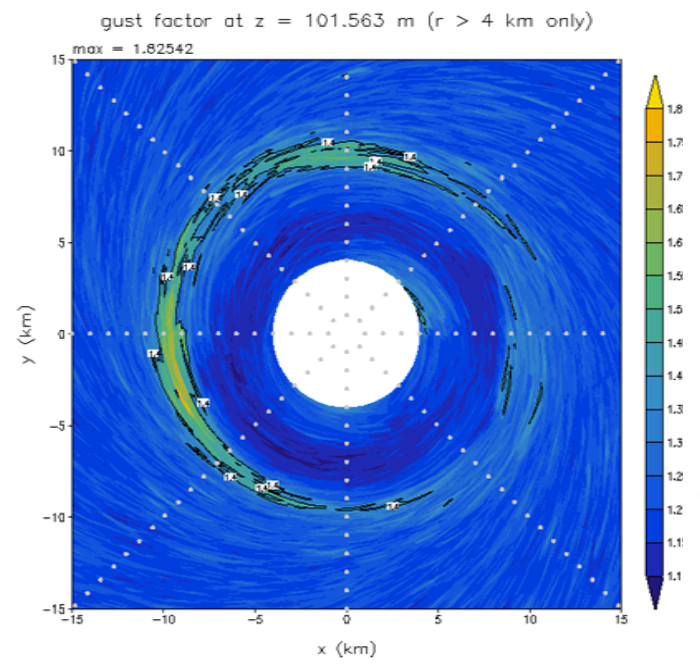

(b)

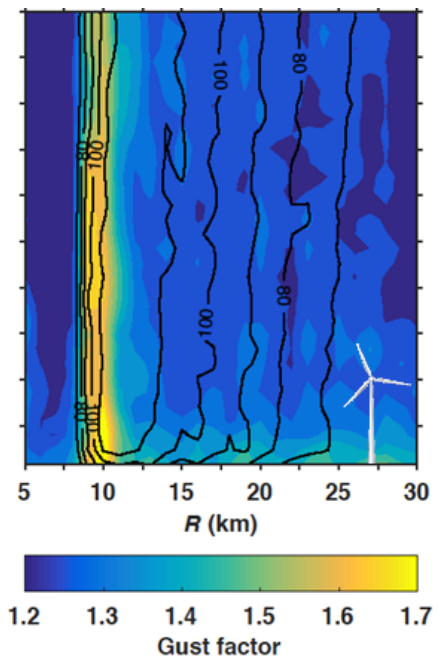

(c)

Figure 9. Examples of LES-calculated wind field quantities within a category 5 hurricane: (a) 3s gust probability density function (PDF) at 50,100 , and $200 \mathrm{~m}$ above sea level (a); (b) gust factors as a function of horizontal location at $100 \mathrm{~m}$ above sea level with the black contour indicating a value of 1.4 ; (c) gust factors as a function of radial distance $(R)$ from the center of the hurricane and as a function of height above sea level. Courtesy of $J$. Lundquist and R. Worsnop

At a much lower resolution level than LES simulations, synthetic hurricane modeling is used in the development of the design wind speed maps in the United States (e.g., SEI 2010), the Caribbean (CCS 1985), and Australia (SAA 1989). The reduced-order models demand lower computational resources than LES simulations, therefore they can be run more easily in a Monte Carlo fashion. These computer models use estimates, via probability density functions (PDFs), of the Holland B parameter as well as the radius of maximum wind speed, together with Monte-Carlosimulated tracks and central pressure data to create hurricane wind fields (see also Figure 10) and extract data of 
interest (e.g., wind speeds and wave heights). Occurrence rate is another specific aspect that increases uncertainty in hurricane hazard prediction. Each input probability distribution contains uncertainties (e.g., in the shape, mean, and/or standard deviation). The physical models also have uncertainties because of the lack of understanding of the true physical processes and the associated assumptions (e.g., size-central pressure-wind relationships, heading at landfall, and effects associated with climate change). These phenomena can be examined with great fidelity as more computational power becomes available and with the increase in accuracy of the physical models.

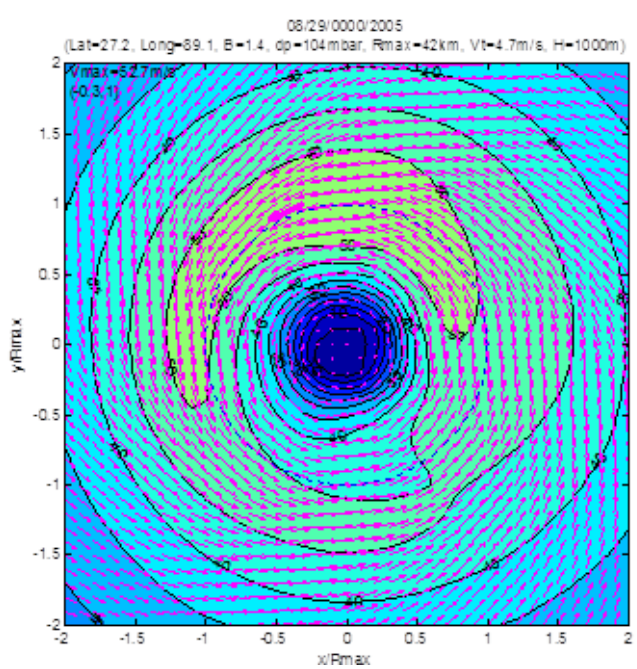

(a)
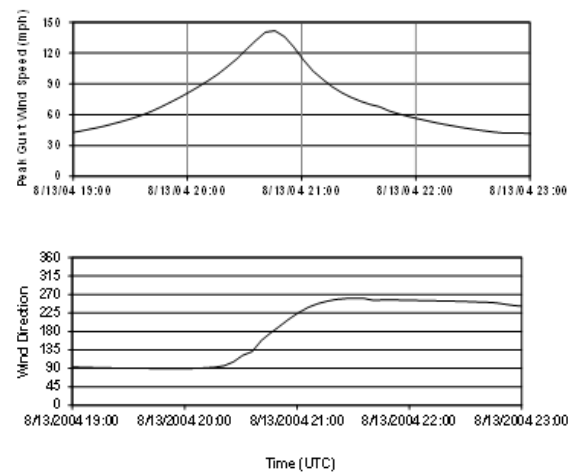

(b)

Figure 10. Sample outputs of the synthetic hurricane modeling: (a) three-dimensional wind vector field; (b) expected gust speeds and wind direction at a given geographical location. Courtesy of P. Vickery

The outputs of the reduced-order models can be compared to observations to provide COV for point-prediction errors (see Figure 11). Typical values are on the order of $10 \%$, with COVs decreasing with increasing wind speeds. Using these results, and by changing parameters in the input PDFs, multiple sets of Monte Carlo storm tracks can be simulated and distributions of the desired output quantities can be achieved (see Figure 11b), thereby estimating their respective COVs. This process works quite well for combining uncertainties associated with parameter estimation and those deriving from the wind field modeling. When adding a fragility curve (response of the system to wind forcing) and a probability of occurrence to the family of wind POE curves, the load hazard curves can be calculated. Although codes and standards generally only consider aleatory uncertainty, by combining all of the uncertainties within this process, a more conservative estimate of the mean hazard curves is attained.

The wind turbine design standards are being improved to capture some of the aspects associated with hazard overload as derived from the oil and gas experience. The concepts of hazard curves (see Figure 12) and reserve strength ratio (RSR) (reserve strength ratio, defined in Eq. (2.4)) are now included in a recommended 500-yr robustness check, in which the load associated with a return period of 500 years is compared to the ultimate resistance of the structure:

$$
R S R=\frac{R_{u l t}}{L}
$$

where $R_{u l t}$ is the ultimate structure resistance, and $L$ is the load for the given return period (e.g., 50 years for the robustness check). The hazard curve is a simple but powerful tool to assess how the ultimate load increases with the return period when compared to a baseline ultimate load (e.g., 50-yr return period load). For offshore structures, the overturning moment at the mudline is normally employed as the channel of interest. The curve can be used to directly assess what load factor is required to achieve a certain RSR, or to determine the probability of failure 


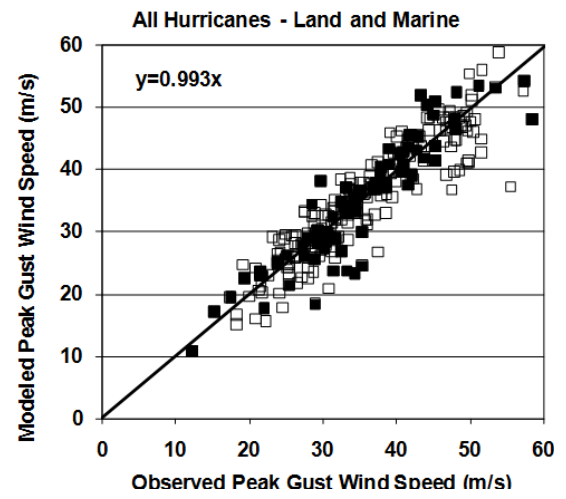

(a)

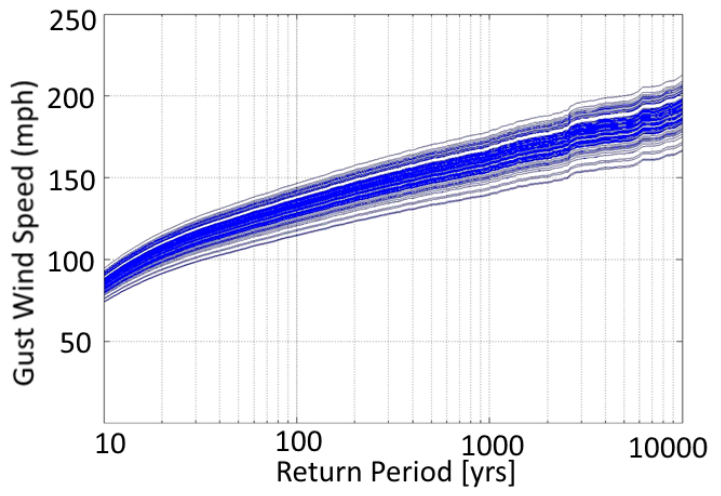

(b)

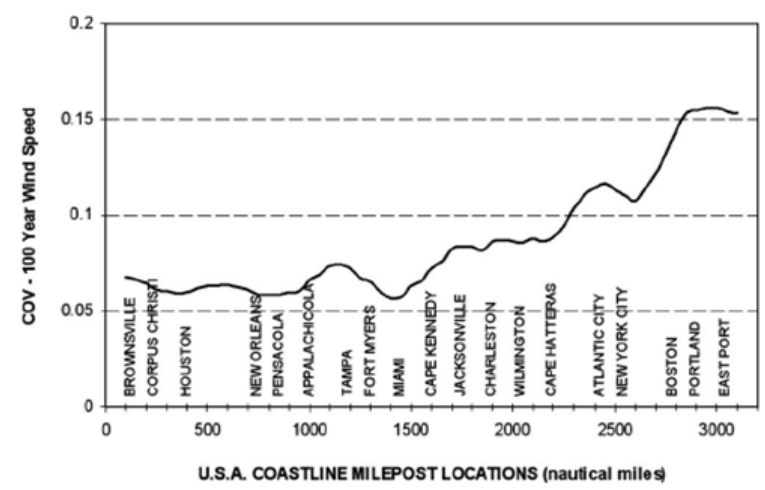

(c)

Figure 11. (a) Assessment of synthetic hurricane model errors: calculated vs. observed hurricane wind speeds (hollow (filled) squares denote land-based (offshore)). (b) Example of family of POE curves for gust wind speeds derived from multiple Monte Carlo hurricane N-year simulations. (c) Calculated COV for the 100-year wind speed for various coastal locations in the U.S.. Courtesy of P. Vickery

associated with a prescribed load factor. Figure 12 shows how a given load factor translates into different reliability levels for various geographical locations. Figure 12b, for example, shows that designated wind energy lease areas offshore of New Jersey and Virginia have steeper hazard curves than the Gulf of Mexico. Although the design wind speeds are higher and the ULS load for a given return period is anticipated to be larger in the Gulf of Mexico, the overload hazard can be expected to increase faster for New Jersey and Virginia than the Gulf of Mexico.

In Figure 13, an example from a recent study conducted by NREL for a location in the Southern Atlantic region demonstrates that the robustness check requires a load factor higher than the IEC recommended one. As discussed earlier, there is uncertainty in the definition of hurricane wind fields and turbulence characteristics, and one way to overcome this is to propose modifications to the standards, so that these factors get more rigorously defined based on simulation or other field data.

Another proposal to the standard (61400-1. Wind turbines-Part 1: Design requirements forthcoming) adds a tropical storm designation to standard turbine classes (class ' $\mathrm{T}$ '), with a new, higher $V_{\text {ref }}\left(57.5 \mathrm{~m} \mathrm{~s}^{-1} \mathrm{vs} .50 \mathrm{~m} \mathrm{~s}^{-1}\right.$ of Class I) and the choice of a higher reference turbulence intensity (e.g., 0.18 vs. 0.16 of subclass A). It is not certain, however, that extreme event field characteristics (e.g., wind shear, vertical shear, gust factors) can still be applied as described by the standards and just with the new turbine class definition. 


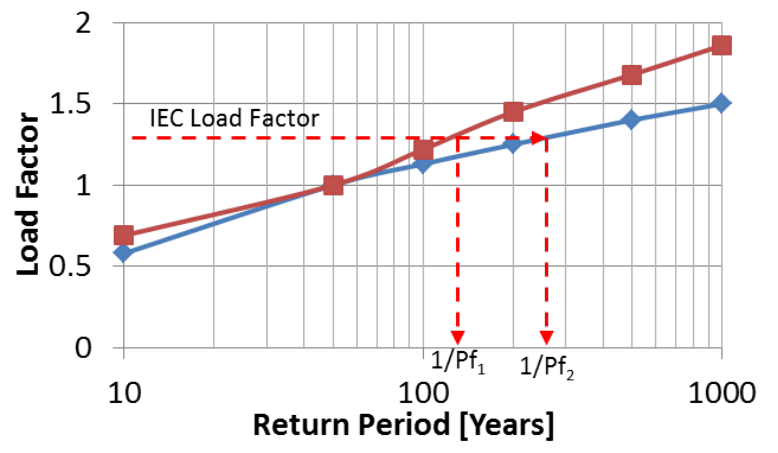

(a)
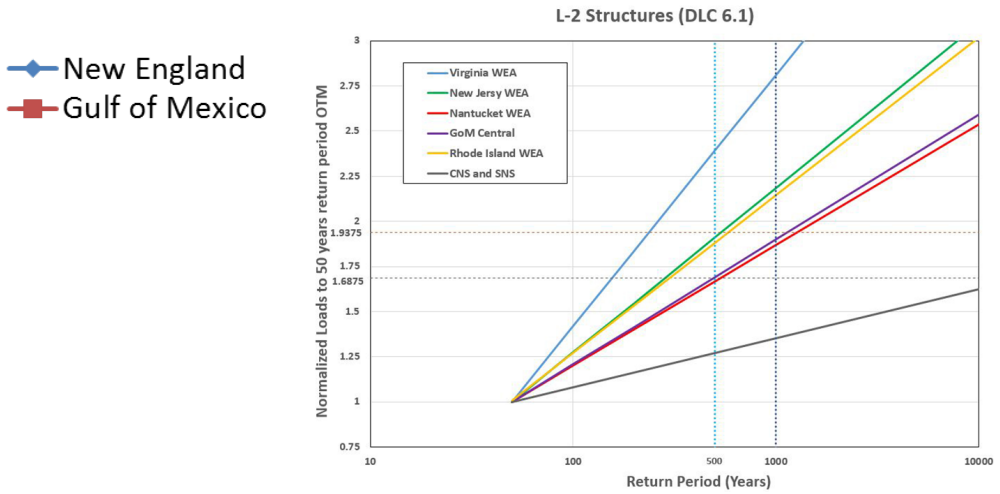

(b)

Figure 12. Examples of hazard curves for a jacket substructure and for different geographical regions. Comparison of the U.S. New England region to the Gulf of Mexico (GOM) and the associated probability of failures for a given safety factor (1.35) (a); overload hazard varying by geographical region (b). (Meaning of the acronyms used in the legend and y-axis: OTM is the overturning moment at the mudline; WEA is wind energy area; CNS and SNS are central and south North Sea regions, respectively). Courtesy of R. Hall

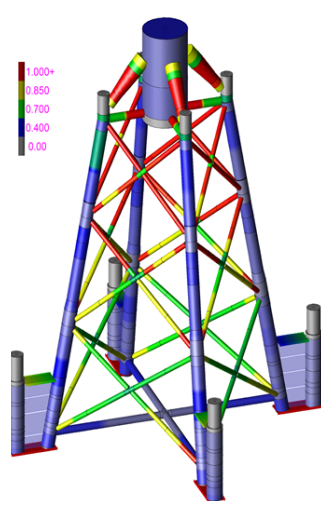

(a)

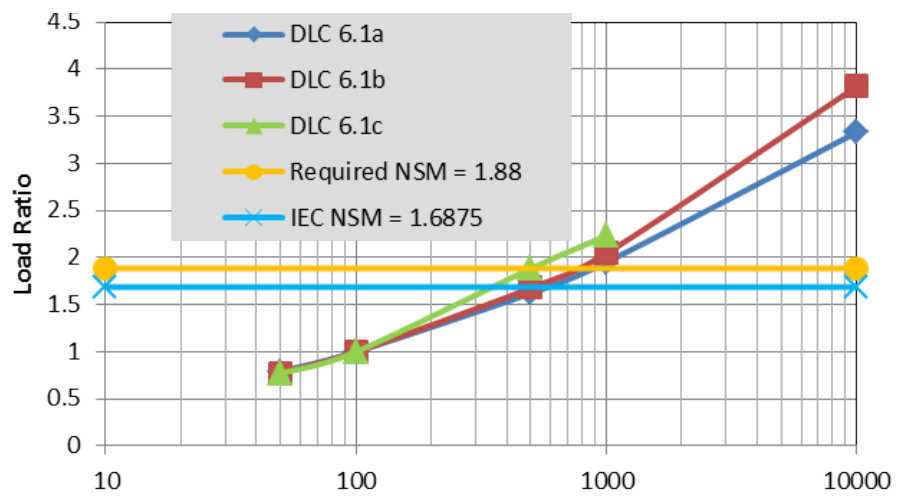

(b)

Figure 13. Example of member utilization calculated for an offshore wind turbine jacket located in the South Atlantic region of the United States. (a); colors indicate the utilization ratio. (b) associated hazard curves for DLC 6.1 normalized to 100 -yr load. The nominal safety margin, defined as $\gamma_{L}$ times the pile axial safety factor (=1.25 per (ISO 2007)), must be at least 1.88 to satisfy the 500 -yr robustness check. This translates into a required load PSF of $\sim 1.5$, which is larger than the IEC-recommended 1.35.

Another important aspect in tropical cyclone events is that of battery back up during extended periods of grid loss in tropical cyclone events. Is battery back up necessary to keep the protection control system (primary yaw control) active, and, if so, will it be enough to reduce risk of overload to the turbine? In Figure 15, the relative impact of a yaw misalignment on the tower-base bending moment is shown. Yaw-error-induced loading must be assessed in hurricane ride-through strategies because tower-base shear can increase up to four times when the rotor is not aligned with the wind direction (Damiani and Musial 2014).

Beside uncertainty in the wind physics and structural response, large variability exists in breaking-wave loading because of wave characteristics and in the wave load interaction with the structural dynamics (see Figure14).

The certification process and design standards for offshore wind turbines are relatively immature, and this contributes 


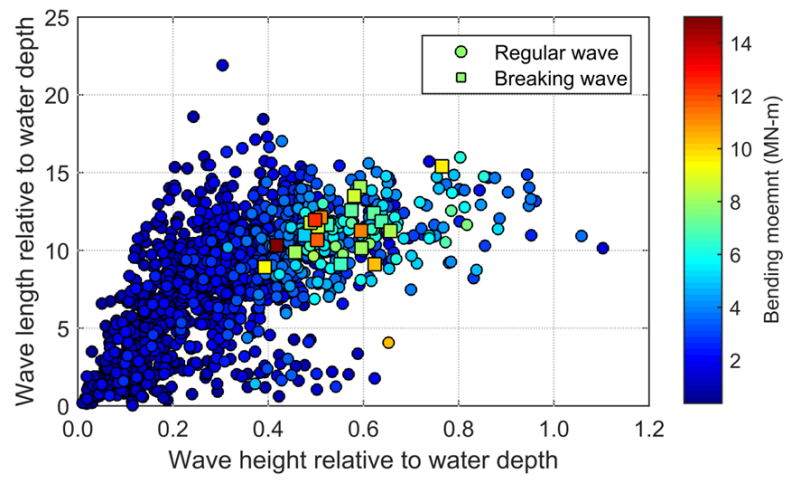

Figure 14. Monopile mudline bending moment as a function of wave characteristics. Breaking wave loads can differ because of the wave characteristics themselves as well as the dynamic state of the structure at the time of wave impact. Courtesy of A. Myers

to larger uncertainties and higher costs than land-based wind. Revised codification of a new physical understanding including tropical cyclone environmental conditions and structural response will help lower the perceived risk to the project and LCOE. Understanding reliability targets for offshore wind is a key research opportunity.

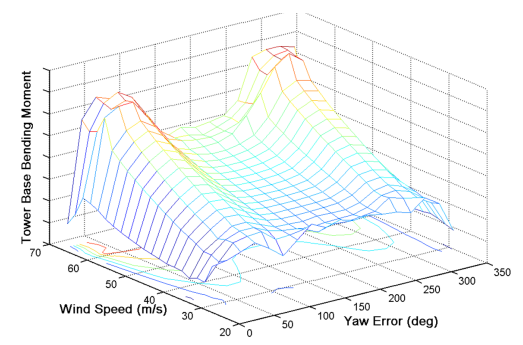

(a)

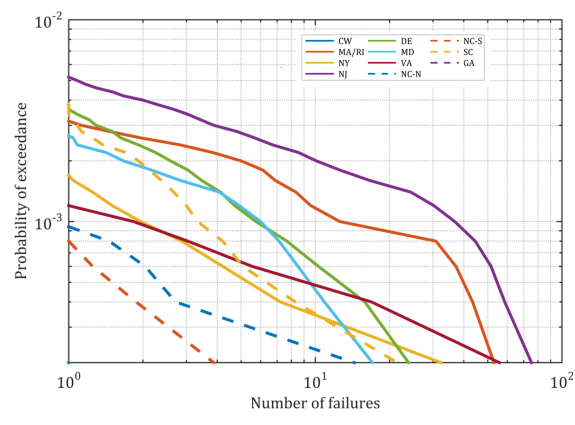

(b)

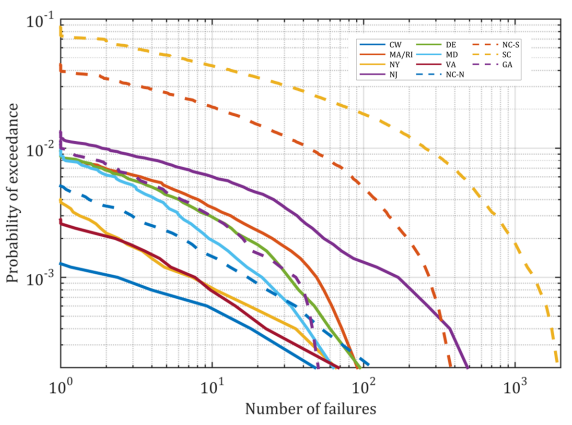

(c)

Figure 15. Tower-base bending moment as a function of wind speed and yaw error under parked conditions for a typical offshore wind turbine (a) (Damiani and Musial 2014). Calculated probability of failures for offshore wind turbines on monopiles for various sites (denoted by the U.S. state abbreviation)(b); effects of yaw error on that probability (c). Courtesy of A. Myers

\subsubsection{Uncertainty in the Aerodynamics and Controls}

The uncertainty from aerodynamics comes from a number of factors. Airfoil characteristics are to a degree uncertain, and the effects on the loads can be significant (Abdallah, Natarajan, and Sørensen 2015). Not only do uncertainties in the polar curves exist for controlled (wind tunnel), clean conditions, but so do those related to the state of the geometry (actual vs. design airfoil geometry), surface roughness, and geometric attitude in the field. Dynamic stall and unsteady phenomena, together with three-dimensional effects, such as centrifugal pumping and delayed stall phenomena, also create significant uncertainty in the aerodynamics of turbine blades. Moreover, the control system impacts the loads, both directly and indirectly. Changes in resisting rotor torque as a result of control demands are examples of direct effects on the turbine loads, whereas flow-field changes due to the blade pitch modulation are examples of indirect, servo-aero-elastic effects. It is thus not surprising that load COVs can be largely affected by the type of controls. 
COV values from 5\% to $12 \%$ can be expected in the 50-yr return period rotor and support structure loads (Sørensen and Toft 2014). Consequently, one could anticipate that the load PSF could significantly change for a given reliability level. Figure 16 shows the calculated trends for the reliability $(\beta)$ as a function of the COV of $X_{\text {aero }}$ for a generic turbine blade, and the effect on the $\gamma_{L}$ for a given level of reliability. As expected, a significant decrease in reliability can be observed for increasing values of the COV; furthermore, larger and larger $\gamma_{L} \mathrm{~s}$ are needed to maintain the same level of reliability. The figure also shows the impact of different PDFs used to model $X_{\text {aero }}$.
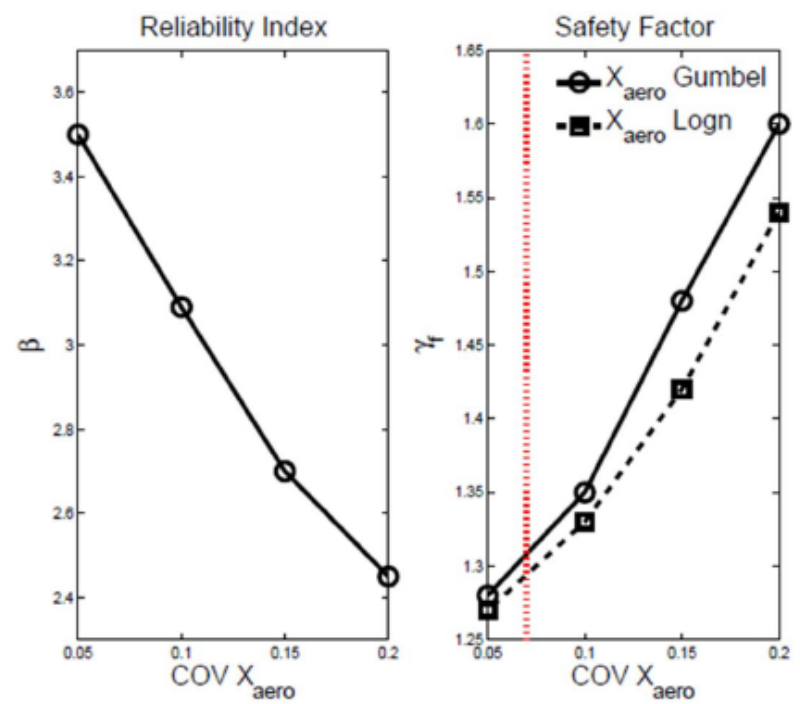

Figure 16. Impact of uncertainty in the airfoil characteristics in terms of $X_{\text {aero }}$ 's COVs on $\beta$ (lefthand side) and on $\gamma_{L}$ for a given reliability (denoted as $\gamma_{f}$ ) (right-hand side). Source: J. Sorensen

\subsubsection{Soil and Foundation Properties}

Soil mechanical properties are highly variable even within a relatively homogeneous layer. This variation has obvious implications on the foundation and soil-foundation dynamics. The resulting uncertainty in system response must be dealt with in design. Offshore, these aspects are very important as the entire wind turbine structure is bound to be larger and taller than land-based turbine structures, which normally implies more compliant structural characteristics that must be controlled. Offshore, the site investigation can be even more limited than land-based, given the inherent logistical difficulties and higher costs. In foundation design, the following must be verified:

- Global stability check (ULS)

- Overturning and sliding

- Capacity checks (ULS and FLS)

- Soil-bearing capacity

- Concrete shear and bearing

- Grout bearing

- Reinforced concrete flexure

- Reinforcement and bolt tension

- Performance in operation (service limit state) 
- Concrete cracking

- Settlement and differential settlement

- Foundation stiffness.

The traditional approach is to associate limit-state equations to the above checks in a LRFD fashion similar to what is shown in Eq. (2.2). Various standards (e.g., SEI 2010; ACI 2014) offer different variants of Eq. (2.2), which require calibration of the load and resistance factors to achieve the same levels of reliability (Nadim et al. 2015). Moreover, it can be argued that different combinations of these factors can lead to the same reliability levels, creating some confusion as there would not be a one-to-one relationship between PSF and the $P_{f}$ (or $\beta$ ) and in the determination of the uncertainties.

In particular, the current standard (IEC 2005) assumes that the resistance factors are applied by the designer following the respective national practice. However, resistance factors for geotechnical design are not fully established. A new standard (IEC 2017b) is under development with the main goal of harmonizing the worldwide practice.

Fully probabilistic approaches to the geotechnical analysis are becoming more widely accepted, not only as code calibration tools, but also as an alternative to the more traditional 'safety factor' approach (e.g., Ben-Hassine and Griffiths 2012). The key goal of these methods is to directly identify the risk of failure (not necessarily catastrophic failure, but also missed performance and risk of external excitation) by accounting for the probability of different soil and material parameters without the need for uncertainty factors. Event trees, First Order Reliability Method (FORM), First Order Second Moment Method, and Monte Carlo are methods that aim to achieve a reliability-based design (see also Figure 17) and to estimate probabilities of failures. A more recently proposed technique, the random finite element method (RFEM), combines elements of the finite-element and random field methodologies in a Monte Carlo approach. RFEM properly accounts for (anisotropic) spatial correlation structures in soil deposits, thus allowing for an accurate estimate of the probabilities of soil-foundation failure (e.g., bearing capacity). This technique is very promising and can be integrated in a more general reliability-based design, such as the direct reliability based design (d-RBD) (main concepts shown in a graphical format in Figure 18). In d-RBD, the input, random, soil parameters can be easily spanned to investigate cross correlations and their effects on final reliability, or alternatively a reliability level can be selected, and the design can be targeted to achieve the associated probability of failure.

More research is needed to better quantify the effectiveness of these methods, and to codify the process for the harmonization of foundation design reliability.

\subsubsection{Uncertainty in the Operational Load Extrapolation}

The IEC standard (IEC 2005) requires an assessment of the operational load corresponding to a 50-yr return period, or a probability of exceedance of $3.87 \cdot 10^{-7}$ over a 10 -min period. Changes have been proposed (e.g., Ragan and Manuel 2008) to clarify the extrapolation process required to estimate the 50-yr load in DLC 1.1 to associate with a $\gamma_{L}=1.25$. The revised proposal to the IEC standard Ed. 4 suggests the use of a 'calibrated' PSF (1.35) in lieu of a Monte Carlo-type of approach, which would multiply the largest load calculated by the simulations in DLC 1.1 together with the $\gamma_{L}$ of 1.25. It is not exactly clear, however, that this calibration is universal, and the extent of turbine models over which it applies. Various methods, beside extrapolation, could be potentially exploited to arrive at the probability that load $Y$ is greater than load $Y_{50}$ (50-yr return period load level) in a 10-min interval (Graf et al. 2017):

$$
P_{10 m}\left(Y>Y_{50}\right)=1-P\left(Y<Y_{50}\right)^{N_{10 m}}=\int P_{10 m}\left(Y<Y_{50} \mid x\right)^{N_{10 m}} f(x) d x
$$

where $P_{10 m}\left(Y>Y_{50}\right)$ is the probability that load $Y$ is greater than load $Y_{50}(50$-yr return period load level) in a 10-min interval; $P\left(Y<Y_{50}\right)$ is probability that load $Y$ is less than load $Y_{50} ; N_{10 m}$ is the number of load peaks in a 10-min interval; $f(x)$ is a joint distribution of the environmental parameters (e.g., wind speed for a land-based turbine). A brute-force method, a Monte Carlo set of simulations, could certainly provide a ground truth to the estimate of $Y_{50}$, but it requires very large computational resources and time allocation. Other methods use statistical strategies to arrive at very low POE with a fraction of the resources needed for a full Monte Carlo method. In Figure 19, 


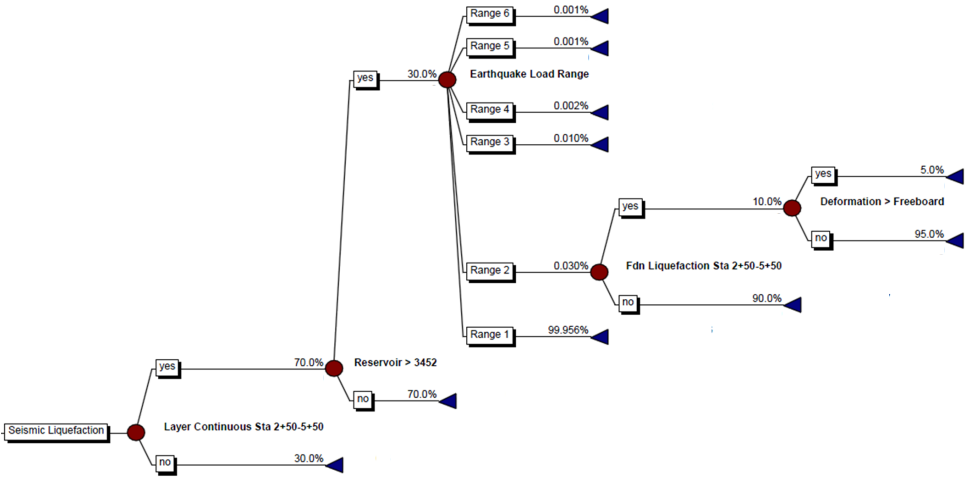

(a)

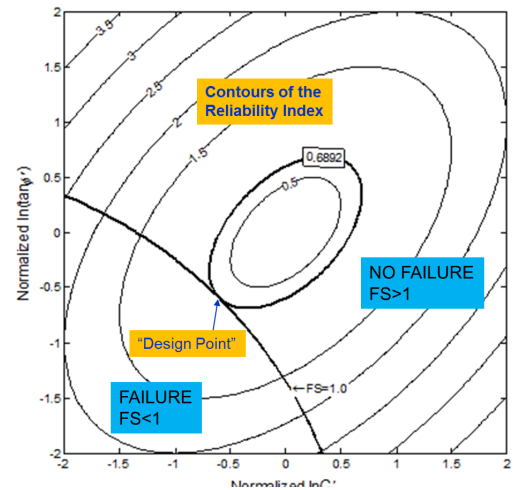

(b)

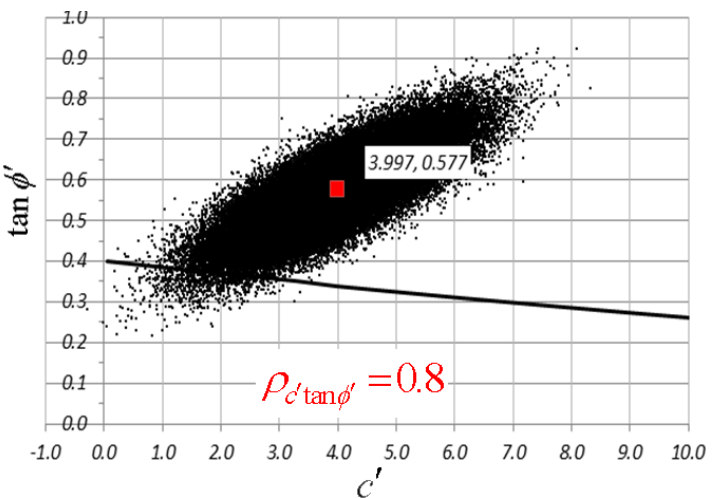

(c)

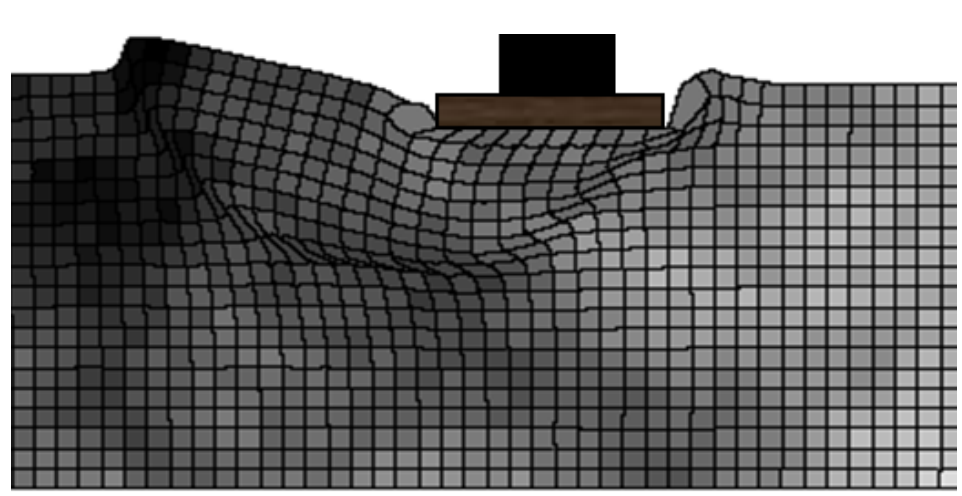

(d)

Figure 17. Examples of geotechnical engineering results of studies using (a) event tree, (b) FORM, and (c)-(d) RFEM. In (a), the probabilities found at each fork along a branch can be combined (multiplied) to attain the final probability of failure. In (b), the FORM-calculated reliability is contoured in the space of the soil variables $c^{\prime}$ and $\phi_{s}$, which is divided into two semiplanes by the thick line denoting the limiting state solution (margin of safety $\mathrm{FS}=1$ ). The same space is shown in (c) (in this case a positive correlation is evident with a 0.8 correlation coefficient between $c^{\prime}$ and $\phi_{S}$ ), where a Monte Carlo approach is used to explore the resulting design limit state in combination with a finite element representation of the soil continuum under a foundation bearing load (d). Courtesy of D. V. Griffiths

various methods from Graf et al. (2016) are shown; the Monte Carlo results are from 100,000 runs with 10 different repetitions. As the figure shows, the extrapolation tends to overestimate the load at the 50-yr return period. This was shown by other authors (e.g., Ragan and Manuel 2008; Choe, Pan, and Byon 2016). The importance sampling and adaptive stratified importance sampling methods perform much better and can lead to an estimate with much fewer aeroelastic runs when compared to Monte Carlo. The adaptive stratified importance sampling (ASIS) approach is particularly appealing as it seems to perform very well with only some 100 simulations.

Another method, which is particularly useful when the environmental conditions are made up of more than just wind speed parameters, such as for offshore wind turbines, is the Inverse First Order Reliability Method. This method is standard design practice for generating the environmental contours associated with given return periods (see Figure 20 for a 50-yr contour surface of wind speed, significant wave height, and wave peak spectral period). Other efforts have recently been proposed that make use of the so-called response surrogates and seem to be promising for uncertainty quantification (e.g., Murcia et al. 2016; Larsen et al. 1999). In these methods, surrogates of wind turbine and plant aeroelastic models are generated via sophisticated stochastic approaches, such as polynomial chaos 


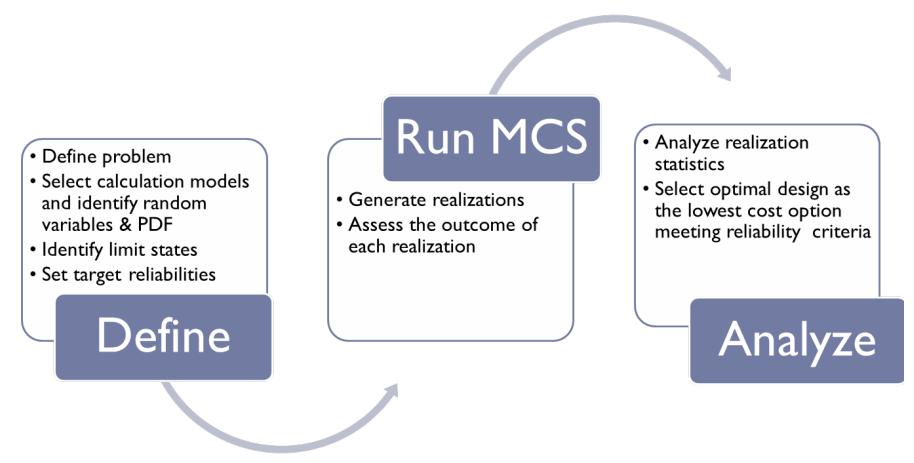

Figure 18. Proposed approach to d-RBD. Courtesy of J. Ben-Hassine

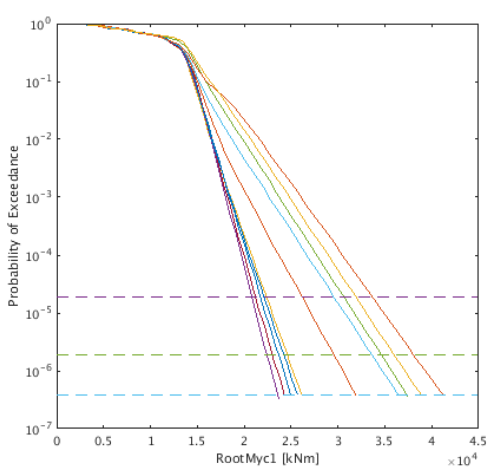

(a)

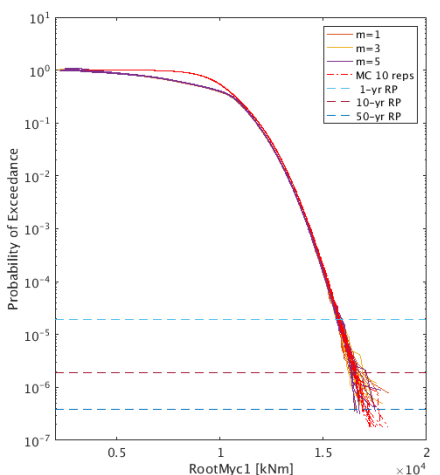

(b)

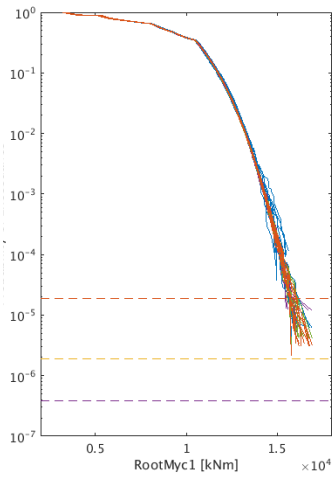

(c)

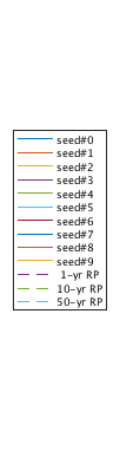

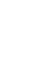

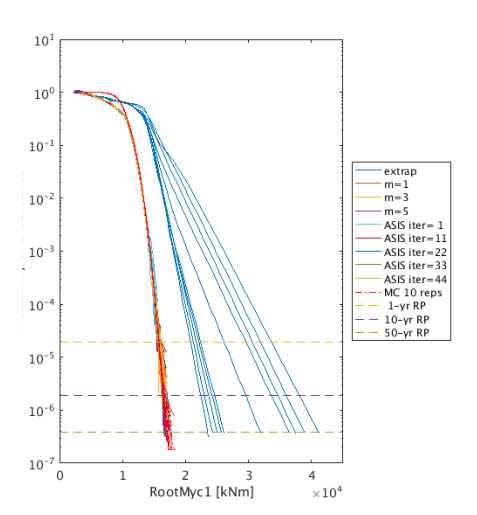

(d)

Figure 19. Comparison of various methods to estimate the $Y_{50}$ load for the root flapwise bending moment: (a) extrapolation (IEC 2005); (b) importance sampling; (c), adaptive stratified importance sampling; (d) all methods on the same plot. Note there are 10 different repetitions for each method. Source: Graf et al. 2016

expansion; the surrogates are then used to span the space of environmental parameters and map out the response of the wind power plant very effectively, thereby providing estimates of performance as well as loads under ULS and FLS. 


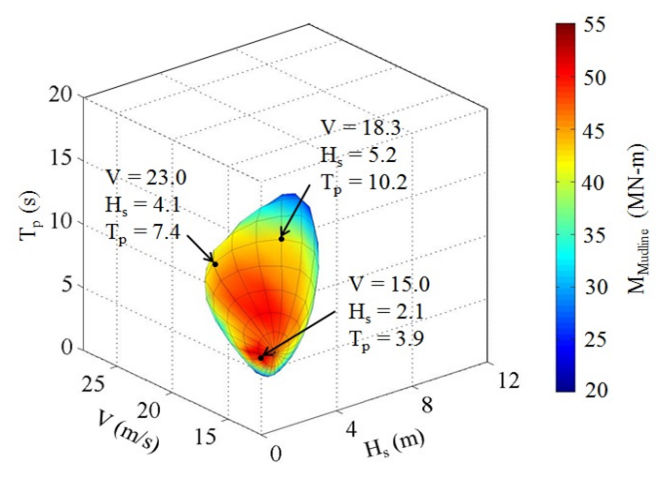

Figure 20. Example of constructed 50 -yr environmental surface and search
for maximum structural response. The space spans wind speed $(V)$, signifi-
cant wave height $\left(H_{s}\right)$, and wave peak spectral period $\left(T_{p}\right)$. Courtesy of $\boldsymbol{A}$. Myers

Regardless of the method employed, a spread still exists in the estimates associated with each independent realization because of the stochastic nature of wind, but this variability can at least, in principle, be estimated from each method's statistics.

\subsection{Material and Structure Resistance}

The common perception in the industry is that most current failures are caused by quality issues in the manufacturing. Turbine component manufacturing is complex, involves the use of high-tech materials, delicate curing and bonding processes, and critical welds, and it requires a lot of manual work. Variability in the material resistance (the $\delta_{R}$ in Eq. (2.1)) is normally well characterized for established materials such as steel or unidirectional e-glass, but it is more uncertain for innovative composites or multiaxial load applications and mixed placement of composites with highly different elastic properties. All of these aspects create challenges for quality control methods that, for the wind industry, are deemed still in development and have ample margin for improvement. The standard codification of manufacturing quality assurance is also deemed not sufficient.

Some system properties are strictly controlled (e.g., bolt torque level and standard material mechanical characteristics), whereas others are not (e.g., blade mass, blade mass moment, and pitch and yaw alignment). Some pitch and mass imbalance is considered in the standards, as are tolerances on system eigenfrequencies, but many nonconformities are not, including those related to material surface characteristics.

Some of the common failures in wind power plants are caused by control/protection system faults and improper connection designs. Even in the cases in which the control algorithm was correctly designed, its hardware implementation might have been deficient because of less-than-ideal testing and quality inspections, or by applications outside the design envelope.

Yet, a great deal of uncertainty still permeates the failures of drivetrain and other components, where manufacturing quality does not seem to be the leading cause.

The typical distribution of failures observed in wind power plants is shown in Figure 21 as a function of equipment age and broken down into four categories (refer to Sheng and O'Connor 2017): infant, premature, random, and wear-out. Infant failures are mostly cause by wear-in problems or quality defects, and largely covered by original equipment manufacturer (OEM) warranty. Examples of infant failures are abrasion in bearings, wrinkles in the blade laminates, insulation failure in the generators. Premature failures are a result of latent defects in the design, manufacturing process, or operation and maintenance (O\&M). Axial cracks, raceway white etching and micropitting in gearbox bearings, composite delamination and cracks in the bond line for blades, and fatigue cracks in the raceway 
of pitch bearings are typical examples of premature failures. Random failures appear at a constant rate regardless of the equipment age, and are caused by low probability events such as overloads due to extreme gusts or other weather phenomena. The risk of these failures is mitigated by insurance. Material strength or characteristic load exceedance are examples of random failures. Wear-out failures are those that are expected toward the end of the project life, for which the component lifetimes are specified, and that can be mitigated by O\&M strategies and replacement plans. Because these failure types can be planned for, they are preferred by the owners and operators (Sheng and O'Connor 2017). Typical examples of wear-out failures are bending or surface fatigue for gear mesh in gearboxes and pitch systems, leading-edge erosion in blades, and bearing or insulation fatigue failures in generators.

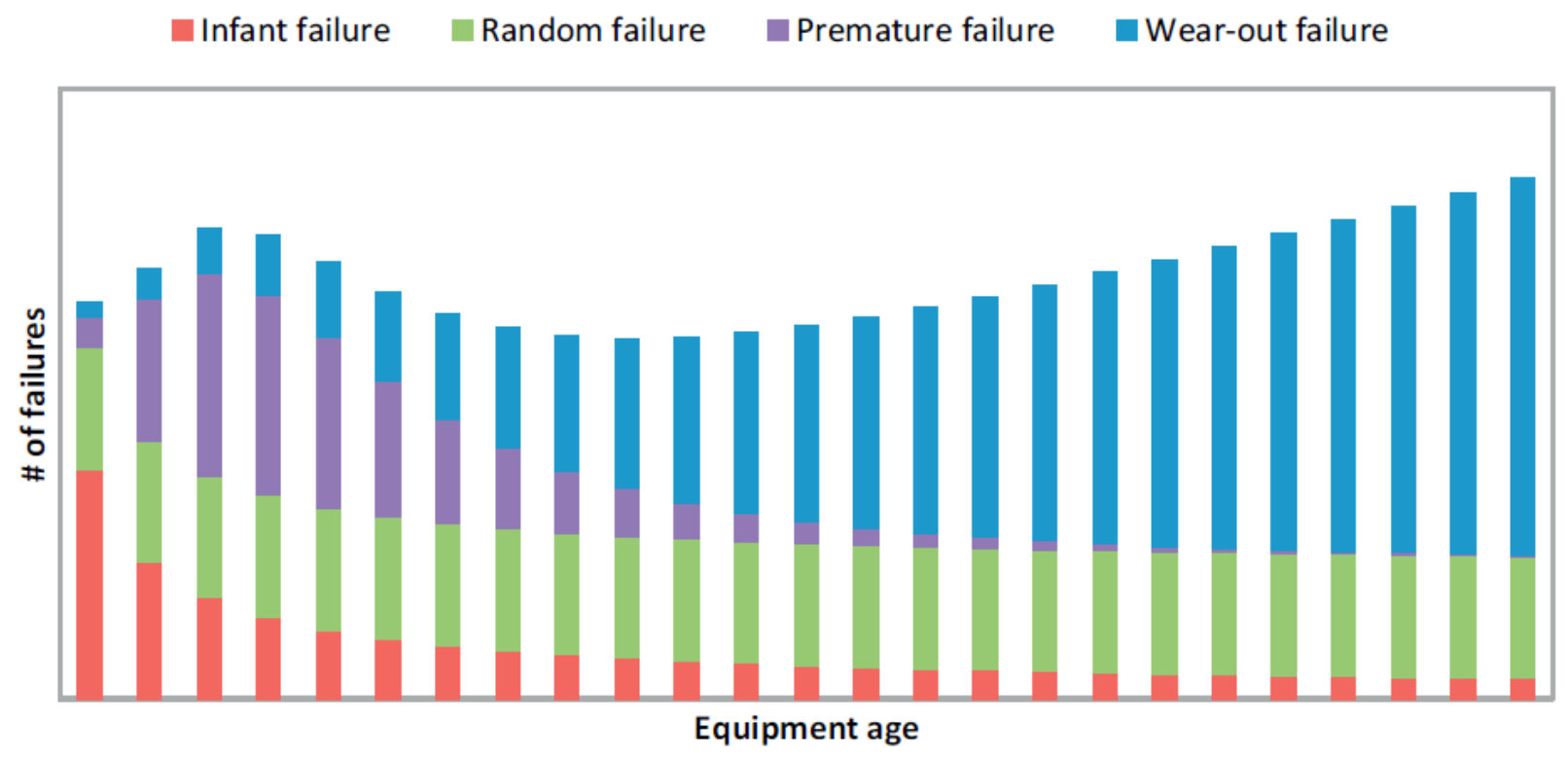

Figure 21. Typical failure-type relative distribution for wind turbine equipment as a function of equipment age throughout a 25-year project lifetime (each bar station represents one year). Source: Sheng and O'Connor 2017

The failure distribution curve should be following the so-called "bath-tub" behavior, in which the combined infant and wear-out failure modes lead to elevated numbers of breakdowns at the beginning and end of the project, and in which the failure rate is low and approximately constant in the middle part of the project lifetime. The presence of premature failures, however, modifies the "bath-tub" trend as shown in Figure 21, and increases the O\&M costs and, ultimately, the LCOE.

The top three contributors to the wind power plant downtime are the power module, drivetrain module, and rotor module (Sheng and O'Connor 2017).

Drivetrain failures are relatively rare, but they are associated with extensive downtime therefore they weigh considerably on the overall LCOE. Significant progress has been made in the understanding of failure modes especially with regard to the load paths (e.g., LaCava, Keller, and McNiff 2012; Guo, Keller, and LaCava 2012) and the wear of surfaces in relative motion (for a review see also Errichello et al. 2012). The surface failures observed in wind turbine mechanical systems are not fundamentally different from those observed in other applications; however, their severity, frequency, and uncertainty of root causes demand continued investigation of the fundamental science and of the testing methodologies (Errichello et al. 2012). Recent studies (e.g., Zaretsky and Branzai 2017) confirm that classic bearing fatigue accounts for less than $5 \%$ of bearings removed from service, further demonstrating the complexity of the field of tribology. A number of issues still need to be addressed in this field, such as: lubricant additive effects under different operation conditions; changes in lubricant properties with age; effects of black oxide treatments on 
failure modes; surface finish and surface engineering. Some of these aspects pertain to the pitch system mechanics as well.

Recent studies by turbine OEMs are also emphasizing the importance of surface engineering for other components. For example, blade leading-edge erosion (see Figure 22) is a focus of concern because it leads to reduced power generation and, potentially, structural damage; the quantification and prediction of erosion effects, however, is elusive. Leading-edge erosion increases with relative air speed and with rotational speed, but renewed understanding of the physics of erosion propagation and load/performance effects is required, especially in light of the adoption of ever-growing rotors.
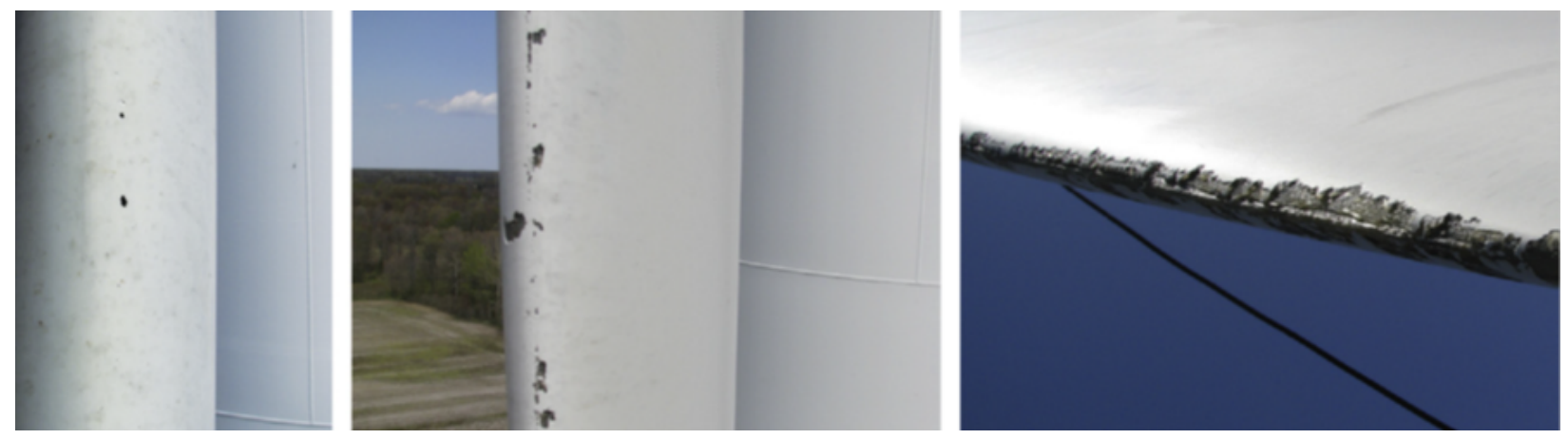

Figure 22. Examples of blade surface erosion. Source: Slot et al. 2015

Electric and electronic component failures, such as those in power converters, generators, and control systems, are still the most frequent (Sheng and O'Connor 2017). Temperature and temperature cycling, humidity, corrosive and sea-salt laden air are major driving factors for failures in power electronics and generators (e.g., Shipurkar et al. 2015), but uncertainties still exist in the determination of the thermal stress and in the strength modeling of these components.

These existing gaps shall be addressed with better probabilistic models for component resistance, codified methods of quality assurance in the manufacturing processes, and dedicated testing and physical modeling of the components under different environmental conditions.

\subsection{Site-Suitability and Due-Diligence Aspects}

Beside the turbine design, the issue of turbine siting is of paramount importance, as atmospheric conditions outside the design envelope can be encountered if the knowledge of site conditions is less than ideal.

In IEC (2005), site assessment is treated via a deterministic approach by selecting characteristic values for the design and environmental conditions and applying PSFs, thereby assuming that a nominal reliability level is achieved. However, the actual reliability of the wind turbine will depend on site-specific factors, which can make it greater or lesser than the standard design site:

- Quality (sample distributions and duration) and available amount of site data (land-based and offshore metocean data)

- Mean wind speed, turbulence, shear, veer, and air density

- Stochastic wake effects

- Site-specific extreme turbulence model

- Terrain effects. 
For instance, the amount of data in the various bins determines the certainty with which the site conditions can be compared to the standards' turbulence characteristics (e.g., extreme turbulence model wind speed standard deviation). Recent studies based on actual field data demonstrated how confidence intervals (thus uncertainty) increase with fewer data years and larger wind speeds (see also Figure 23).

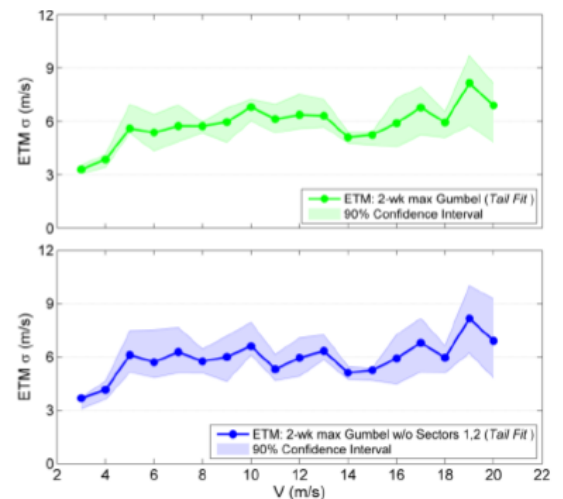

(a)

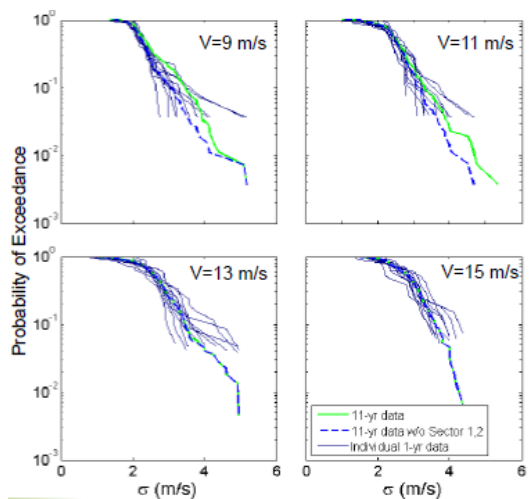

(b)

Figure 23. Effect of data sample size (1 yr vs. $11 \mathrm{yr}$ ) on the extreme turbulence model estimate of the wind-speed standard deviation (a) and probability of exceedance distributions (b). Note the year-to-year variability in the POE. Courtesy of L. Manuel

Site-suitability evaluation seems to be lagging behind the modeling advances on the design front. For instance, averaging of the real-world variations of vertical shear, a common practice in site assessments, can lead to underestimation of fatigue life. Shear distributions can even include negative values that are masked by the normal averaging (see Figure 24), which could have important consequences on the loads experienced by the turbine components. For example, during negative shear events, the blades experience higher winds as they approach the tower, potentially increasing the risk of tower strike. Moreover, increases in turbulence accompanying negative shear have been observed, thereby leading to increased blade and hub loads by up to $10 \%$ (see Figure 25).

Recent findings showed that other aspects associated with the site-suitability assessment can contribute to unexpected failures. For instance, extensive idling below cut-in can lead to reduced levels of lubrication, just when the risk of off-axis loading caused by turbulence is higher. This could lead to main bearing damage. Frequency of grid outages and number of emergency stops and faults beyond design assumptions are further issues often contributing to uncertainty in due diligence. Furthermore, although $V_{\text {ref }}$ (reference wind speed per IEC 2005) is provided by the standards, wind turbines 'do not respond to 10-min averages,' and therefore due-diligence engineers are now questioning the validity of IEC classes related to site-suitability assessments.

These subtle aspects become more important as the design margins are used up to allow larger machines to be deployed, thus understanding and controlling the associated site-specific uncertainty on the loading conditions becomes crucial.

A new standard is being developed (IEC 2017a) to improve aspects associated with field data measurement and analysis to help with power performance estimates as well as site-suitability. In particular, the new standard establishes a 'universal' framework for dealing with site suitability, and for handling uncertainty and power loss calculations. Within the site-suitability framework, amongst other parameters to be cataloged, are wind speed and direction frequency distributions, turbulence intensity summaries, coherent turbulence information, extreme wind estimations, and extreme turbulence models. However, open questions still exist with regard to what other measurements should be specified for site assessment. 


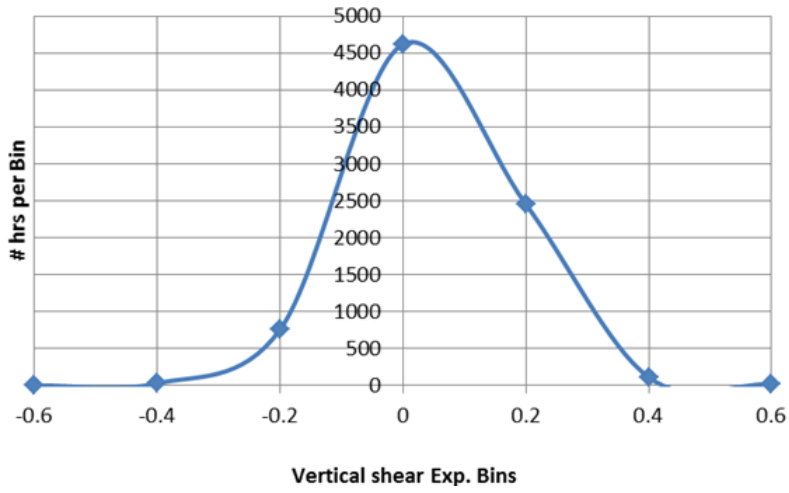

(a)

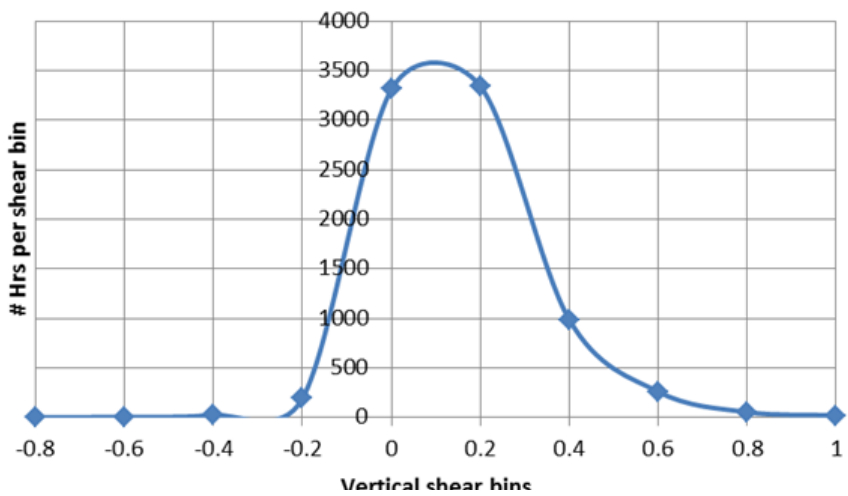

(b)

Figure 24. Shear distributions at two different sites with mean shear exponents: 0.05 (a) and 0.15 (b). Courtesy of E. Moroz

\begin{tabular}{|l|r|c|}
\hline & $\begin{array}{c}\mathrm{m} \\
\text { \% increase in loads resulting } \\
\text { from Variable method relative } \\
\text { to Standard method }\end{array}$ \\
\hline Blade root $\mathrm{Mx}$ & 4 & $0.10 \%$ \\
\hline & 10 & $0.10 \%$ \\
\hline Blade root My & 4 & $6.40 \%$ \\
\hline & 10 & $2.40 \%$ \\
\hline Blade root $\mathrm{Mz}$ & 4 & $1.90 \%$ \\
\hline & 10 & $3.30 \%$ \\
\hline Blade root Fx & 4 & $6.30 \%$ \\
\hline & 10 & $2.90 \%$ \\
\hline Blade root Fy & 4 & $0.00 \%$ \\
\hline & 10 & $0.00 \%$ \\
\hline Blade root Fz & 4 & $0.30 \%$ \\
\hline & 40 & $3.60 \%$ \\
\hline
\end{tabular}

(a)

\begin{tabular}{|l|c|c|}
\hline & $\begin{array}{c}\mathrm{m} \\
\text { from increase in loads resulting } \\
\text { to Stande method relative }\end{array}$ \\
\hline Rotating hub Mx & 10 & $1.70 \%$ \\
\hline Rotating hub My & 10 & $10.00 \%$ \\
\hline Rotating hub Mz & 10 & $9.70 \%$ \\
\hline Rotating hub Fx & 10 & $5.60 \%$ \\
\hline Rotating hub Fy & 10 & $0.00 \%$ \\
\hline Rotating hub Fz & 10 & $0.00 \%$ \\
\hline Stationary hub Mx & 10 & $1.70 \%$ \\
\hline Stationary hub My & 10 & $-2.50 \%$ \\
\hline Stationary hub Mz & 10 & $4.90 \%$ \\
\hline Stationary hub Fx & 10 & $5.60 \%$ \\
\hline Stationary hub Fy & 10 & $2.90 \%$ \\
\hline
\end{tabular}

(b)

Figure 25. Percent increase in damage equivalent loads for blade root (a) and hub (b) when accounting for variable wind shear as opposed to a fixed shear value. Excerpt from a study by Garrad-Hassan. Courtesy of E. Moroz

\subsubsection{Performance Risk}

Tied to site-suitability measurements is the prediction of power plant performance, with the associated uncertainty and financial risk assessment. A new initiative within the Wind Energy Technologies Office program and somewhat parallel to IEC 61400-15 (IEC 2017a) is the Performance Risk, Uncertainty, and Finance (PRUF) project. The primary objective of PRUF is to increase the value of wind energy by lowering the risk and uncertainty associated with developing, investing in, owning, and operating wind power plants (see Figure 26a). PRUF is focused on identifying uncertainties and mitigating risk via targeted research. The general consensus in the industry is that although an underlying broad disagreement on accuracy of energy prediction methods exists, the bias (1\%) on energy production is acceptable (see Figure 26b). Despite this positive result, which has been achieved via largely improved wind resource methods, there is still no correlation between predicted uncertainty (because of prebuild wind measurements, climatic changes, wake and other losses, wind flow modeling, and so on) and measured production error (see Figure 26c). A performance uncertainty working group is being created to perform systematic validation of preconstruction energy estimate practices on large databases of wind power plants, as well as devise a platform for detailed research and development on uncertainty practices. The group will work in collaboration with the guidelines 
and formatting proposed by IEC (2017a) to create an uncertainty and risk characterization framework to investigate uncertainty propagation from design to financial investment.

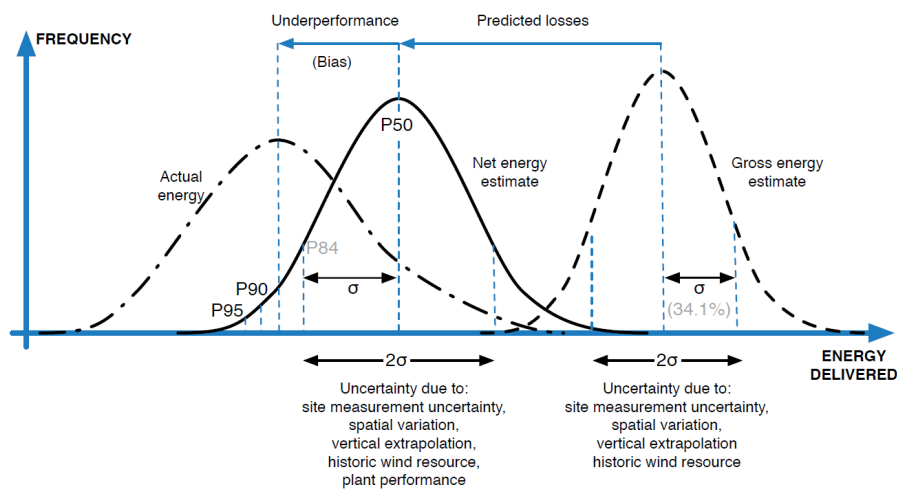

(a)

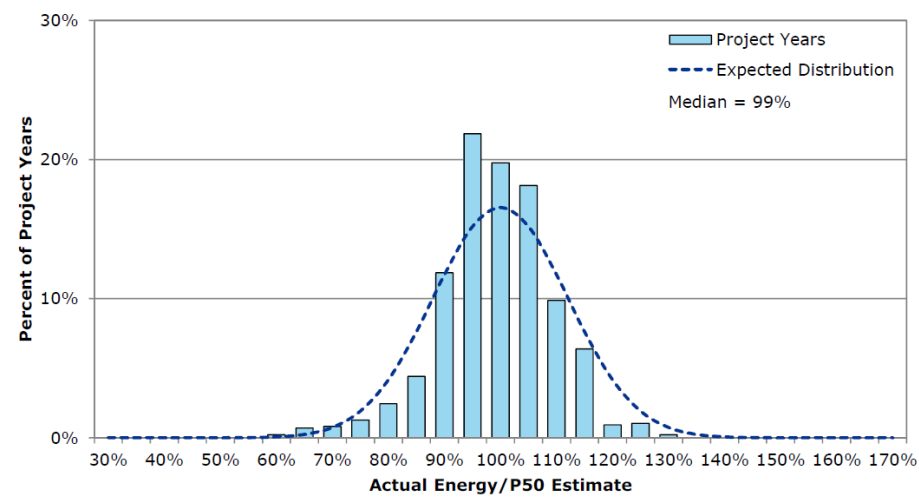

(b)

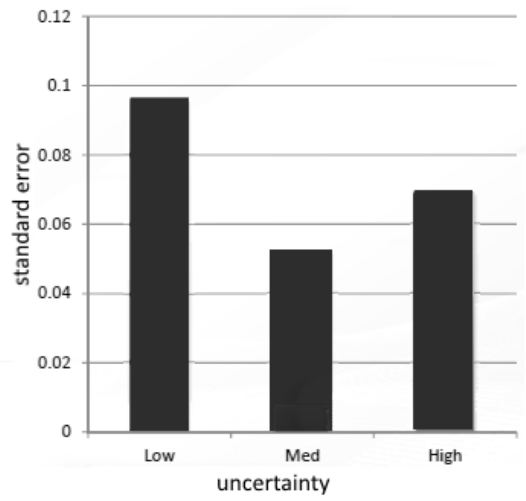

(c)

Figure 26. (a) Wind power plant annual energy production (AEP) prediction uncertainty and central estimates; (b) distribution of the ratio of observed-over-predicted-AEP for 249 wind plants across North America; (c) lack of relationship between standard error in AEP prediction and calculated uncertainties (from AWS Truepower). Courtesy of J. Fields

\subsubsection{Nonconformities}

As mentioned earlier, some material, inertial, and operational properties are not tightly controlled (e.g., damping values, mass moments, pitch, and yaw alignments). These nonconformities translate into loads, vibrations, and gravity effects. NerWind measurements indicate that more than $45 \%$ of the turbines examined had more than a $1^{\circ}$ error in the pitch setting. RomoWind measured that more than $33 \%$ of the wind turbines (out of 152 investigated) had a yaw error larger than $8^{\circ}$ (J. Van De Bosche, personal communication).

There is no standard on tolerance bands for mass, let alone mass moment, and more subtle properties such as damping. In some cases, it is common practice to assume certain damping coefficients, but more recent examples are showing longitudinal cracking and problematic edgewise vibrations that can be traced back to optimistic assumptions on the damping (see Figure 27). 


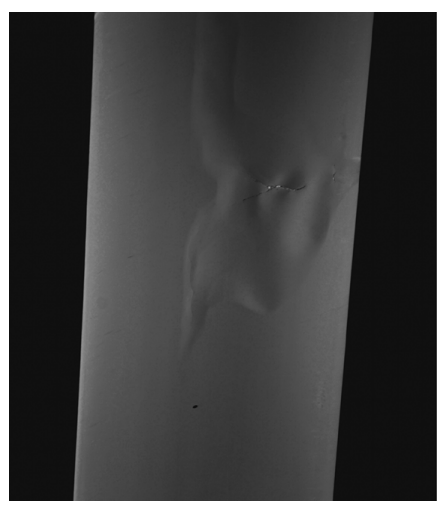

(a)

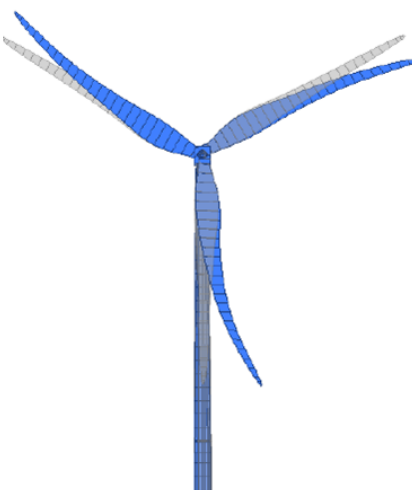

(b)

Figure 27. Edgewise vibrational mode (a) and potential chordwise cracking (b). Courtesy of J. Bosche

Table 2. Needed Value of $\gamma_{R}$ (material or resistance PSF) to Achieve a Reliability Index $\beta=3.3$ with $\gamma_{L}=1.35$, for Different Levels of Uncertainties of $R$ and $\delta_{R}$ as Indicated by their Respective COVs.

\begin{tabular}{c|ccccc}
\hline \hline \multirow{2}{*}{$R \mathrm{COV}$} & \multicolumn{5}{|c}{$\delta_{R} \mathrm{COV}$} \\
& 0 & 0.05 & 0.1 & 0.15 & 0.2 \\
\hline 0.05 & 1.16 & 1.18 & 1.24 & 1.35 & 1.49 \\
0.10 & 1.12 & 1.14 & 1.20 & 1.29 & 1.43 \\
0.15 & 1.11 & 1.13 & 1.19 & 1.28 & 1.40 \\
0.20 & 1.13 & 1.15 & 1.20 & 1.28 & 1.40 \\
0.25 & 1.17 & 1.18 & 1.23 & 1.31 & 1.42 \\
\hline
\end{tabular}

\subsection{PSF and Reliability Levels}

Currently, the standard (IEC 2005) is semiprobabilistic, i.e., the uncertainties are taken into account, but the safety factors are built more on experience than actual calibration. Recent efforts have gone into calibrating the partial safety factors (e.g., Sørensen and Toft 2014) for the fourth edition of the IEC 61400-1 design standards, which involves comparing Eq. (2.1) to Eq. (2.2). To minimize the total expected life cycle costs, the sum of initial costs, O\&M costs, and failure costs should be considered. Besides the O\&M strategy and availability, these costs directly depend on the structural reliability.

Although mechanical and electrical components fall into the classical reliability theory, structural components fall within structural reliability theory (safety factor approach). The relevant standards are ISO 2394 (ISO 2015), IEC 61400-1 (IEC 2005), and JCSS Probabilistic Model Code (Structural Safety 2000). Following these references, models for the statistical uncertainties in Eq. (2.1) $\left(X_{d y n}, X_{\text {aero }}\right.$, and so on) are based on assumed probability distributions and associated COV (Sørensen and Toft 2014). The PDFs change from load case to load case. For power production DLCs, the lognormal and Gumbel PDFs are normally used to model the uncertainties. For $R$ and $\delta_{R}$, the lognormal PDFs are generally used. Sørensen and Toft (2014) assume a characteristic value for $R$ equal to the 5\% quantile of its distribution, and the mean value for $\delta_{R}$. With these assumptions, the functions in Eq. (2.1) and Figure 1 can be analytically expressed, thus the reliability can be calculated for different values of COV for both $\delta_{R}$ 's and $R$ 's PDFs. By enforcing the target reliability to be $\beta=3.3$, the PSFs in Eq. (2.2) can be set. For instance, assuming a $\gamma_{L}=1.35$, the resulting material PSF can be calculated as shown in Table 2.

Analogous considerations can be made for $\gamma_{L}$. It has been calculated that the $\gamma_{L}$ could be reduced if the COV of 


\section{Table 3. Potential Reduction Factor Achieved for $\gamma_{L}$ (Load PSF) under the Indicated Changes in the $X_{d y n}-X_{s t r}$ Uncertainties (as Shown by the Changes in their COVs) (see Eq. (2.1)).}

\begin{tabular}{c|cc}
\hline \hline uncertainty & COV pre $\rightarrow$ post & reduction factor \\
$\operatorname{COV}\left(X_{\text {dyn }}\right)$ & $0.05 \rightarrow 0.03$ & 0.99 \\
$\operatorname{COV}\left(X_{\text {exp }}\right)$ & $0.15 \rightarrow 0.10$ & 0.93 \\
$\operatorname{COV}\left(X_{\text {aero }}\right)$ & $0.10 \rightarrow 0.03$ & 0.93 \\
$\operatorname{COV}\left(X_{\text {str }}\right)$ & $0.03 \rightarrow 0.00$ & 0.99 \\
\hline
\end{tabular}

$X_{\text {aero }}-X_{\text {str }}$ (i.e., the uncertainties in Eq. (2.1)) can be reduced (Sørensen and Toft 2014, see Table 3).

For FLS, the COV of the load $\left(\mathrm{COV}_{f a t}\right)$ should account also for the stochastic variability of the stress concentration factor:

$$
C O V_{f a t}=\sqrt{C O V_{\text {wind }}^{2}+C O V_{s c f}^{2}}
$$

where $C O V_{\text {wind }}$ is the coefficient of variation in the uncertainty PDF of the wind load, and $C O V_{s c f}$ is the coefficient of variation in the uncertainty PDF of the stress concentration factor. Values of $C O V_{s c f}$ can range from 0 to 0.2 with increasing complexity of the fatigue detail; $C O V_{\text {wind }}$ range from 0.1 for high confidence in the measured climatic data and simple terrain, to 0.2 for little or no site measurement data and complex terrain.

\subsection{Uncertainties in Modeling}

As the industry adopts new, multifidelity, numerical capabilities there is a need to understand the risk and uncertainty associated with the new tools. Uncertainty quantification (UQ) and verification and validation (V\&V) become essential to advancing computational capabilities while introducing innovations in the quest toward lower LCOE. Characterizing the uncertainty in the models and its propagation can support validation activities, but also leads to more reliable predictive tools, and more accurate preconstruction estimates.

UQ will also lead to efficient optimization and trade-off in design. V\&V will further help in prioritizing the importance of physical and model parameters, identifying gaps and needs for model improvements, while also guiding the fine-tuning of PSFs and reduction of project risk.

\subsubsection{Uncertainty Quantification}

New methods are being developed to account for the uncertainty propagation from the environment to the system response. An aeroelastic wind turbine model has stochastic/nondeterministic outputs. Different turbulent inflow realizations (Toft et al. 2016; Moriarty 2008; Graf et al. 2016) give rise to very different response dynamics. The difficulties of studying fatigue and extreme loads under different inflow conditions reflect an important source of uncertainty in the prediction of the model outputs (Murcia et al. 2016).

The polynomial chaos expansion (PCE) is one method that promises efficient handling of the uncertainty propagation and thus the computation of the output statistics (e.g., mean, standard deviation of power loads, etc.), effectively providing a powerful sensitivity-analysis tools. Surrogate aeroelastic models can be generated with this method to arrive at an accurate prediction of both the local and global distribution of the power, thrust, and damage equivalent loads (DELs). A surrogate for ultimate loads, however, is expected to be more difficult to achieve, and there would be a need for surrogates well verified against industry-proven engineering models.

It is also possible to use the surrogate inside a wind power plant optimization framework and inside uncertainty estimations of AEP and lifetime DEL. Figure 28 shows an example of the potential of these sophisticated methods in assessing the uncertainties in the simulation output channels. For this example, the output was calculated via PCE and based on assigned distributions of the input parameters. These parameters included: wind speed Weibull 
Table 4. Parameter Distribution Parameter Values for the Surrogate Construction from Murcia et al. 2016.

\begin{tabular}{c|ccc}
\hline \hline Variable & Distribution & \multicolumn{2}{c}{ Parameters } \\
$A$ & Normal & $\mu_{A}=0$ & $\sigma_{A}=0.5 \mathrm{~m} / \mathrm{s}$ \\
$k$ & Normal & $\mu_{k}=2$ & $\sigma_{k}=0.1$ \\
\hline$x_{0}=U$ & Weibull & scale $=A$ & shape $=k$ \\
$x_{1}=\sigma_{1}$ & Lognormal & $\mu_{\sigma_{1}}(U)$ & $\sigma_{\sigma_{1}}(U)$ \\
$x_{2}=\alpha_{s}$ & Normal & $\mu_{A}(U)$ & $\sigma_{\alpha_{s}}(U)$ \\
$x_{3}=\gamma$ & Normal & $\mu_{\gamma}=0^{\circ}$ & $\sigma_{\gamma}=5^{\circ}$ \\
\hline
\end{tabular}

shape and mode parameters, each modeled with a normal distribution; the turbulence standard deviation, i.e., the $\sigma_{1}$ parameter (see IEC 2005), modeled with a lognormal distribution; and the power-law shear exponent and the yaw (error) angle, each modeled with normal distributions.
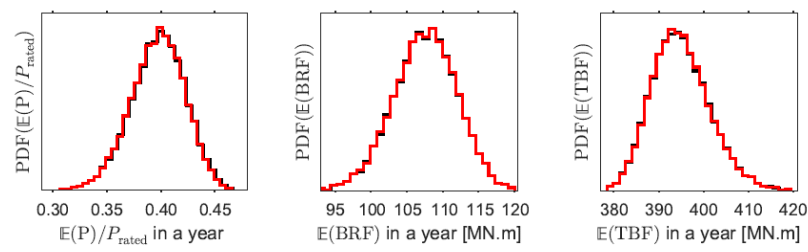

Figure 28. Examples of uncertainty propagation onto power (left-hand side), blade root flapwise bending moment (middle), and tower-base fore-aft bending moment (right) obtained via the PCE method for wind field uncertainties as described in Table 4. Courtesy of J. P. Murcia, Technical University of Denmark

The surrogates also make up an efficient way to obtain power and load estimates under site-specific characteristics without sharing the proprietary aeroelastic design of the turbines.

\subsubsection{Verification and Validation}

To design wind turbines, computer models are built to predict the performance and loads in a variety of environmental and operating conditions. The deployment of larger and larger machines and offshore variants introduces a conundrum: on the one hand, the physics at play become more complicated (complex aero-hydro-elastic behavior), challenging the assumptions behind current design tools. On the other hand, the risk to the project must be reduced, which requires increased confidence in the estimates of machine loads and performance. To solve this conundrum, efforts must focus on verifying and validating the simulation tools used to build the computer models. As software programs acquire higher and higher fidelity, users must learn how to properly use these tools as well as understand the risk and uncertainty associated with using them, and this can only be achieved through a systematic method of $\mathrm{V} \& \mathrm{~V}$.

Generally speaking, the goals of $\mathrm{V} \& \mathrm{~V}$ include:

- Assessing simulation accuracy and reliability for a specific purpose (use case)

- Evaluating numerical accuracy of implemented theories

- Refining analysis methods and proposing design guidelines

- Identifying gaps and required research and development.

Examples of such activities include the Offshore Code Comparison Collaboration (2005-2009) (OC3) and Offshore Code Comparison Collaboration, Continued with Correlation (2014-2018) (OC5) series of projects (see 
Figures 29-30) aiming at qualifying offshore wind turbine computer-aided engineering tools. In these projects, a set of benchmark problems was developed, and then simulated via all of the participating tools. The main goal of OC 3 and OC5 was to accurately predict the load response of the system in a variety of conditions. The accuracy of the simulated loads and motion response was assessed by comparing the solutions amongst the different modeling tools, first to each other and then to experimental data. Experiments were conducted in controlled wave tanks, and full-scale data were acquired from an existing offshore wind power plant. Experiments and field data are, however, laden with uncertainty sources ranging from the physical test specimen properties (e.g., scaling limitations, mass/geometry/stiffness distribution approximations) to the influence of measuring devices on the structural dynamics, to the uncertainties associated with wind/wave forcing and data acquisition. Unfortunately, many of these uncertainties are not quantifiable because they were not clearly identified before the beginning of the OC5 project.

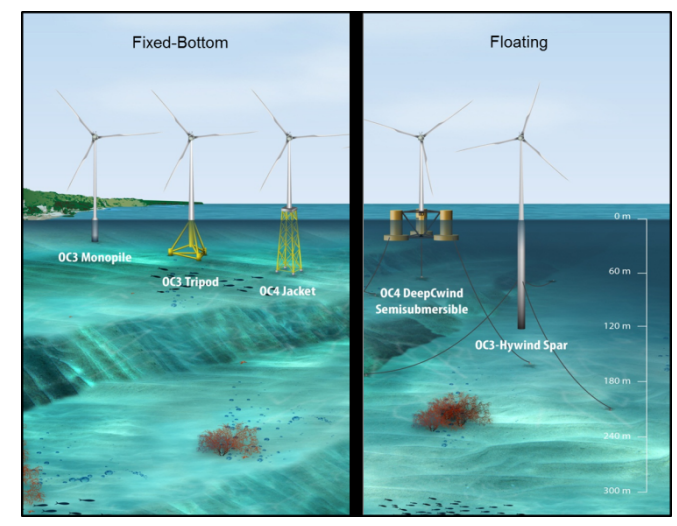

(a)

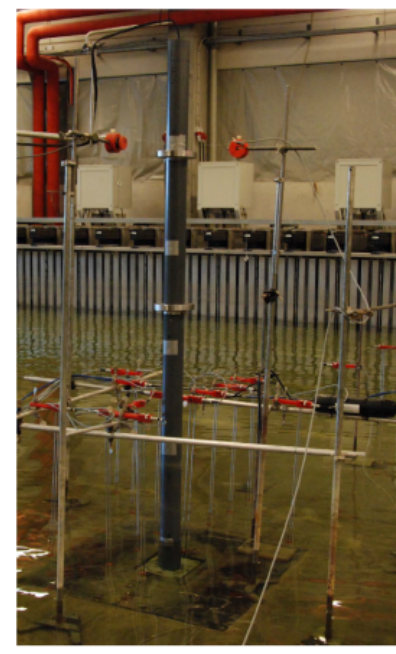

(b)

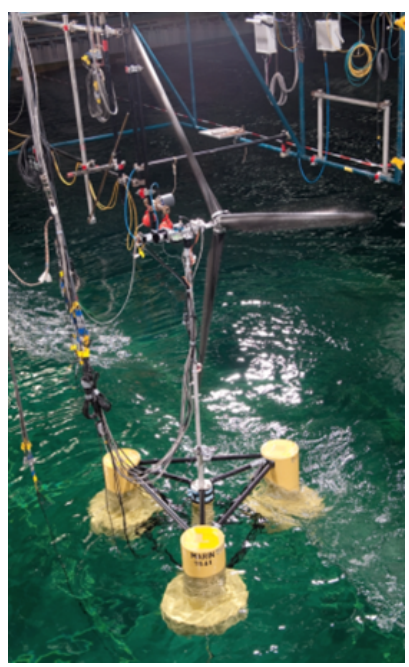

(c)

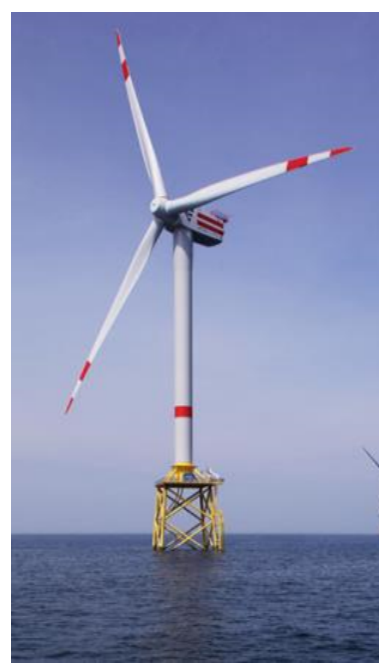

(d)

Figure 29. Configurations examined throughout the OC3 through OC5 projects: (a) diagram showing the configurations examined; monopile (b) and semisubmersible (c) tested in a wave tank; full-scale measurement data from jacket-based offshore wind turbine (d). All models and simulation results from $\mathrm{OC} 3$ and $\mathrm{OC} 5$ will be made public after the projects are completed, and will serve as benchmark problems for future investigations and research. Courtesy of A. Robertson, NREL

DOE has recently put resources toward the formalization of a $V \& V$ process within the Atmosphere to Electrons program. DOE believes that this process is essential for advancing modeling capabilities. In particular, the new 

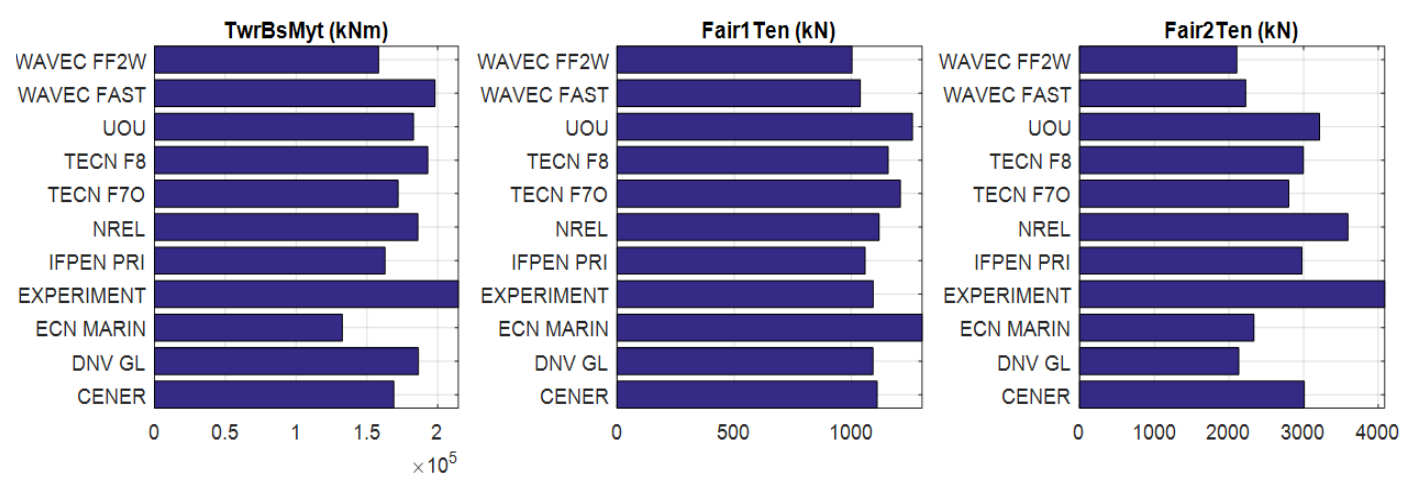

Figure 30. Examples of V\&V results (various code outputs) from the OC3OC5 projects. From left to right, tower-base fore-aft bending moment and tensile loads in the mooring lines at the fairlead. Courtesy of A. Robertson

higher-fidelity models are expected to utilize high-performance computing while spanning a range of scales, from the mesoscale to the turbine blade boundary layer scale. These models are the foundation of the deployment of the System Management of Atmospheric Resources through Technology wind plants (see also Figure 31), which demonstrate:

- Significant improvement in the predictive capability for short- and long-term power production

- Real-time power plant flow control strategies capable of increased energy capture and loads mitigation

- Improved wind power plant reliability and significantly extended operational plant life.

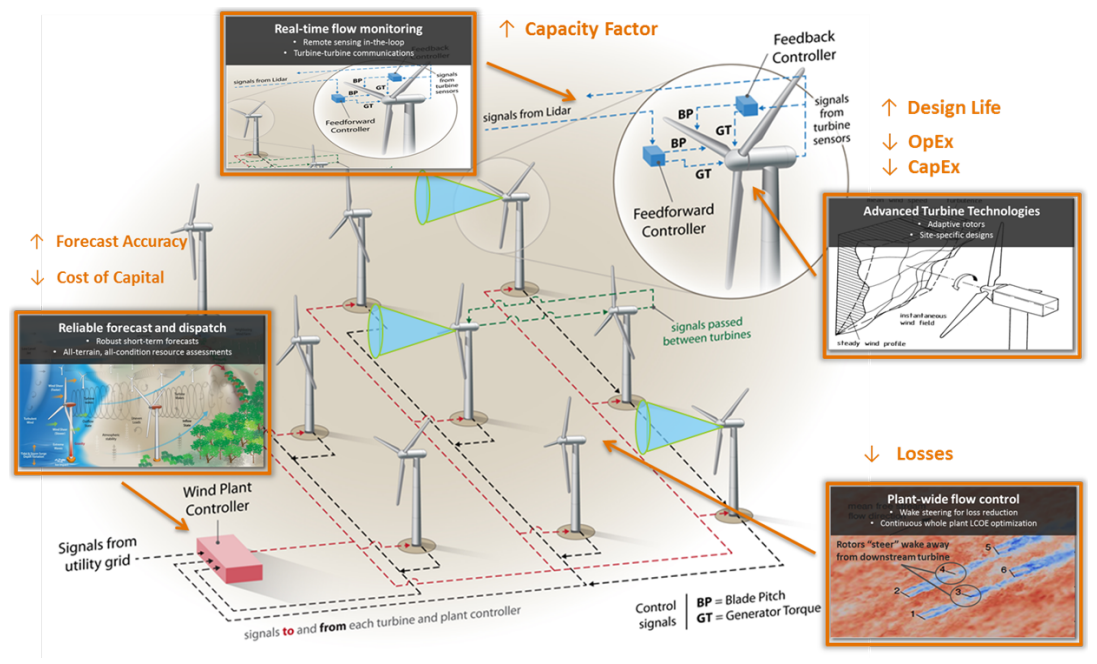

Figure 31. System Management of Atmospheric Resources through Technology (SMART) wind plant. Source: DOE

The new $\mathrm{V} \& \mathrm{~V}$ processes for model development are derived, in part, from those developed by the National Aeronautics and Space Administration, American Institute of Aeronautics and Astronautics, and American Society of Mechanical Engineers (Hills, Maniaci, and Naughton 2015; Maniaci and Naughton, forthcoming). V\&V can lead to optimized structures with appropriate PSFs and lower the cost of financing by reducing the level of perceived risk, which will lead to reduced LCOE. The framework that is being proposed for wind (Maniaci and Naughton, 
forthcoming) includes:

- Identification of the model objective (to guide the entire $\mathrm{V} \& \mathrm{~V}$ process)

- Verification

- Determine the level of accuracy in the representation of the conceptual model and its numerical solution

- Phenomena identification ranking table

- Prioritize physical phenomena for the intended application

- Identify gaps in the modeling capabilities

- Guide experiment design and UQ process

- Definition of experimental objectives

- Modeling-supported table of experiments

- Develop methods to quantify uncertainties in modeling and measurements

- Characterize model parameter uncertainty

- Sensitivity analyses and Monte Carlo approaches

- Uncertainty propagation

- Validation

- Assess level of agreement between the experimental results and the model predictions

- Evaluate uncertainty from measurements, model parameter, and numerical algorithms.

The framework promotes a formalized, highly collaborative approach to planning and executing joint experimen$\mathrm{tal} /$ modeling programs for the purpose of characterizing model accuracy. It provides guidelines to integrate program planning at various scales, and it is applicable to models of all fidelity, while quantifying prediction uncertainty. The framework guides the prioritization of the experiments and objectives within the large system complexity and uncertainty. 


\section{Design Criteria Identification and Ranking Table}

Given all the sources of uncertainties in the design of wind power plants that were identified in Section 2, an effort was made to organize and rank them in terms of priority. A table was compiled with input from a group of experts from the industry and academia that also participated in the workshop. The design criteria identification and ranking table (DCIRT) was used to gather information and opinions on the subject matter of uncertainty in design and sitesuitability assessment as well as to provide a prioritization guide.

The DCIRT divides the various sources of uncertainty, provides key characteristics for each one, and uses color codes to identify priorities and areas in need of more research. Red is for high priority (deep gaps), yellow for intermediate priority (knowledge is incomplete), and green for low priority (good status of knowledge). 
Table 5. DCIRT Obtained from the Contribution of All Participants to the First Workshop on Uncertainty in Design

\begin{tabular}{|c|c|c|c|c|}
\hline \multirow{2}{*}{$\begin{array}{l}\text { Design } \\
\text { Criteria }\end{array}$} & \multicolumn{3}{|c|}{ Level of Understanding of the... } & \multirow{2}{*}{$\begin{array}{l}\text { Expert Opinion: Impact on System } \\
\text { Risk and Reliability }\end{array}$} \\
\hline & Process Physics & Load Modeling & Uncertainty & \\
\hline Inflow & $\begin{array}{l}\text { - Turbulence length scales, spec- } \\
\text { tra, co-spectra, coherence with } \\
\text { phase information } \\
\text { - Complex terrain } \\
\text { - Wakes and coherent structures } \\
\text { - Wake interaction with structures } \\
\text { and impact on controls and wind } \\
\text { farm design } \\
\text { - Wind shear and veer across ro- } \\
\text { tor } \\
\text { - Extreme wave characteristics } \\
\text { - Wind/wave misalignment and } \\
\text { characteristics during tropical } \\
\text { cyclone events } \\
\text { - Non-neutrally stable atmo- } \\
\text { spheric condition load cases, } \\
\text { including events such as tropical } \\
\text { cyclones, microbursts, tornadoes }\end{array}$ & $\begin{array}{l}\text { - Number of ran- } \\
\text { dom seeds; im- } \\
\text { pact of phase } \\
\text { variability for } \\
\text { turbulence field } \\
\text { - Adequacy of the } \\
\text { existing models } \\
\text { for wakes } \\
\text { - Control system } \\
\text { response and } \\
\text { plant control and } \\
\text { design } \\
\text { - Modeling steep- } \\
\text { /breaking wave } \\
\text { impact } \\
\text { - Address stability } \\
\text { issues }\end{array}$ & $\begin{array}{l}\text { HIGH except for } \\
\text { standard conditions } \\
\text { (flat terrain/neutrally } \\
\text { stable atmosphere) }\end{array}$ & $\begin{array}{l}\text { - Impact unknown because of a } \\
\text { lack of experimental/modeling } \\
\text { data of nonstandard conditions } \\
\text { - Is the standard basis enough for } \\
\text { machines with smaller safety } \\
\text { margins? } \\
\text { - Aggressive siting/suitability } \\
\text { reducing safety margins- do } \\
\text { we have a good handle on this? } \\
\text { - Mann turbulence model outper- } \\
\text { forms the others, but it is more } \\
\text { difficult to implement (stability- } \\
\text { enhanced Mann model being } \\
\text { worked on) }\end{array}$ \\
\hline
\end{tabular}


Table 5. (DCIRT continued)

\begin{tabular}{|c|c|c|c|c|}
\hline \multirow{2}{*}{$\begin{array}{l}\text { Design } \\
\text { Criteria }\end{array}$} & \multicolumn{3}{|c|}{ Level of Understanding of the... } & \multirow{2}{*}{$\begin{array}{l}\text { Expert Opinion: } \\
\text { Impact on System } \\
\text { Risk and Reliability }\end{array}$} \\
\hline & Process Physics & Load Modeling & Uncertainty & \\
\hline Extreme Conditions & $\begin{array}{l}\text { - Uncertainties in design wind } \\
\text { speeds/hazard curves } \\
\text { - Non-Gaussian, nonstationary } \\
\text { - Deterministic DLCs (Extreme } \\
\text { Coherent Gust with Directional } \\
\text { Change/Extreme Directional } \\
\text { Change) } \\
\text { - Convective storms: actual } \\
\text { physics, downbursts not cap- } \\
\text { tured } \\
\text { - Duration of storm generating } \\
\text { gusts } \\
\text { - Duration of gusts } \\
\text { - Breaking waves } \\
\text { - Icing events } \\
\text { - Pee floe loading } \\
\text { issues in cold climates }\end{array}$ & $\begin{array}{c}\text { Non-Gaussian, } \\
\text { nonstationary events }\end{array}$ & $\begin{array}{l}\text { HIGH especially } \\
\text { with regard to } \\
\text { breaking waves: } \\
\text { ISO treatment } \\
\text { not accurate }\end{array}$ & $\begin{array}{l}\text { Unclear how many installations } \\
\text { are impacted by icing and lightning }\end{array}$ \\
\hline
\end{tabular}


Table 5. (DCIRT continued)

\begin{tabular}{|c|c|c|c|c|}
\hline \multirow{2}{*}{$\begin{array}{l}\text { Design } \\
\text { Criteria }\end{array}$} & \multicolumn{3}{|c|}{ Level of Understanding of the... } & \multirow{2}{*}{$\begin{array}{l}\text { Expert Opinion: } \\
\text { Impact on System } \\
\text { Risk and Reliability }\end{array}$} \\
\hline & Process Physics & Load Modeling & Uncertainty & \\
\hline Tropical Cyclones & $\begin{array}{l}\text { - Probability of occurrence of } \\
\text { gusts in hurricanes } \\
\text { - Probability of occurrence of } \\
\text { storms, and probability of fail- } \\
\text { ures of aux devices (diesel } \\
\text { gensets) } \\
\text { - Wind/wave misalignment; fre- } \\
\text { quency content can change } \\
\text { - Tu model for hurricanes: differ- } \\
\text { ent length scales? Tuned coeffi- } \\
\text { cients for Kaimal? Spectrum/co- } \\
\text { herence? } \\
\text { - Turbine class conundrum: Class } \\
3 \text { for rarity of events, but Class I } \\
\text { for loads but uneconomical } \\
\text { - Fatigue impact and effect of } \\
\text { event sequence (end-of-life ULS } \\
\text { vs. beginning-of-life FLS/ULS): } \\
\text { time-varying reliability } \\
\text { - Coherent structures in hurri- } \\
\text { canes }\end{array}$ & $\begin{array}{c}\text { Modeling of } \\
\text { hurricanes/typhoons }\end{array}$ & $\begin{array}{l}\text { More knowledge } \\
\text { for hurricanes } \\
\text { than tornadoes, } \\
\text { and so on, but co- } \\
\text { herent structures } \\
\text { may exist } \\
\text { Uncertainty at } \\
\text { hub height higher } \\
\text { than elsewhere }\end{array}$ & $\begin{array}{l}\text { Need to assess fatigue im- } \\
\text { pact of tropical cyclones }\end{array}$ \\
\hline
\end{tabular}


Table 5. (DCIRT continued)

\begin{tabular}{|c|c|c|c|c|}
\hline \multirow{2}{*}{$\begin{array}{l}\text { Design } \\
\text { Criteria }\end{array}$} & \multicolumn{3}{|c|}{ Level of Understanding of the... } & \multirow{2}{*}{$\begin{array}{l}\text { Expert Opinion: } \\
\text { Impact on System } \\
\text { Risk and Reliability }\end{array}$} \\
\hline & Process Physics & Load Modeling & Uncertainty & \\
\hline $\begin{array}{l}\text { Plant-Level Specific } \\
\text { for Reliability } \\
\text { Assessment }\end{array}$ & $\begin{array}{l}\text { - Extreme events, hurricanes, spa- } \\
\text { tial correlation } \\
\text { - Uncertainty in wind plant de- } \\
\text { sign vs. machine design } \\
\text { - Atmospheric stability } \\
\text { - Partial wake effects } \\
\text { - Layout/turbine selection/mi- } \\
\text { crositing } \\
\text { - Different economic drivers } \\
\text { - Each design phase/level should } \\
\text { have its own UQ and treatment } \\
\text { - Risk assessment }\end{array}$ & & $\begin{array}{l}\text { Atmospheric } \\
\text { stability and partial } \\
\text { wake effects are the } \\
\text { highest uncertainties }\end{array}$ & \\
\hline $\begin{array}{l}\text { Soil Structure } \\
\text { Interaction }\end{array}$ & $\begin{array}{l}\text { - Geotechnical variability and } \\
\text { needed number of investigation- } \\
\text { s/borings } \\
\text { - Need of data for offshore } \\
\text { - Time-varying characteristics for } \\
\text { offshore soil conditions } \\
\text { - Dynamic aspects } \\
\text { - Cone penetration test (CPT) } \\
\text { data quite uncertain } \\
\text { - Seismic load combination with } \\
\text { other DLCs }\end{array}$ & $\begin{array}{l}\text { - Critical to im- } \\
\text { prove the accu- } \\
\text { racy of the soil- } \\
\text { structure interac- } \\
\text { tion (SSI) model } \\
\text { - d-RBD } \\
\text { - Event Trees } \\
\text { - FORM } \\
\text { - RFEM }\end{array}$ & & $\begin{array}{l}\text { - Need better guidance on vari- } \\
\text { ability of soils and modeling } \\
\text { approaches } \\
\text { - RFEM can be used to get PSFs } \\
\text { Do not use stochastic finite ele- } \\
\text { ment method (FEM) for design, } \\
\text { but to extract correlations }\end{array}$ \\
\hline
\end{tabular}


Table 5. (DCIRT continued)

\begin{tabular}{|c|c|c|c|c|}
\hline \multirow{2}{*}{$\begin{array}{l}\text { Design } \\
\text { Criteria }\end{array}$} & \multicolumn{3}{|c|}{ Level of Understanding of the... } & \multirow{2}{*}{$\begin{array}{l}\text { Expert Opinion: } \\
\text { Impact on System } \\
\text { Risk and Reliability }\end{array}$} \\
\hline & Process Physics & Load Modeling & Uncertainty & \\
\hline Offshore & $\begin{array}{l}\text { - Robustness checks } \\
\text { - Coupled system dynamics } \\
\text { - Max heel angle (service limit } \\
\text { state) } \\
\text { - Decommissioning }\end{array}$ & & & \\
\hline $\begin{array}{l}\text { Site-Suitability, } \\
\text { Due Diligence, } \\
\text { and Certification }\end{array}$ & $\begin{array}{l}\text { - 'Visibility' of design basis } \\
\text { - Adequacy of } V_{r e f} \text { and } V_{e 50} \text { defi- } \\
\text { nition } \\
\text { - Visibility of certification caveats } \\
\text { - Limitations and assumptions up } \\
\text { front, at the moment they are } \\
\text { hidden } \\
\text { - Conditions exceeding loads in } \\
\text { the envelope } \\
\text { - Shear/veer distributions } \\
\text { - Mean of shear vs. distribu- } \\
\text { tion tails: what are the im- } \\
\text { pacts } \\
\text { - Negative shear: impacts on } \\
\text { tower clearance? } \\
\text { - Idling at low rpm: impacts on } \\
\text { main bearing lubrication while } \\
\text { highest bending stresses on } \\
\text { races at low rpm } \\
\text { - Offshore conditions: geotechni- } \\
\text { cal and metocean }\end{array}$ & & $\begin{array}{l}\text { HIGH especially } \\
\text { with regard } \\
\text { to shear/veer } \\
\text { distribution and } \\
\text { adequacy of } \\
V_{\text {ref }} \text { and } V_{e 50}\end{array}$ & $\begin{array}{l}\text { Too simplistic approach used; } \\
\text { highly dependent on inputs } \\
\text { Massive impact commercially, } \\
\text { but still lagging? } \\
\text { Overlooked fatigue issues for } \\
\text { small margins } \\
\text { - Site suitability affects plant de- } \\
\text { sign, not turbine } \\
\text { Machine does not respond to } \\
V_{\text {ref }} \text { and the associated time } \\
\text { scale; } V_{\text {ref }} \text { is not enough, but } \\
\text { gust factors and actual response } \\
\text { and deeper understanding is } \\
\text { needed: example of typhoon- } \\
\text { collapsed turbines }\end{array}$ \\
\hline
\end{tabular}


Table 5. (DCIRT continued)

\begin{tabular}{|c|c|c|c|c|}
\hline \multirow{2}{*}{$\begin{array}{l}\text { Design } \\
\text { Criteria }\end{array}$} & \multicolumn{3}{|c|}{ Level of Understanding of the... } & \multirow{2}{*}{$\begin{array}{l}\text { Expert Opinion: } \\
\text { Impact on System } \\
\text { Risk and Reliability }\end{array}$} \\
\hline & Process Physics & Load Modeling & Uncertainty & \\
\hline $\begin{array}{l}\text { As-Built and } \\
\text { Nonconformities }\end{array}$ & $\begin{array}{l}\text { - As-built nonconforming to } \\
\text { specs } \\
\text { - Pitch errors } \\
\text { - Yaw errors } \\
\text { - Mass/inertia errors } \\
\text { - Temperature effects on material } \\
\text { - Material properties/manufactur- } \\
\text { - ing quality and variability } \\
\text { - Failures 'outside the box' }\end{array}$ & $\begin{array}{l}\text { - Raise QA/QC } \\
\text { level vs. design } \\
\text { for lower QC } \rightarrow \\
\text { focus on increas- } \\
\text { ing QC } \\
\text { - Cascading ef- } \\
\text { fects of errors } \\
\text { (e.g., pitch/yaw) }\end{array}$ & $\begin{array}{l}\text { Uncertainty, } \\
\text { its propagation, } \\
\text { and impacts are } \\
\text { known, but they } \\
\text { do not diminish }\end{array}$ & $\begin{array}{c}\text { Human error filtered by QA/QC, } \\
\text { but not covered by PSFs }\end{array}$ \\
\hline $\begin{array}{l}\text { Standard De- } \\
\text { sign Conditions }\end{array}$ & $\begin{array}{l}\text { - Dimensionality of design space } \\
\text { - Beyond tu, how do you handle } \\
\text { other conditions (shear, veer, } \\
\text { and so on) } \\
\text { - How do we improve turbine } \\
\text { classes to be more representa- } \\
\text { tive of real site conditions? } \\
\text { - Perhaps develop new design } \\
\text { classes to address location- } \\
\text { specific issues } \\
\text { - Offshore DLC 6.2: how can } \\
\text { the yaw error be better defined? } \\
\text { What is missing? }\end{array}$ & $\begin{array}{l}\text { - Extrapolation } \\
\text { modeling (meth- } \\
\text { ods being used } \\
\text { by OEM may be } \\
\text { proprietary) } \\
\text { - Account for } \\
\text { time spent under } \\
\text { different-than- } \\
\text { standard condi- } \\
\text { tions (stability/s- } \\
\text { hear, and so on) }\end{array}$ & $\begin{array}{l}\text { This ties to } \\
\text { site suitability: } \\
\text { mapping capacity } \\
\text { to particular site }\end{array}$ & $\begin{array}{l}\text { - } V_{r e f} \text { issue as in site suitability; } \\
\text { - Current standard not explicit in } \\
\text { the intent of goals } \\
\text { - Expected values of gust factors } \\
\text { vs. considering uncertainty } \\
\text { - PRUF-like exercise for loads } \\
\text { - Site-suitability standards? } \\
\text { - Adjustable products are the } \\
\text { trend: mix and match compo- } \\
\text { nents suitable for site-specific } \\
\text { design }\end{array}$ \\
\hline
\end{tabular}


Table 5. (DCIRT continued)

\begin{tabular}{|c|c|c|c|c|}
\hline \multirow{2}{*}{$\begin{array}{l}\text { Design } \\
\text { Criteria }\end{array}$} & \multicolumn{3}{|c|}{ Level of Understanding of the... } & \multirow{2}{*}{$\begin{array}{l}\text { Expert Opinion: } \\
\text { Impact on System } \\
\text { Risk and Reliability }\end{array}$} \\
\hline & Process Physics & Load Modeling & Uncertainty & \\
\hline Reliability Target & $\begin{array}{l}\text { - PSF calibration } \\
\text { - Target reliability levels } \\
\text { - Assessing criticality of com- } \\
\text { ponents, exposure, and safety } \\
\text { levels, consequence of failure } \\
\text { - Rare events difficult to capture } \\
\text { in the field } \\
\text { - Actual failure rates caused by } \\
\text { design problems } \\
\text { - Lifetime cost }\end{array}$ & $\begin{array}{l}\text { - Model risk (prob- } \\
\text { ability of failure } \\
\text { and consequence) } \\
\text { and evaluate ac- } \\
\text { ceptable risk } \\
\text { - Fully probabilistic } \\
\text { design } \\
\text { - Harmonize re- } \\
\text { liability levels } \\
\text { across system (es- } \\
\text { pecially offshore) } \\
\text { - What level } \\
10^{-6} \text { (ECS } \\
2002 \text { ) or } \\
5 * 10^{-4} \text { (API } \\
2014 ; 61400- \\
1 . \text { Wind } \\
\text { turbines-Part } \\
1: \text { Design re- } \\
\text { quirements } \\
\text { forthcom- } \\
\text { ing); in the } \\
\text { past } 10^{-3} \text { (IEC } \\
2005) ; 5 * 10^{-} 4 \\
\text { is } \sim \text { annual } \\
\text { failure rate }\end{array}$ & $\begin{array}{l}\text { How steep is the } \\
\text { curve in wind for } \\
\text { cost vs. load factor }\end{array}$ & $\begin{array}{l}\text { Multiple levels for col- } \\
\text { lapse, limit states, different } \\
\text { components (ECS 2005) }\end{array}$ \\
\hline
\end{tabular}


Table 5. (DCIRT continued)

\begin{tabular}{|c|c|c|c|c|}
\hline \multirow{2}{*}{$\begin{array}{l}\text { Design } \\
\text { Criteria }\end{array}$} & \multicolumn{3}{|c|}{ Level of Understanding of the... } & \multirow{2}{*}{$\begin{array}{l}\text { Expert Opinion: } \\
\text { Impact on System } \\
\text { Risk and Reliability }\end{array}$} \\
\hline & Process Physics & Load Modeling & Uncertainty & \\
\hline Modeling Aspects & $\begin{array}{l}\text { - Aerodynamics uncertainty } \\
\text { - Aeroelastic assumptions with } \\
\text { bigger rotors and lower solidity } \\
\text { - Edgewise vibration and blade } \\
\text { cracks } \\
\text { - Damping: aero/structural/soil } \\
\text { - Turbulence scale, veer/shear, } \\
\text { how to parameterize } \\
\text { - Are } 10-\text {-minute simulations suf- } \\
\text { ficient to capture the coherent } \\
\text { structures? } \\
\text { - SSI } \\
\text { - Pedestal base moment transfer } \\
\text { - Epoxy grout fatigue } \\
\text { - DEL and S-N curves in hybrid } \\
\text { composite components } \\
\text { - Sequence effect on DEL and } \\
\text { rainflow counting, how is that } \\
\text { captured? }\end{array}$ & & & $\begin{array}{l}\text { - At what point systemic QC is- } \\
\text { sues overcome loading calcu- } \\
\text { lation errors? At what point } \\
\text { should we stop chasing loads } \\
\text { refinement? } \\
\text { - Siting errors: } \\
\text { - Better site measurements } \\
\text { (great but expensive) could } \\
\text { make up for failures and un- } \\
\text { certainties more than model- } \\
\text { ing } \\
\text { - Feedback loop from aeroelas- } \\
\text { tic model to as-built } \\
\text { - Should modeling require as- } \\
\text { sessing worst-case condition } \\
\text { (worst manufacturing sce- } \\
\text { nario)? } \\
\text { - Is it better to increase QC, } \\
\text { or test/model for worst-case } \\
\text { (manufacturing, site, and so } \\
\text { on) scenario? }\end{array}$ \\
\hline
\end{tabular}




\section{Conclusions}

Failures still occur in the wind industry, though the lead causes are still largely unknown because of the overall stochastic nature of the wind and wind turbine response. Fatigue-related and noncatastrophic failures are the most common types of failures. In some cases, the structural failures are originated by either control and protection system failures, manufacturing defects, mistakes in siting, or human errors in operations.

The loading stochasticity creates important challenges for the designers. For example, in contrast to aerospace engineering, in which much less uncertainty exists in site assessment, planning of O\&M, and inspections, the probabilistic design of wind turbines is much more involved. Although a systematic approach to the uncertainty modeling would be ideal, it is hard to realize.

This document aims to capture the key sources of the uncertainty in wind turbine and power plant design as emerged from a broad analysis of the current procedures, industry best practices, design codification, and expert opinions. Although uncertainty is widespread across the value chain of the typical wind project and links its various phases, some aspects emerged as needing higher priority and renewed analysis.

The turbine inflow remains the most important source of uncertainty for the design of both the individual wind turbine and the entire wind power plant. The inflow encompasses uncertainties in the stochastic properties of wind and wave fields and the turbine-to-turbine wake interaction. Atmospheric characteristics, such as thermal stability, are currently not included in the wind system design, but have, at least from real-life experience, contributed to questioning the reliability and performance of wind projects.

Further sources of uncertainties in the inflow are associated with the scarcely sampled extreme events, which include severe convective events and tropical cyclones. In the United States, severe thunderstorms and tornadoes are responsible for most of the damage to man-made structures on an annual basis. These phenomena are rare by nature, and thus not widely measured or adequately understood especially as far as the associated wind loading and structure response are concerned. There is some evidence that the probabilistic and physical nature of these events is different than it is currently assumed in wind design, and that geographical location characteristics drive these differences possibly beyond what is currently prescribed in the standards for the load calculation. Similarly, tropical cyclones appear to contain specific turbulent structures that could significantly overload the turbine components, and more studies are needed to understand their structural significance. Furthermore, new questions have come up on the subject of what should be considered a "design event," as have renewed calls for more measurements and modeling. Even though high-fidelity modeling is expensive, it can provide critical high-temporal and high-spatial resolution data for design criteria extending beyond the limited observations.

When considering offshore wind projects, complexity further increases because of the unknowns within the metocean conditions. Other uncertainties arise from the still-limited experience and data, especially from projects with floating substructures. The lack of clearly codified guidance among the complex hierarchy of standards increases the risk and costs of offshore wind. Research must then contend with the scarcity of field data and codified guidance, despite the difficulty to obtain it (when present) and decipher it because of the number of uncertain variables.

One aspect that applies to both land-based and offshore wind energy is associated with the uncertainties in the soil properties and the resulting soil-structure interaction, which require better guidance to safely and effectively model their variability during the design phases. New methods, such as the random finite element method, are now being proposed to account for the stochastic nature of soil characteristics and help identify appropriate PSFs.

In addition to everything mentioned earlier, there are still challenges related to site suitability and due diligence created by the rapid pace of innovation and increased system complexity. These challenges are, at least partially, a result of the proprietary nature of the innovations and the lack of open-access turbine models. For example, wake steering via independent pitch control or yaw misalignment can increase or decrease machine loads depending on yaw offset direction, magnitude, pitch rates, and turbine size.

Moreover, as design margins are squeezed to allow for the deployment of ever-enlarging rotors, the importance of 
representing the environment more accurately and with site-specific conditions becomes critical. This is particularly important for due-diligence phases in which both AEP and O\&M cost (operational expenditure) estimates are produced and that can affect the success of a wind project. Some other aspects that are not fully understood pertain to the adequacy of $V_{r e f}$ and $V_{e 50}$ in the evaluation of a turbine design and its applicability to the site, and conditions that may impact the lifetime of components, such as idling at low levels of lubrication and reduced damping conditions. Again connected to the inflow, shear, and veer distributions might affect loading beyond what is calculated with mean values. For example, instances of negative shear combined with independent pitch control (IPC) could produce blade-tip deflections near the tower that are not considered in the design process.

Although these uncertainties are daunting, they may still be less important than those coming from either manufacturing or installation procedures. QA/QC codified protocols are still in their infancy in the wind industry. Also of interest are nonconformities in operational parameters (e.g., pitch and yaw errors) as well as in mass and inertial properties that could lead to failures caused by out-of-design-envelope occurrences.

There is consensus in the community that the design conditions described by the standards are not comprehensive enough to capture the complexity of the actual turbulent wind field, and that a better description of actual site conditions within the standard turbine classes is needed to account for the sources of uncertainties mentioned earlier. Further work is needed to better characterize the annual extreme operating loads and the even lower-probability-ofoccurrence (higher return period) loads. This together with a (re)calibration of the PSFs would ensure an optimal probability of failure to guarantee minimum life cycle costs. The latter, or the structural reliability target, should be assessed based on a socio-techno-economic risk analysis to define what the acceptable risk is for the industry as a whole and to pave the road for fully probabilistic design processes. Reliability levels obviously affect the LCOE and therefore should be addressed from a systems engineering perspective. This approach applies especially to offshore, wherein harmonization of reliability levels between foundation, substructure, and turbine should be sought more aggressively. The determination of economically optimal reliability targets is a key research need. For example, hurricane design is not fully addressed by the standards, but new versions of the IEC 61400-1,-3 are incorporating new design approaches, such as a typhoon class and substructure robustness checks that are initial steps to deal with the unresolved issues and bridge the gaps. More mature standards will reduce uncertainty and project risk in offshore wind and help lower cost.

Tying all of these aspects together are the modeling activities. Modeling is needed to explain and simplify the physics of the inflow, but also to assess the structural probability of failure and to evaluate the appropriate PSFs. Yet, models have their own uncertainty sources: from the aerodynamics and servo-aeroelastic response calculation (especially with larger, more flexible rotors) to the representation of fatigue damage for composites. Unsteady and three-dimensional facets of the rotor aerodynamics are examples of uncertainty in the aerodynamic load calculation that are directly related to the physics of the inflow.

Commercial challenges for wind power plant due diligence and modeling also include the requirement of:

- Specialist's knowledge for full, site-specific, aeroelastic load evaluations

- Significant multidisciplinary cooperation between atmospheric scientists and structural engineers for sitespecific load evaluation and optimization

- Dealing with intellectual-property-protected aeroelastic models.

New techniques, such as using surrogate models based on polynomial chaos, promise to unlock the uncertainty characterization in AEP as a result of wind resources variability. They further allow for robust plant layout optimization and site-suitability analyses by considering the specific uncertainties of each site, while also accounting for reliability. These tools could further provide generic load response surface models, which would allow wind analysts to do site-specific load evaluations by using generic turbine representations, without infringing intellectual property clauses.

Still, within the modeling realm, better characterization of probabilistic models is desirable as well as better validation of simulations against field tests. New guidance (see, for example Hills, Maniaci, and Naughton 2015; Maniaci 
and Naughton, forthcoming) has already emerged on the utilization and validation of new models at various levels of fidelity and breadths of scope (from individual components to entire wind power plants). In particular, the new guidance is focusing on how to quantify and propagate uncertainties in the models. Yet, one important question is when model refinement reaches a point of diminishing returns because systemic QA/QC issues exist that could overwhelm load calculation errors. It is speculated that models should include the analysis of worst-case scenarios, wherein larger manufacturing defects and siting errors are accounted for. There still is no clear validation of the modeling capability that defines the modeling uncertainties with respect to specific design requirements. One consequence is that calibration, application, and the origin of the PSFs should be further revisited in the standards, especially in light of the new advances in understanding the physics of the environment and modeling capabilities.

Tackling the uncertainty in the wind design process is multifaceted, expensive, and difficult to prioritize. Quantifying the uncertainty can lead to an improvement in performance via better optimization, efficiently utilized materials, accurately estimated risks, and, finally, lower LCOE. Although this is a very first attempt at summarizing the status of the industry and a few suggestions are offered in Section 5, a lot more work is in store for the wind industry to become more mature and competitive, especially with more aggressively engineered machines, and even more challenging offshore configurations. 


\section{Recommended Actions}

A list of initial suggested actions based on feedback from industry experts (consultants, developers, OEMs) is provided here, but with no attempt at prioritization.

- Modeling

- Use HPC to drive UQ and V\&V processes, which will be the basis for standards development, and to transfer design from a single component to a wind plant perspective

- Improve engineering models for design, including their aerodynamics and structural mechanics to better capture the physics of ultra-large composite structures

- Improve the understanding of surface engineering (e.g., blade erosion physics) and the impact on very large rotor blades

- Evaluate whether more complex models can really be used for design or whether accurate tuning of simpler models with a better understanding of uncertainty is more appropriate

- Assess whether time scales other than 10-min and 3-s are better suited for large wind turbine and plant design

- Site Suitability

- Account for site (nonmean) vertical wind shear distributions in the assessment of suitability of a wind turbine for a particular site

- Carefully evaluate $V_{r e f}$ and how it impacts survivability and estimates of the number of shutdowns (U.S. vs. non-U.S. locations)

- Increase transparency in site suitability, including exchanges of control strategies between the independent engineer and OEM

- Characterize and reduce uncertainty from due diligence to make projects more cost effective

- Include worst-case scenarios in the load simulation suite, by also accounting for manufacturing tolerances, thus linking and improving the design and certification process

- Standard Classes

- Improve class description to be more reflective of site-specific conditions

- Improve definitions and modeling of atmospheric phenomena such as shear, veer, and stability

- Revisit PSF calibration via systems engineering and socio-techno-economic risk analyses and determine optimal reliability level. 


\section{Appendix: July 12-13, 2016 Meeting Agenda}

\section{Day 1: Wind Vision Overview and Activity Prioritization}

8:00 - Badging, Continental Breakfast

8:30-8:45 - Welcome, Workshop Introduction, and Expectations - Paul Veers and Rick Damiani

8:45-9:15 - A2e Approach and Goals to Uncertainty in Design - Nick Johnson

9:15-9:25 - Poster/Outline Presentation - Rick Damiani

Current Status of Standards and Industry-Perceived Needs to Address Uncertainties

9:25-9:50 - Wind Turbine Structural Design Uncertainty: Fact and Opinion - Bill Holley

9:50-10:15 - Uncertainty Modeling for Calibration of Partial Safety Factors for Design of Wind Turbine Components John Dalsgaard Sørensen

10:15-10:40 - Poster/Outline Presentation - Lance Manuel

10:40-10:45 - BREAK

Industry Practice in Dealing with Uncertainties

10:45-11:10 - Uncertainty in As-Built Versus Design Specifications - John Bosche

11:10-11:35 - Uncertainty and Technical Due Diligence - Emil Moroz

11:35-12:35 - LUNCH

12:35-13:00 - Review of Current Efforts Toward Reliability-Based Design of Wind Turbine Foundations - Jomaa BenHassine

13:00-13:25 - Design for Reliability - DV Griffiths

13:25-13:40 - Open Discussion of the Current Standards and Perceived Action Items/Feedback on Poster Topic

Uncertainty in the Environmental Conditions and Effects on Turbine Design

13:40-14:05 - Wind Speed Uncertainty - Peter Vickery

14:05-14:30 - Role of Thunderstorm and Tornado Events in the Design Process - Frank Lombardo

14:30-14:55 - Closing the Loop Between Preconstruction Measurements and Site Suitability: Harmonized Site-Suitability Reporting Within IEC 61400-15 - Jason Fields

14:55-15:05 - BREAK

15:05-15:35 - Open Discussion of the Current Standards and Perceived Action Items/Feedback on Poster Topic

Uncertainty in Modeling and Design for Offshore Situations

15:35-16:00 - Verification/Validation What to Expect - Dave Maniaci

16:25-16:25 - Lessons from OC3-OC5 - Amy Robertson 
Day 2: Wind Vision Overview and Activity Prioritization

8:00 - Badging, Continental Breakfast

8:30-8:45 - Intro of the Day, Summary of Yesterday

Hazard Risks for Offshore Wind Design

8:45-9:15 - Offshore vs Onshore - Walt Musial

9:15-9:25 - Hurricane Design Criteria - Rick Damiani

9:25-9:50 - Assessing Turbulence in the Hurricane Boundary Layer Using Large-Eddy Simulations - Julie Lundquist

10:15-10:40 - Coherence and Power Spectra of Hurricane Winds Using Large-Eddy Simulations - Rochelle Worsnop

10:40-10:45 - BREAK

State of the Art in Uncertainty Quantification

10:45-11:10 - Summary of Work on Load Extrapolation and Future Work - Katherine Dykes

11:10-11:35 - Efficient Uncertainty Propagation Through an Aeroelastic Wind Turbine Model - Juan Pablo

Open Discussion/PIRT-like table

11:35-12:25 - Discussion

12:25-13:25 - Working Lunch

13:25-13:55 - Concluding Remarks

The presentations can be found at https://nwtc.nrel.gov/Uncertainty-Risk-Mini-Workshop. 


\section{References}

61400-1. Wind turbines_Part 1: Design requirements. Forthcoming. Forthcoming. International Electrotechnical Commission (IEC), IEC TC-88.

Abdallah, I., A. Natarajan, and J.D. Sørensen. 2015. "Impact of Uncertainty in Airfoil Characteristics on Wind Turbine Extreme Loads.” Renewable Energy 75:283-300.

ABS. 2011. Design Standards for Offshore Wind Farms. Tech. rep. American Bureau of Shipping Plaza, 16855 Northchase Drive, Houston, TX 77060 USA: American Bureau of Shipping. https://www.bsee.gov/sites/bsee.gov/ files/tap-technical-assessment-program//670aa.pdf.

ACI. 2014. 318-14 - Building Code Requirements for Structural Concrete and Commentary. Code. ACI, American Concrete Institute, 38800 Country Club Drive- Farmington Hills, MI 48331.

API. 2014. Planning, Designing and Constructing Fixed Offshore Platforms - Working Stress Design. API Recommended Practice 2A-WSD. American Petroleum Institute, American Petroleum Institute Publishing Services, 1220 L Street, NW, Washington, DC 20005.

AWEA. 2012. Offshore Compliance Recommended Practices - Recommended Practices for Design, Deployment and Operation of Offshore Wind Turbines in the United States. AWEA.

Ben-Hassine, J., and D. V. Griffiths. 2012. "Reliability Based Design of Shallow Foundations Subjected to Combined Loading with Application to Wind Turbine Foundations." In CIMENICS 2012 - 11th International Congress on Numerical Methods in Engineering and Scientific Applications. Isla de Margarita, Venezuela.

CCS. 1985. Structural Design Requirements WIND LOAD. Caribbean Community Secretariat, Georgetown, Guyana.

Choe, Y., Q. Pan, and E. Byon. 2016. "Computationally Efficient Uncertainty Minimization in Wind Turbine Extreme Load Assessment.” J. of Solar Energy Engineering 138 (4): 041012-041012-8.

Clifton, A., A. Smith, and M. Fields. 2016. Wind Plant Preconstruction Energy Estimates: Current Practice and Opportunities. Tech. rep. NREL/TP-5000-64735. Golden, CO: NREL.

Damiani, R., and W. Musial. 2014. "Hurricane Design Guidance for US Waters: Engineering Offshore Wind Systems to Survive Hurricanes.” In AWEA Offshore WindPower. Invited Talk. Atlantic City, NJ: American Wind Energy Association.

Davenport, A. G. 1961. "The spectrum of horizontal gustiness near the ground in high winds." Q. J. R. Meteor. Soc. 87:194-211.

ECS. 2002. Eurocode 3: Basis of Structural Design. European Committee for Standardisation, ECS.

- . 2005. Eurocode 3: Design of Steel Structures-Part 1-1: GenStructures and rules for buildings. European Committee for Standardisation, ECS.

Errichello, R., S. Sheng, J. Keller, and A. Greco. 2012. Wind Turbine Tribology Seminar. Tech. rep. DOE/GO102012-3496. Broomfield, CO: U.S. Department of Energy.

Graf, P., G. Stewart, M. Lackner, K. Dykes, and P. Veers. 2016. "High-Throughput Computation and the Applicability of Monte Carlo Integration in Fatigue Load Estimation of Floating Offshore Wind Turbines." Wind Energy 19 (5): 861-872.

Graf, P., R. Damiani, K. Dykes, J. Jonkman, and A. Ning. 2017. "Advances in the ASSESSMENT of WIND TURBINE Operating EXTREME loads via more efficient calculation Approaches." In AIAA SciTech 2017 - 35th Wind Energy Symposium. National Harbor, MD.

Guo, Y., J. Keller, and W. LaCava. 2012. "Combined Effects of Gravity, Bending Moment, Bearing Clearance, and Input Torque on Wind Turbine Planetary Gear Load Sharing." In American Gear Manufacturers Association (AGMA) Fall Technical Meeting. Dearborn, MI.

Haupt, S.E., et al. 2015. First Year Report of the A2e Mesoscale to Microscale Coupling Project. Tech. rep. PNNL25108. Richland, WA: Pacific Northwest National Laboratory.

Haupt, S.E., et al. 2017. Second Year Report of the Atmosphere to Electrons Mesoscale to Microscale Coupling Project: Nonstationary Modeling Techniques and Assessment. Tech. rep. PNNL-26267. Richland, WA: Pacific Northwest National Laboratory.

Hills, R. G., D. C. Maniaci, and J. W. Naughton. 2015. V\&V Framework. Sandia Report SAND2015-7455. Albuquerque, NM: Sandia National Laboratories. 
Holland, G. J. 1980. “An analytical model of the wind and pressure profile in hurricanes.” Mon. Wea. Rev. 108:12121218.

IEC. 2005. 61400-1. Wind turbines-Part 1: Design requirements. International Electrotechnical Commission, IEC TC-88.

- . 2017a. 61400-15. Wind turbines-Part 15: Assessment of site specific wind conditions for wind power stations. Forthcoming. International Electrotechnical Commission, IEC TC-88.

- . 2017b. 61400-6 - Wind turbines - Part 6: Tower and Foundation Design. Forthcoming. International Electrotechnical Commission, IEC TC-88.

ISO. 1998. 4354:2009 Wind Actions on Structures. ISO, ISO.

- . 2007. 19902:2007 - Petroleum and natural gas industries - Fixed steel offshore structures. ISO, Geneva, Switzerland.

- . 2013. 19900:2013 - Petroleum and natural gas industries - General requirements for offshore structures. Revision to 2002 edition. ISO, Geneva, Switzerland.

- . 2015. 2394:2015 -General principles for reliability of structures. ISO, Geneva, Switzerland.

Kelley, N., J. Bonnie, G. N. Scott, J. T. Bialasiewicz, and L. S. Redmond. 2005. “Analysis of Transportation and Logistics Challenges Affecting the Deployment of Larger Wind Turbines: Summary of Results.” In WindPower2005. CP-500-38074. Denver, CO: AWEA.

LaCava, W., J. Keller, and B. McNiff. 2012. "Gearbox Reliability Collaborative : Test and Model Investigation of Sun Orbit and Planet Load Share in a Wind Turbine Gearbox." In 53rd Structures, Structural Dynamics and Materials Conference. Honolulu, HI: SDM.

Larsen, G. C., K. Ronold, H. Ejsing Jørgensen, K. Argyriadis, and J. de Boer. 1999. Ultimate loading of wind turbines. Tech. rep. 1111. Forskningscenter Risoe, Denmark: Technical University of Denmark.

Maniaci, D. C., and J. W. Naughton. Forthcoming. V\&V Integrated Program Planning for Wind Plant Performance. Sandia Report SAND2015-7455. Albuquerque, NM: Sandia National Laboratories.

Maniaci, D. C., P. Moriarty, M. Sprague, M. Churchfield, S. Arunajatesan, and M. Barone. Forthcoming. Atmosphere to Electrons High Fidelity Model Verification and Validation Plan. Sandia Report SAND2017-XXXX. Albuquerque, NM: Sandia National Laboratories.

Moriarty, P. 2008. “Database for Validation of Design Load Extrapolation Techniques.” Wind Energy 11 (6): 559576.

Murcia, J. P., P. E. Réthoré, N. Dimitrov, A. Natarajan, Sørensen, J. D. Jø.rensen, P. Graf, and T. Kim. 2016. “Uncertainty propagation through an aeroelastic wind turbine model using polynomial surrogates." Submitted, Renewable Energy.

Nadim, F., Y. J. Choi, S. Lacasse, and Z. Liu. 2015. "Calibration of Partial Safety Factors for Offshore Foundation Design.” Inter. J. Reliability \& Safety 9 (1): 51-69.

Ragan, P., and L. Manuel. 2008. "Statistical Extrapolation Methods for Estimating Wind Turbine Extreme Loads.” J. Solar Energy Engineering 130 (3): 03101111-03101115.

SAA. 1989. Loading Code, Part 2 - Wind Forces - AS1170 Part 2. Standards Association of Australia, Sydney, Australia.

Saranyasoontorn, K., and L. Manuel. 2008. "On the propagation of uncertainty in inflow turbulence to wind turbine loads." J. of Wind Engineering and Industrial Aerodynamics 96.

Schreck, S. Forthcoming. Existing Experiment and Test Databases for A2e HFM Model Validation. Tech. rep. NREL/TP. Golden, CO: National Renewable Energy Laboratory.

SEI. 2010. Minimum design loads for buildings and other structures (ASCE/SEI 7-10). 3rd printing. 388 pp. ASCE Standard, ASCE/SEI 7-10. 1801 Alexander Bell Drive, Reston, Virginia 20191: American Society of Civil Engineers.

Sheng, S., and R. O'Connor. 2017. "Wind Energy Engineering - A Handbook for Onshore and Offshore Wind Turbines." Chap. 15 -Reliability of Wind Turbines, 299-327. Elsevier Inc. doi:10.1016/B978- 0- 12 - 8094518.00015-1.

Shipurkar, U., K. Ma, H. Polinder, and J. A. Ferreira. 2015. "A review of failure mechanisms in wind turbine generator systems.” In EPE' 15 ECCE Europe. Geneva, Switzerland. 
Slot, H. M., E. R. M Gelinck, C. Rentrop, and E. van der Heide. 2015. "Leading edge erosion of coated wind turbine blades: Review of coating life models." Renewable Energy 80:837-848.

Solari, G., and G. Piccardo. 2001. "Probabilistic 3-D Turbulence Modeling for Gust Buffeting of Structures." Probabilistic Engineering Mechanics 16 (1): 73-86.

Sørensen, J. D., and H. S. Toft. 2014. Safety factors - IEC 61400-1 ed. 4 - background document. Tech. rep. Denmark Technical University, Copenhagen, DK: DTU.

Structural Safety, Joint Committee on. 2000. Probabilistic Model Code. JCSS, Copenhagen, DK.

Toft, H. S., L. Svenningsen, J. D. Sørensen, W. Moser, and M. L. Thøgersen. 2016. "Uncertainty in Wind Climate Parameters and their Influence on Wind Turbine Fatigue Loads." Renewable Energy (Denmark Technical University, Copenhagen, DK) 90:352-361.

Tusing, R., and J. Fields. "Atmosphere to Electrons Performance Risk, Uncertainty and Finance (PRUF) Overview (presentation)."

Womble, D. E., M. F. Barone, S. W. Hammond, and M. A. Sprague. 2015. A2e High Fidelity Modeling: Strategic Planning Meetings. Sandia Report SAND2015-9499. Albuquerque, NM: Sandia National Laboratories.

Worsnop, R., J. K. Lundquist, G. H. Bryan, R. Damiani, and W. Musial. 2017. "Gusts and Shear Inside Hurricane Boundary Layers Exceed Offshore Wind Turbine Design Thresholds.” In review, Geophys. Res. Lett. 44. doi:10. 1002/2017GL073537.

Zaretsky, E. W., and E. V. Branzai. 2017. "Rolling Bearing Service Life Based on Probable Cause for Removal - A Tutorial." Tribology Transactions 60 (2): 300-312. doi:10. 1080/10402004.2016.1163761. eprint: http: //dx.doi.org/10.1080/10402004.2016.1163761. http://dx.doi.org/10.1080/10402004.2016.1163761. 